Louisiana State University

LSU Digital Commons

1977

\title{
A Pyrolytic Method for the Determination of Sulfate in Water.
}

Leeann Marie Thoma

Louisiana State University and Agricultural \& Mechanical College

Follow this and additional works at: https://digitalcommons.Isu.edu/gradschool_disstheses

\section{Recommended Citation}

Thoma, Leeann Marie, "A Pyrolytic Method for the Determination of Sulfate in Water." (1977). LSU Historical Dissertations and Theses. 3171.

https://digitalcommons.Isu.edu/gradschool_disstheses/3171

This Dissertation is brought to you for free and open access by the Graduate School at LSU Digital Commons. It has been accepted for inclusion in LSU Historical Dissertations and Theses by an authorized administrator of LSU Digital Commons. For more information, please contact gradetd@lsu.edu. 


\section{INFORMATION TO USERS}

This material was produced from a microfilm copy of the original document. While the most advanced technological means to photograph and reproduce this document have been used, the quality is heavily dependent upon the quality of the original submitted.

The following explanation of techniques is provided to help you understand markings or patterns which may appear on this reproduction.

1. The sign or "target" for pages apparently lacking from the document photographed is "Missing Page(s)". If it was possible to obtain the missing page(s) or section, they are spliced into the film along with adjacent pages. This may have necessitated cutting thru an image and duplicating adjacent pages to insure you complete continuity.

2. When an image on the film is obliterated with a large round black mark, it is an indication that the photographer suspected that the copy may have moved during exposure and thus cause a blurred image. You will find a good image of the page in the adjacent frame.

3. When a map, drawing or chart, etc., was part of the material being photographed the photographer followed a definite method in "sectioning" the material. It is customary to begin photoing at the upper left hand corner of a large sheet and to continue photoing from left to right in equal sections with a small overlap. If necessary, sectioning is continued again - beginning below the first row and continuing on until complete.

4. The majority of users indicate that the textual content is of greatest value, however, a somewhat higher quality reproduction could be made from "photographs" if essential to the understanding of the dissertation. Silver prints of "photographs" may be ordered at additional charge by writing the Order Department, giving the catalog number, title, author and specific pages you wish reproduced.

5. PLEASE NOTE: Some pages may have indistinct print. Filmed as received. 
78-7562

THOMA, LeeAnn Marie, 1949-

A PYROLYTIC METHOD FOR THE DETERMINATION

OF SULFATE IN WATER.

The Louisiana State University and

Agricultural and Mechanical College, Ph.D., 1977

Chemistry, analytical

University Microfilms International, Ann Arbor, Michigan 48106 
A PYROLYTIC METHOD FOR THE DETERMINATION

OF SULFATE IN WATER

A Dissertation

Submitted to the Graduate Faculty of the Louisiana State University and Agricultural and Mechanical College in partial fulfillment of the requirements for the degree of Doctor of Philosophy

in

The Department of Chemistry

by

LeeAnn Marie Thoma

B.A., University of Northern Iowa, 1971

December, 1977 


\section{ACKNOWLEDGENENTS}

The author wishes to express her thanks and appreciation to Dr. Philip W. West and to the National science Foundation (RANN Grants ESR74-18932 and AEN74-18932-A01) for the financial support provided while the research for this dissertation was in progress.

The author would also like to thank the University of Northern Iowa Merchant Scholarship Fund for providing the monetary support used in the preparation and publication of this dissertation. 
TABLE OF CONTENTS

$\underline{\text { PAGE }}$

ACKNOWLEDGEMENTS ....................... ii

LIST OF TABLES......................... vi

LIST OF FIGURES.......................... vii

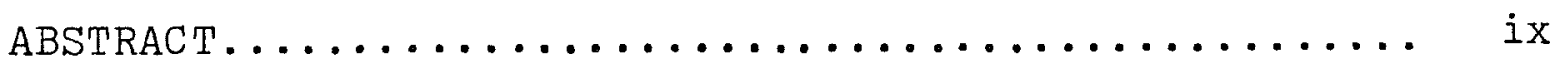
CHAPTER

I. INTRODUCTION...................... 1

II. A REVIEW OF THE LITERATURE.............. 6

A. Gravimetric Methods................ ?

B. Titrimetric Methods................. 11

1. Methods Using Barium.............. 12

a) Indirect Titration Methods......... 12

i) Use of Chromate............ 12

ii) Use of Anions Other Than Chromate

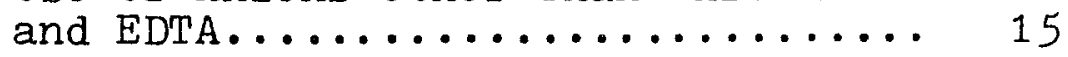

iii) Use of EDTA................. 19

b) Direct Titration Methods........... 22

2. Methods Using Lead................ 30

a) Indirect Titration Methods......... 30

b) Direct Titration Methods........... 31

3. Methods Using Other Precipitants....... 33

4. Reduction Methods................. 34

C. Colorimetric Methods................ 36

1. Methods Using Chromate............ 3 ?

2. Methods Using Lead or Benzidine....... 38

3. Methods Using Barium............... 39

4. Methods Using Thorium or Zirconium Complexes...................... 41

5. Methods Using Iron Complexes.......... 43

6. Reduction Methods.................. 44

D. Spectrophotometric Methods........... 46

1. Turbidimetry and Nephelometry......... 47

a) Methods Using Barium............. 47

b) Methods Using Other Precipitants..... 51

2. Flame Photometry................ 52

3. Atomic Absorption Spectroscopy......... 54

4. Fluorimetry...................... 55

5. Ultraviolet Spectroscopy............ 57 
E. Electrochemical Methods.............. 57

1. Potentiometric iitrations............ 58

a) Methods Using Lead............... 58

b) Methods Using Barium.............. 60

2. Conductometric Methods............. 62

a) Conductometric Titrations.......... 62

b) Direct Measurement of Conductance.... 63

c) High Frequency Titrations........... 64

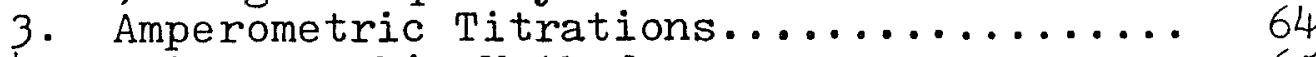

4. Polarographic Methods............... 65

F. Miscellaneous Methods.............. 67

1. Methods Using Radioisotopes........... 67

2. Thermometric Methods................ 69

3. Volume Methods.................. 70

4. Spot Test and Ring Oven Methods........ 71

5. Gas Chromatographic Method.......... 72

III. EXPERIMENTAL......................... 74

A. Pyrolytic Method.................. 75

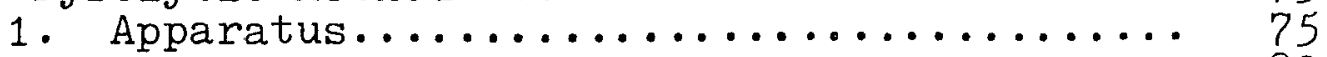

2. Reagents...................... 80

3. Procedures..................... 81

a) Water Samples................. 81

b) Sulfur Dioxide Calibration Curve..... 84

c) Chloride Study................ 85

d) Anion Interference Study......... 88

e) Bicarbonate Study............... 88

B. Gravimetric Method................ 90

1. Apparatus and Reagents............. 90

2. Procedure...................... 91

C. Turbidimetric Method................ 91

1. Apparatus and Reagents............. 91

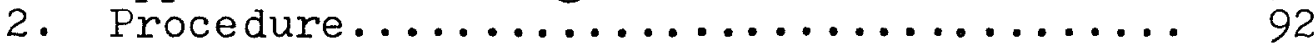

D. Barium Chloranilate Spectrophotometric

Method......................... 92

1. Apparatus and Reagents............. 93

2. Procedure....................... 93

E. Stephen's Nephelometric Method........... 94

1. Apparatus and Reagents.............. 94

2. Procedure....................... 94 
IV. RESULTS AND DISCUSSION.............. 96

A. Pyrolytic Method................. 97

1. Background Information............. 97

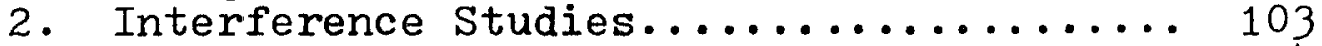

3. Sulfate Calibration Curve.......... 124

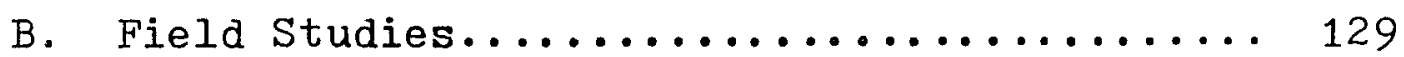

1. Comparison of Five Methods........... 129

2. Comparison of Data Between Two

Laboratories....................... 134

v. CONCLUSION........................ 142

LITERATURE CITED...................... 147

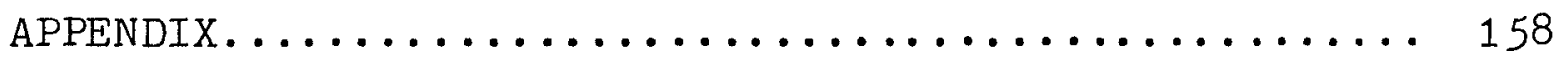

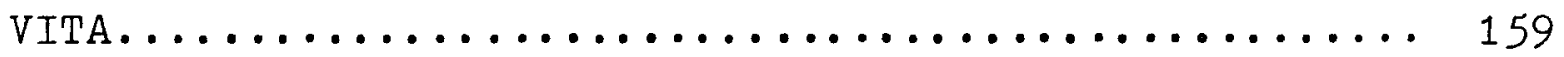




\section{LIST OF TABLES}

\section{TABLE}

$\underline{\text { PAGE }}$

1. U.S. Public Health Service Drinking

Water standards, 1962................... 4

2. Metalloindicators Derived From Bis(phenylazo)chromotropic Acid, Reaction

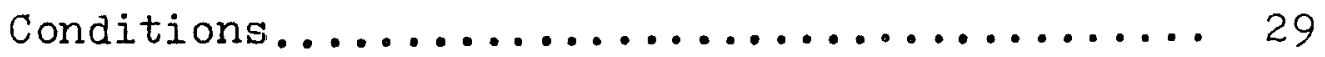

3. Chloride Concentration Study.............. 106

4. Effect of Increased Volume of PDA-Br........ 107

5. Effect of $20 \mathrm{~mm}$ i.d. Pyrolysis Dish......... 109

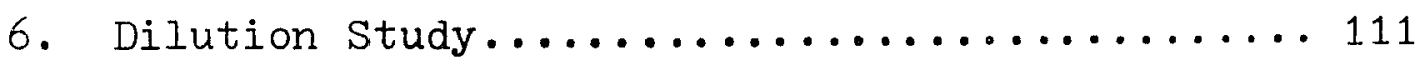

7. $10 \mu \mathrm{g}$ Anion Interference Study............. 113

8. $100 \mu g$ Anion Interference Study............ 114

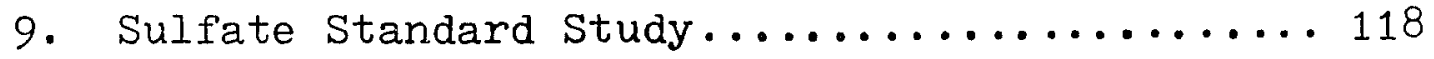

10. Bicarbonate Removal Study -- Effect of

Various Acid and Base Concentrations........ 120

11. Bicarbonate Removal Study -- Control of pH... 123

12. Bicarbonate Removal Study -- Comparison

of Three Proposed Procedures.............. 125

13. Precision of the Nethod................. 130

14. Sulfate Data (ppm) for the Five Methods...... 131

15. Pyrolytic Method -- Use of an Ion-

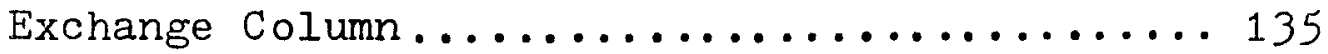

16. Pyrolytic Method -- Pyrolysis Aliquot Size... 136 


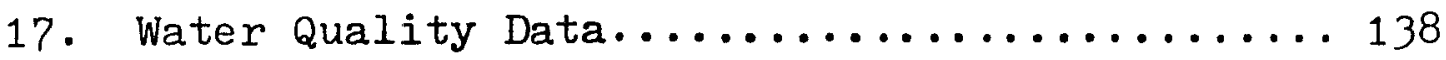

18. Sulfate Data (ppm) From Two Laboratories

Using Different Methods.................. 139

19. Sulfate Data (ppm) Between Two Labs Using

the Turbidimetric Method............... 141 


\section{LIST OF FIGURES}

$\underline{\text { PAGE }}$

\section{FIGURES}

1. Structure of Metalloindicators Derived

From Bis(phenylazo)chromotropic Acid...... 27

2. Pyrolysis Apparatus............... 77

3. Sulfur Dioxide Calibration Curve........ 86

4. Precipitation Reaction................ 99

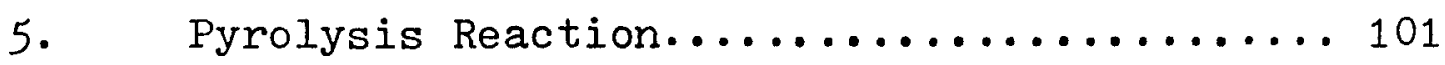

6. Sulfate Calibration Curve............ 127 


\section{ABSTRACT}

The determination of sulfate in water has long posed an interesting problem for the analyst. Several years ago, work on a sulfuric acid aerosol determination led to the development of a new sulfate procedure, which appeared to be applicable to water analysis. This dissertation contains the results of an investigation of this method, which included a study of the potential interferences and how they might be removed, and the development of a procedure for determining sulfate in drinking and natural waters.

The actual procedure utilized three distinct, separate sulfate reactions: a precipitation reaction, a pyrolysis reaction, and a colorimetric reaction. The sample was first treated to remove any potential interferences. Cations were removed with an ion-exchange column, while anions such as carbonate and bicarbonate were removed with a hydrochloric acid treatment.

Following this treatment, the sulfate as well as any remaining anions were precipitated as their 2-perimidinylammonium salts using 2-perimidinylammonium bromide as the precipitant. These salts were then placed in a $500^{\circ}$ nitrogen-purged oven, where the 2-perimidinylammonium sulfate thermally decomposed to form sulfur dioxide. The sulfur dioxide was then trapped and determined according 
to the West-Gaeke colorimetric procedure.

Sulfate calibration curves were prepared according to the same procedure using sodium sulfate standards. The working range for the method is $0-120 \mathrm{ppm}$, although larger concentrations can be determined by using a smaller initial sample size $(<10 \mathrm{ml})$. For samples containing 0-10 ppm, the initial sample size was maintained at $10 \mathrm{ml}$, but the pyrolysis aliquot was increased from $100 \mathrm{\mu l}$ to $200 \mu 1$ to obtain more reliable results. The method has a sensitivity of $1.8 \mathrm{ppm}$ sulfate with a relative standard deviation of $\pm 2.0 \%$ at the $100 \mathrm{ppm}$ sulfate level.

A set of actual water samples was obtained and analyzed according to several different procedures and the results were compared. A second set of water samples was analyzed and used for an interlaboratory comparison. 
CHAPTER I

INTRODUCTION 
Man is a curious beast. Down through the ages, he has continually asked questions concerning the nature of the world around him. Why does the sun move across the sky? What makes plants grow? How do clouds form?

His search for answers led man to ask new questions. As his knowledge increased, so did the number and depth of his questions. How many planets besides Earth, revolve around the sun? Why are some roses red while others are yellow? What is the difference between hematite and magnetite?

Early chemists asked questions too -- questions concerning the nature of their world. In their search for the answers, they studied the air, the water, the soil, the rocks -- all aspects of their environment. They wanted to know not only which elements were present, but also how much of each element was present. As they began to accumulate and compare data, they found that certain elements or compounds were always present in the soils, waters and various types of rocks that they studied.

Industrialization slowly began to bring about a change in these compositions. When it became clear that the health and safety of mankind could be endangered, government agencies and responsible organizations developed guidelines and standards to insure the quality of our environment, 
in particular, the quality of our water and of our air.

One such set of standards was prepared for drinking waters by the U. S. Public Health Service. As Table 1 shows, many elements may be present in drinking waters, but only within or under specified concentration limits. If any water supply contains more than the allowable concentration of a given component, that water should not be used for drinking water.

Such standards invariably mean that in water and analytical laboratories throughout the nation, water samples must routinely be analyzed for each of these components. Thus it is desirable to have analytical procedures which are fast, easy to operate, inexpensive, sensitive, free of interferences, accurate, and reliable. Although it is difficult to find methods which meet all of the above criteria, most methods meet one or more of them, often sacrificing speed or expense for accuracy and reliability

Sulfate is among those drinking water components which is routinely determined. Current methods include the time-honored gravimetric procedure, the turbidimetric procedure and several colorimetric procedures. The gravimetric procedure is the most accurate and precise of the methods, but it is also the most time-consuming. The turbidimetric procedure is fast, but lacks precision and accuracy. The colorimetric methods are subject to inter- 
TABLE 1

U.S. PUBLIC HEALTH SERVICE DRINKING WATER STANDARDS ${ }^{1}$

1962

\begin{tabular}{lc}
\hline \multicolumn{1}{c}{ Parameter } & $\begin{array}{c}\text { Maximum Allowable } \\
\text { Concentration }(\mathrm{mg} / \mathrm{l})\end{array}$ \\
\hline Arsenic & 0.01 \\
Barium & 1.0 \\
Cadmium & 0.01 \\
Chloride & 250 \\
Chromium (VI) & 0.05 \\
Copper & 1 \\
Cyanide & 0.01 \\
Fluoride & $0.7-1.2$ \\
Iron & 0.3 \\
Lead & 0.05 \\
Manganese & 0.05 \\
Nitrate & 45 \\
Phenols & 0.001 \\
Selenium & 0.01 \\
Silver & 0.05 \\
Sulfate & 250 \\
Total Dissolved Solids & 500 \\
Zinc & 5
\end{tabular}


ferences and often require the use of expensive reagents or equipment.

Recently, a new sulfate method was introduced, which appeared promising for use in water analysis. Utilizing this method, a new analytical procedure for determining sulfate in water has been developed and is the subject of this dissertation. The method utilized several separate steps or reactions to achieve the accuracy, precision, specificity and sensitivity desired. The actual development, including a detailed interference study, and an evaluation of this method as it applies to water samples, have been included and will be discussed in detail in the following chapters. 
CHAPTER II

A REVIEW OF THE LITERATURE 
A. Gravimetric Methods

The gravimetric determination of sulfate as barium sulfate is the most widely known sulfate method. "Standard Methods for the Examination of Water and Wastewater", published by the American Public Health Association, the American Water Works Association, and the Water Pollution Control Federation, considers this method to be the most accurate method for sulfate concentrations above $10 \mathrm{mg} / 1.1$ For this reason the gravimetric method has been recognized by "Standard Methods" and by the American Society for Testing and Materials ${ }^{2}$ as the preferred method or the standard reference method. Although recognized as the most accurate, the gravimetric method is also the most timeconsuming.

The general principles and reactions involved in the method are relatively straight forward. A sample solution containing sulfate is acidified with hydrochloric acid and is heated to boiling. A dilute solution of barium chloride is slowly added to the sample with gentle stirring until the precipitation of barium sulfate appears complete. A slight excess of barium chloride is added and the sample is digested at $80-90^{\circ}$ for a suitable period of time. The precipitate is filtered and washed free of chloride with distilled water. At this point the precipitate is either ignited at $800^{\circ}$ for one hour or dried in an oven at $105^{\circ}$. 
After being cooled in a desiccator, the precipitate is weighed as barium sulfate and the sulfate concentration is calculated.

The gravimetric method is not without sources of error or interferences. By understanding these errors and by carefully adhering to the procedure outlined in "Standard Methods", an analyst can correct for or minimize the errors.

Several possible sources of error exist within the procedure itself. The use of a hydrochloric acid medium is necessary to prevent the precipitation of other insoluble barium salts, such as barium hydroxide, barium carbonate, and barium phosphate. The presence of the acid also promotes the formation of a coarse, easily filterable precipitate. However the amount of hydrochloric acid which can be added is limited by the solubility of barium sulfate in an acidic medium. As the concentration of hydrochloric acid increases, so does the solubility of barium sulfate. Hence too much acid will result in the loss of precipitate and low sulfate concentrations will be obtained. A hydrochloric acid concentration of approximately $0.05 \mathrm{M}$ has been found to be the most suitable.

The ignition step of the procedure can be a source of error, particularly if the filtration is carried out using filter paper. Before ignition at $800^{\circ}$, the filter paper is dried and charred at a lower temperature; and any remaining carbon is burned off at a higher temperature with an 
excess of air. If the carbon is not properly bumed off, the barium sulfate will be reduced to barium sulfide and the results obtained will be low.

The presence of suspended matter and silica in a water sample lead to high results. The suspended matter can be removed by filtering the sample through an ashless filter paper before precipitating the barium sulfate. If the silica concentration exceeds $25 \mathrm{mg} / 1$, it must be removed. The removal procedure utilizes repeated evaporations of the sample with hydrochloric acid. The residue which remains is taken up in hot water and the insoluble silica is filtered off and washed with water. The resulting filtrate and subsequent washings are combined and treated as before for sulfate.

Sulfite in the sample may be oxidized by dissolved oxygen to sulfate if the $\mathrm{pH}$ of the solution is above eight. High sulfate results would be obtained. Adjusting the $\mathrm{pH}$ of the sample shortly after its collection will prevent this from happening.

Coprecipitation of interfering anions and cations and occlusion of water result in the contamination of the barium sulfate. Chloride, nitrate and chlorate are coprecipitated as their barium salts. When nitrate and chlorate are present, they can be removed by repeated evaporation with hydrochloric acid:

$$
2 \mathrm{NO}_{3}{ }^{-}+6 \mathrm{Cl}^{-}+8 \mathrm{H}^{+} \rightarrow 2 \mathrm{NO}+3 \mathrm{Cl}_{2}+4 \mathrm{H}_{2} \mathrm{O}
$$




$$
\mathrm{ClO}_{3}{ }^{-}+5 \mathrm{Cl}^{-}+6 \mathrm{H}^{+} \rightarrow 3 \mathrm{Cl}_{2}+3 \mathrm{H}_{2} \mathrm{O}
$$

Usually they are in such low concentrations as to be of negligible importance.

The problem of barium chloride coprecipitation cannot be neglected, since excess barium chloride is used to precipitate the sulfate. The coprecipitation can be minimized by adding the reagent slowly, by stirring the solution during the precipitation, and by digesting the precipitate for at least two hours.

Cations which are coprecipitated as their sulfates or bisulfates include protons, the alkali metals, calcium, and iron(III). The removal of these interfering species is accomplished by passing the sample solution through a cation exchange column prior to precipitating the barium sulfate. For a more complete discussion of the errors involved, the reader is referred to "Textbook of Quantitative Inorganic Analysis" by I. M. Kolthoff and E. B. Sandell. 3

The occlusion of water is considered as an interference. Ignition of the precipitate at $800^{\circ}$ drives off the occluded water. However drying the barium sulfate precipitate at $105^{\circ}$ results in a precipitate that may contain several tenths of a per cent of water.

Despite the possible sources of error, the interferences and the amount of time required for the determination, 
the barium sulfate gravimetric method remains the preferred method. It is used whenever the greatest accuracy is necessary and when theoretical ion balances are to be obtained.

Attempts have been made to find sulfate compounds which are less soluble than barium sulfate and which could be used for gravimetric determinations. Several researchers have proposed the use of coordination compounds of cobalt as possible precipitants for sulfate ions. Nahr and Krauss $^{4}$ suggested precipitating sulfate as the hexaamminecobalt(III) bromide sulfate, $\left[\mathrm{Co}\left(\mathrm{NH}_{3}\right)_{6}\right] \mathrm{BrSO}_{4}$.

Belcher and Gibbons ${ }^{5}$ studied five other coordination compounds of cobalt and recommended the use of one of them for a gravimetric determination. Octaammino- $\mu$-amino- $\mu-$ nitro-dicobaltic nitrate, $\left[\left(\mathrm{NH}_{3}\right)_{4} \mathrm{Co} \backslash_{\mathrm{NO}_{2}}^{\mathrm{NH}_{2}} \mathrm{CO}_{\mathrm{Co}}\left(\mathrm{NH}_{3}\right)_{4}\right]\left(\mathrm{NO}_{3}\right)_{4} \cdot \mathrm{H}_{2} \mathrm{O}$ was used to precipitate the corresponding sulfate, which they found to have a solubility in water at $25^{\circ}$ of 22.4 $\mathrm{mg} / 1$. Although this was more soluble than barium sulfate $\left(2.5 \mathrm{mg} / 1\right.$ at $\left.25^{\circ}\right), 6$ it could still be used to obtain quantitative results if the volume of solution were carefully controlled. Belcher and Gibbons found few interferences. In particular, nitrate did not interfere.

\section{B. Titrimetric Methods}

Early researchers recognized the need for faster, more 
efficient methods of determining sulfate. Titrimetric or volumetric methods appeared to provide the alternative they sought. As they were to discover, the titrimetric procedures were indeed faster, but they were fraught with problems. The lack of suitable indicators, the lack of sensitivity of the available indicators, the difficulties of determining the titration end point, and the presence of cationic and anionic interferences often led to methods which were insensitive or complicated.

The first approaches to be used were indirect methods which involved the precipitation of barium sulfate and the determination of the excess barium, often by precipitating a second insoluble barium salt and determining the excess anion. The use of chromate was suggested first, since barium chromate is almost as insoluble as barium sulfate $\left(3.4 \mathrm{mg} / 1\right.$ at $16^{\circ}$ compared to $2.2 \mathrm{mg} / 1$ at $\left.18^{\circ}\right), 5$ and methods for determining chromate were already available.

In 1889 , L. W. Andrews ${ }^{7}$ developed a sulfate method in which the sulfate was precipitated when an excess of an acidified solution of barium chromate was added. The solution was neutralized, and the barium sulfate and excess barium chromate were filtered off, leaving a solution which contained chromate in an amount equal to the amount of sulfate in the original sample. The filtrate was again acidified with hydrochloric acid and potassium iodide was 
added. The chromate was reduced to $\mathrm{Cr}$ (III) and the iodide was oxidized to free iodine, which was titrated with standard sodium thiosulfate in the presence of starch indicator. Ions which precipitate insoluble chromates or barium salts interfered with the method.

Many modifications of Andrew's method have been proposed. J. L. B. Smith $^{8}$ proposed a two-step precipitation using barium chloride followed by potassium chromate, while Koszegi ${ }^{9}$ chose to use potassium dichromate for the second precipitation. The same iodometric finish was used. In both cases, the $\mathrm{pH}$ of the solution had to be carefully adjusted to insure the presence of the appropriate chromium species.

Other researchers chose to modify the determination of the excess chromate. Roemer ${ }^{10}$ titrated the chromate with a standard solution of ferrous ammonium sulfate $\left[\mathrm{FeSO}_{4}\left(\mathrm{NH}_{4}\right)_{2} \mathrm{SO}_{4}\right]$, using potassium ferricyanide as the indicator. Geilmann and Bretschneider ${ }^{11}$ used ferrous sulfate and ferroin indicator to determine the excess chromate. Jellinek and Ens ${ }^{12}$ titrated the excess chromate with a standard barium nitrate solution, using the disappearance of the yellow chromate color from the solution as the end point. A comparison solution was essential for locating the end point. Repiton ${ }^{13}$ determined excess chromate in an acidic solution by titrating with a standard stannous chloride solution using mercuric chloride as an 
indicator. The end point was indicated by the first opalescence in the solution due to the formation of mercurous chloride.

In attempts to shorten the procedure, some researchers chose to determine the excess barium using chromate as the titrant. Jellinek and Czerwinski ${ }^{14}$ titrated the excess barium with potassium chromate in the presence of methyl red indicator. At the end point the chromate hydrolyzed sufficiently to cause a basic reaction with the indicator (red to yellow).

In his titration of the excess barium with potassium chromate, Roth ${ }^{15}$ chose to use an external indicator, consisting of a paper impregnated with p,p'-diaminodiphenylamine. When the end point was reached, a drop of the titrated solution turned the paper blue. Germuth ${ }^{16}$ used lead nitrate on a spot plate as the extermal indicator. When the end point of the chromate titration was reached, a drop of the titrated solution would cause yellow lead chromate to form on the spot plate. Dominikiewicz ${ }^{17}$ suggested benzidine paper as an external indicator. A blue coloration of the paper was observed at the end point of the titration using ammonium potassium chromate.

In $1931, \mathrm{~J} . \mathrm{R}$. Andrews ${ }^{18}$ proposed a most interesting modification of the barium chromate method. He added sodium acetate and barium chromate solutions to the semple, adjusted the $\mathrm{pH}$ to basic, boiled the solution for five min- 
utes, cooled it, and removed the insoluble barium salts by filtration. After washing the precipitates with water, he added sulfuric acid to an appropriate aliquot of the filtrate. This was titrated with standard ferrous ammonium sulfate until the color of the reduced chromium could be seen. A $2 \mathrm{ml}$ excess of ferrous ammonium sulfate was then added. This excess was back titrated with a standard potassium permanganate solution to the faint purple end point. Hydrogen sulfide and any other reducing matter had to be removed before the determination was undertaken. The chromate methods for determining sulfate were subject to a number of errors. ${ }^{19}$ These included the coprecipitation of chromate ion with barium sulfate, the reduction of dichromate by chloride in acid solution, and the precipitation of other barium salts in alkaline solution.

These errors made researchers look at other anions which might be used in an indirect procedure similar to the chromate procedures. Some of the barium salts tried and their solubilities are: barium carbonate, $20 \mathrm{mg} / \mathrm{I}$ at $20^{\circ}$; barium oxalate, $93 \mathrm{mg} / \mathrm{l}$ at $18^{\circ}$; barium phosphate, insoluble; barium iodate, $80 \mathrm{mg} / 1$ at $0^{\circ}$; barium stearate, $40 \mathrm{mg} / 1$ at $15^{\circ}$; barium palmitate, $40 \mathrm{mg} / 1$ at $15^{\circ}$; and barium lauryl sulfate, no data available. 6

The use of carbonate was proposed by Howden ${ }^{20}$ in 1918. Pure barium carbonate was added to a neutralized sample of 
sulfate. Since barium sulfate is less soluble than barium carbonate, the sulfate was precipitated, releasing an equivalent amount of carbonate. After filtering off the precipitates, the filtrate was titrated with standard hydrochloric acid to a methyl orange end point. NorthallLaurie 21 suggested a similar procedure using phenolphthalein as indicator. The discharge of the pink color of the phenolphthalein indicated the end point.

E. P. Schoch ${ }^{22}$ proposed a procedure using thymolphthalein as the indicator. Sulfate was precipitated from a neutral solution with excess standard barium chloride. The excess barium was titrated with standard sodium carbonate. At the end point the carbonate was hydrolyzed, causing an increase in $\mathrm{pH}$ which in turn shifts the color of the indicator to blue. The use of a standard color enabled Schoch to locate the end point more accurately.

Shinkai 23 chose to add another step to the carbonate method. The sulfate was precipitated with excess barium chloride and the solution was filtered. Sodium carbonate was added to the filtrate precipitating barium carbonate. After a second filtration, a $1 \mathrm{ml}$ excess of standard hydrochloric acid was added to the filtrate and the filtrate was boiled for ten minutes. The hydrochloric acid which remained was titrated with a standard sodium hydroxide solution to a methyl red end point.

Rivett ${ }^{24}$ added a large excess of barium oxalate. 
After filtering the barium sulfate and any remaining barium oxalate, a suitable aliquot of the filtrate was acidified, heated to boiling, and titrated with potassium permanganate. The method worked best in solutions of high sulfate content $(>250 \mathrm{mg} / \mathrm{I})$.

Macchia ${ }^{25}$ proposed the use of barium phosphate. The excess phosphate produced when barium phosphate reacts with sulfate, was precipitated with ammonium molybdate. The precipitate was filtered, washed, and redissolved in a slight excess of sudium hydroxide. The base was titrated with hydrochloric acid to the phenolphthalein end point. Soibel'man 26 precipitated the sulfate by adding powdered barium iodate a.. determining the released iodate by adding potassium iodide and titrating with sodium thiosulfate in the presence of starch indicator. Lambert and Manzo 27 placed the barium iodate 1-hydrate in an i.j.n exchange column and passed the sample through it, allowing the sulfate to be exchanged for the iodate. A suitabla aliquot was collected, potassium iodide and acid were added, and the free iodine produced was titrated with standard sodium thiosulfate to the starch end point. The best results were obtained between $200-750 \mathrm{ppm}$. Atkinson 28 precipitated the sulfate with barium chloride. After filtration, the excess barium was titrated with potassium stearate with B. D. H. Universal Indicator. At the end point, the stearate hydrolyzed, giving an alka- 
line reaction to the universal indicator. The method suffered from interference from metals such as aluminum, zinc, calcium, and magnesium. Bahrdt ${ }^{29}$ used a method similar to this, but he substituted potassium palmitate for the stearate and phenolphthalein for the universal indicator.

Sodium lauryl sulfate was used by Davey and Gwilt 30 to precipitate excess barium after the precipitation of barium sulfate by barium chloride. After filtration, the excess sodium lauryl sulfate was titrated in a chloroformwater medium with benzalkonium chloride to a methyl yellow end point (red to yellow). Interferences included calcium, lead and strontium. At high concentrations other cations were also found to interfere.

Rhodizonic acid forms a bright red salt with barium. Attempts to use sodium rhodizonate as a direct end point indicator in the titration of sulfate with barium were unsuccessful. However researchers found that the reverse titration was usable and several methods were proposed. Strebinger and Zombory ${ }^{31}$ were the first to develop an indirect procedure. The sulfate was precipitated with barium chloride as usual. The excess barium was then titrated with a standard sulfuric acid solution, with the end point indicated by the disappearance of the red color of the barium rhodizonate. The $\mathrm{pH}$ of the solution determined the color observed -- yellow in 
neutral solutions and colorless in acid solutions. Potassium sulfate ${ }^{32}$ and ammonium sulfate ${ }^{33}$ were also tried as titrants in similar procedures.

one modification ${ }^{34}$ of the rhodizonate method called for the addition of an organic layer of nitrobenzene and iso-amyl alcohol to the aqueous sample. The barium rhodizonate was gathered at the interface between the two layers, thus effectively separating the indicator and the barium sulfate. When the excess barium was titrated with sulfuric acid, the color change of the indicator was much more distinct. As with the other rhodizonate methods, metal cations such as iron(III), lead, aluminum, zinc, cadmium, calcium, nickel, and cobalt interfered.

Hertyk and Gregorowicz ${ }^{35}$ used Variamine Blue as the indicator in their back titration of the excess barium with sodium sulfate or silver sulfate. The determination was carried out in an acetone-water medium.

The use of insoluble barium compounds to determine the excess barium after precipitation of barium sulfate remained the major approach to indirect sulfate determinations until 1950. In that year, Munger, Nippler, and Ingols 36 proposed an indirect volumetric determination which was based on the formation of a complex between barium ion and disodium dihydrogen ethylenediamine-tetraacetate (EDTA). The method was rather long and complicated, requiring a total of three titrations. EDTA was also known to react with 
magnesium and calcium, and so was being used to determine the hardness of water. This was one of the two independent titrations that had to be done before the sulfate determination. Determination of the alkalinity with hydrochloric acid was the other titration necessary.

The sulfate procedure began by the addition of acid equivalent to the alkalinity. The sample was boiled and excess standard barium chloride was added. After cooling the solution, ammonia-ammonium chloride buffer ( $\mathrm{pH} 10$ ) and Eriochrome Black $T$ indicator were added and the solution was titrated with standard EDTA to the blue end point. Since the end point in the presence of barium was poor, a small amount of standard magnesium ion was added to sharpen the end point.

The sulfate concentration was calculated using the following formula:

$$
(\mathrm{H}+\mathrm{B}+\mathrm{M}-\mathrm{T}) \times 48 \frac{1000}{\mathrm{~S}}=\text { ppm sulfate }
$$

where $H$ is milliequivalents of EDTA required for total hardness, $B$ is milliequivalents of barium chloride solution added, $M$ is milliequivalents of magnesium ion solution added to enhance the end point, $T$ is the total milliequivalents of EDTA used to titrate excess barium and magnesium, and $\mathrm{s}$ is milliliters of sample used. Copper, manganese, cobalt and nickel interfered with the determination. Belcher, Gibbons, and West 37.38 proposed two variations 
of the EDTA method. In one, they filtered off the barium sulfate precipitate, and dissolved it in a twofold excess of EDTA solution and 9M ammonia. The resulting mixture was boiled and cooled, and the excess EDTA was titrated with standard magnesium chloride in the presence of Eriochrome Black $T$ indicator to a clear red end point. In the second variation, after filtration of the barium sulfate precipitate, EDTA was added to the filtrate which contained excess barium. Now the excess EDTA was titrated as before with magnesium chloride.

Sijderius 39 was able to improve the EDTA method by introducing the use of a cation exchange column ( $\mathrm{H}^{+}$form) to remove the interfering cations including calcium and magnesium. This simplified the method by eliminating the need to determine hardness and alkalinity. The sulfate was precipitated after the removal of interferences by adding a precisely measured volume of barium chloride solution. The excess barium was determined with EDTA and Eriochrome Black $T$ as before. The difference between the volume of EDTA needed for a blank determination (i.e. all the barium added) and the volume needed for the sulfate sample, gave the milligrams of sulfate in the sample.

Similar titrations were proposed by changing the titrant, the buffer, or the indicator. Wanninen 40 used the tri-sodium salt of diethylenetriaminepentaacetic acid as the titrant. Casini $i^{41}$ used tetra-sodium ethylene- 
diaminetetraacetate with naphtholphthalein indicator. Bozhevol'nov and Kreingol'd $\mathrm{d}^{42}$ used the fluorescent indicator, Fluorexon. Hence, the titration was carried out in ultraviolet light until the solution matched the fluorescence of a blank. Novak 43 used the same indicator but changed the buffer solution to aid in masking interferences. The buffer solution contained triethanolamine (for aluminum), potassium cyanide (for iron, copper and zinc), tartaric acid and potassium hydroxide. other indicators tried were calce in 44 and phthalein purple. 45

The need for more than one standard solution and the use of multiple steps made the indirect procedures cumbersome. Researchers began looking for new indicators which could be used in a direct titration of sulfate with barium. Some researchers applied already known indicators, while others synthesized new compounds which they used as indicators.

One of the first attempts at a direct titration was made by $A$. W. Wellings 46 in 1932. He proposed titrating sulfate with barium hydroxide in the presence of the adsorption indicator, fluorescein, and a small amount of manganese or magnesium. The indicator was not adsorbed on the surface of the barium sulfate precipitate. It was adsorbed on the magnesium or manganese hydroxide, but only when no sulfate was present. Thus at the end of the titration, when all the sulfate had been precipitated, the 
indicator was adsorbed and a color change was observed. Any metal ions which formed colored hydroxides interfered with the procedure.

Giblin 47 titrated sulfate with barium chloride using an extermal indicator consisting of sodium rhodizonate on filter paper. At the end of the sulfate titration, the slight excess of barium would produce a red spot on the filter paper due to the formation of barium rhodizonate.

The first real breakthrough in the direct titration of sulfate came in 1933, when Schroeder 48 introduced the use of tetrahydroxyquinone as an indicator. A sample containing 80-800 ppm sulfate was carefully neutralized, an equal volume of ethanol and the indicator were added, and the solution was titrated with barium chloride. At the end point, the red barium salt of tetrahydroxyquinone was observed. Specific concentrations of other cations and anions were found to interfere.

Sheen and Kahler 49 studied the tetrahydroxyquinone method and made several observations and recommendations. The range of the method was expanded up to $30,000 \mathrm{ppm}$ and isopropanol was substituted for ethanol. By adjusting the $\mathrm{pH}$ to 4 , phosphate interference of up to $60 \mathrm{ppm}$ was eliminated. With sulfate concentrations over $2000 \mathrm{ppm}$, the end point could be sharpened by adding solid sodium chloride.

The major drawback to the tetrahydroxyquinone method 
was the inability to accurately locate the end point. The appearance of a psuedo end point and an indistinct color change in dilute solutions made researchers look for means of sharpening the end point. Among the approaches suggested were the use of tetrahydroxyquinone as an external indicator (a spot test on filter paper), 50 the use of a standard color filter of the same shade as the end point, 51 the addition of a small amount of silver nitrate, 52 and the addition of an inert blue dye such as xylene cyanol FF, indigo carmine, or methylene blue. 53

It was to be twenty years after Schroeder's introduction of tetrahydroxyquinone before another indicator was to be introduced. In 1954, Fritz and Freeland 54 proposed the use of Alizarin Red S (sodium alizarin-3-sulfonate) for the direct titration of macro quantities of sulfate. Since Alizarin Red $\mathrm{S}$ formed a weak complex with barium, it functioned as an adsorption indicator at the end of the sulfate titration. The procedure was carried out in a 30-40\% alcohol medium at a $\mathrm{pH}$ of $3 \cdot 0-3.5$ with barium chloride or perchlorate as the titrant. The end point was marked by a color change from yellow to pink. Interfering cations such as aluminum, iron(II) and (III), beryllium, tin, thorium, zirconium, copper, and the uranyl ion could be removed through the use of a cation exchange column.

The need to determine small quantities of sulfate led Fritz and Yamamura 55 to use Thorin [2(2-hydroxy-3,6-disulfo- 
1-naphthylazo)benzenearsonic acid] as an indicator. The titration with barium perchlorate was carried out in $80 \%$ ethanol solution at an apparent $\mathrm{pH}$ of 2.5-4.0 with the end point being a color change from yellow to pink. Phosphate and sulfite interfered. Interfering cations were removed by ion exchange. The method was able to determine sulfate concentrations as low as $10 \mathrm{ppm}$ in about five minutes.

Menis, Manning and $\mathrm{Bal1} 1^{56}$ developed an automated sulfate procedure based on the above method. They attached a titration feed assembly to a recording spectrophotometer which was set to record at a fixed wavelength ( $\left.520 \mathrm{~nm}^{*}\right)$ and a constant speed. As the titrant was slowly added, the absorbance of the sample solution was measured and the end point was determined from the recorded curve. By carrying out the titration in an iso-amyl alcohol-methanolwater medium, they were able to determine 6-50 $\mathrm{\mu g}$ of sulfate.

Markova 57 proposed to use stilbnaphthazo $\left[4,4^{\prime}\right.$-bis(2-hydroxy-1-naphthylazo)stilbene-2,2'-disulfonic acid] as the indicator. In an acetone-water medium the end point

*Historically wavelengths have been expressed in terms of millimicrons ( $\mathrm{m \mu}$ ), but the current convention used the term nanometers ( $\mathrm{nm}$ ). Hence for the remainder of this dissertation, wavelengths will be expressed as nanometers ( $\mathrm{nm}$ ). 
was a color change from rose to blue green.

The structures of these last two indicators showed a number of similarities. Several researchers observed this and attempted to synthesize a new metalloindicator for use in sulfate titrations which would be more sensitive and possibly more selective to barium. The result was a series of bis(phenylazo) derivatives of chromotropic acid (Figure 1), that could be used as indicators through their formation of barium complexes. 58,59

These indicators could be expected to react similarly since they have the same basic structure (Figure 1). Minor variations in color changes, $\mathrm{pH}^{\prime} \mathrm{s}$ and reaction medium were observed. The color change from the uncomplexed forms to the complexed forms ranged from rose or violet shades to blue, blue-violet, or green shades. Sulfate titrations usually required a $\mathrm{pH}$ of between 3 and 6 , and the presence of an organic solvent, usually acetone or ethanol. Barium chloride, barium perchlorate or barium nitrate was used as the titrant. Table 2 lists the reaction conditions for specific indicators.

Although these indicators were more sensitive than others, they were not selective. Other metal ions (i.e. beryllium, calcium, lead, aluminum, thorium, copper, nickel, cobalt, zinc, iron(II) and others) interfered, but these could be removed with an ion exchange column. Phosphate seemed to interfere with many of the indicators. 
FIGURE 1

STRUCTURE OF

METALIOINDICATORS DERIVED FROM

BIS (PHENYLAZO)CHROMOTROPIC ACID 


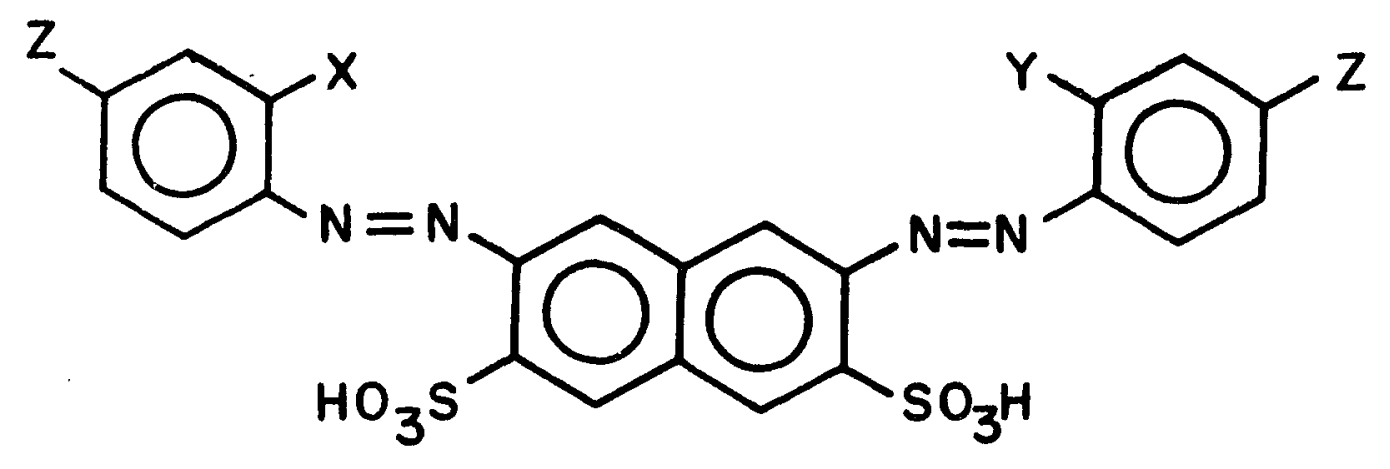

BIS (PHENYIAZO)CHROMOTROPIC ACID

$\mathrm{X}$

a) Carboxyarsenazo

b) Arsenazo III

c) Orthanil $K$

d) Sulfonazo III

e) Dinitrosulfonazo III

or Nitchromazo

f) Dimethylsulfonazo III

g) Dibromosulfonazo III

h) Chlorophosphonazo III

$\begin{array}{lll}-\mathrm{COOH} & -\mathrm{AsO}_{3} \mathrm{H}_{2} & -\mathrm{H} \\ -\mathrm{AsO}_{3} \mathrm{H}_{2} & -\mathrm{AsO}_{3} \mathrm{H}_{2} & -\mathrm{H} \\ -\mathrm{SO}_{3} \mathrm{H} & -\mathrm{COOH} & -\mathrm{H} \\ -\mathrm{SO}_{3} \mathrm{H} & -\mathrm{SO}_{3} \mathrm{H} & -\mathrm{H} \\ -\mathrm{SO}_{3} \mathrm{H} & -\mathrm{SO}_{3} \mathrm{H} & -\mathrm{NO}_{2}\end{array}$

$-\mathrm{SO}_{3} \mathrm{H}$

$-\mathrm{SO}_{3} \mathrm{H}$

$-\mathrm{CH}_{3}$

$-\mathrm{SO}_{3} \mathrm{H}$

$-\mathrm{SO}_{3} \mathrm{H}$

$-\mathrm{Br}$

$-\mathrm{PO}_{3} \mathrm{H}_{2}$

$-\mathrm{PO}_{3} \mathrm{H}_{2}$

$-\mathrm{Cl}$ 
TABLE 2

NETALIOINDICATORS DERIVED FROM BIS(PHENYLAZO)CHROMOTROPIC ACID

REACTION CONDITIONS

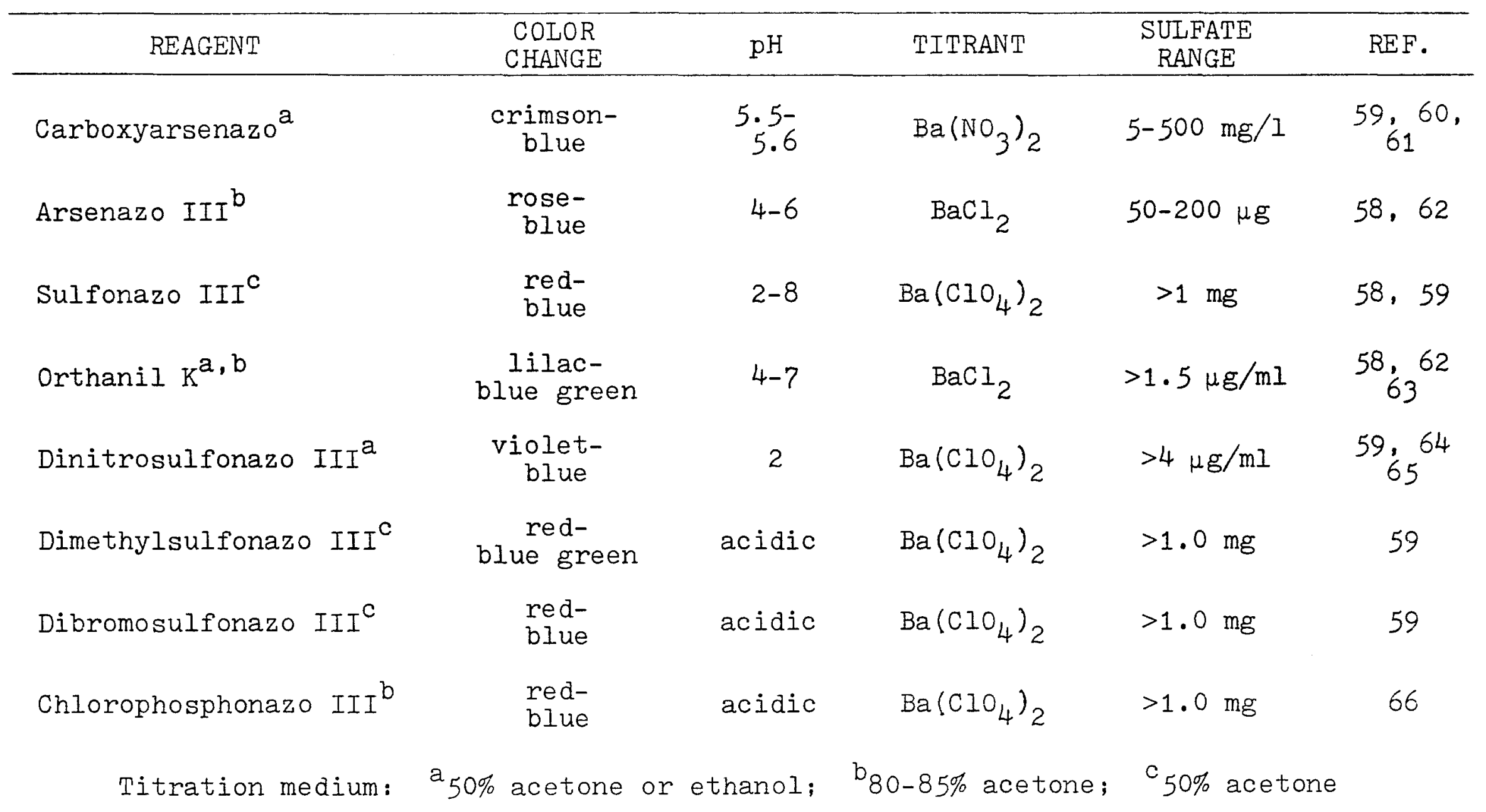


Barium was not the only cation used to determine sulfate. A number of investigators have attempted to use lead even though lead sulfate is much more soluble than barium sulfate $\left(42.5 \mathrm{mg} / 1\right.$ at $25^{\circ}$ compared to $2.2 \mathrm{mg} / \mathrm{l}$ at $\left.18^{\circ}\right) .6$ As with barium, both direct and indirect methods were developed.

One of the first indirect methods was proposed by oddo and Beretta. 67 The sulfate was precipitated with lead nitrate and filtered. The excess lead was titrated with potassium chromate using an extemal indicator consisting of a filter paper which had been dipped in an acetic acid solution of diphenylcarbazone, $\mathrm{CO}\left(\mathrm{NHNHPh}_{2} \cdot\right.$ At the end point, the slight excess of chromate produced a violet stain on the filter paper.

Finch ${ }^{68}$ precipitated the sulfate with an excess of lead acetate. After filtration, the excess lead in the filtrate was titrated with ammonium molybdate $\left[\left(\mathrm{NH}_{4}\right)_{2} \mathrm{MoO}_{4}\right]$ using tannin as an indicator.

The use of the light-emitting indicator, siloxene, was proposed by Kenny and coworkers. 69 After precipitating sulfate with an excess of lead nitrate, the lead was titrated with standard potassium chromate. At the end point, the excess chromate brought about a change in potential in the solution, causing the siloxene to emit light. By doing the titration in a dark chamber, the 
emitted light could be measured by a photometer. The photometer reading that signified the end point was predetermined by titrating a standard sulfate solution and observing the reading at the stoichiometric point of the titration.

Ethylenediaminetetraacetic acid (EDTA) was used by odler and Gebauer ${ }^{70}$ for two slightly different lead procedures. In both procedures, the sulfate was precipitated with lead acetate and was filtered. The first procedure dissolved the precipitate in sodium acetate, and titrated the lead with EDTA in the presence of Xylenol Orange. The second procedure involved titrating the excess lead in the filtrate with EDTA and Xylenol orange indicator. Riego ${ }^{71}$ described another EDTA-lead procedure. The sulfate was precipitated with lead acetate and filtered. It was then dissolved with excess EDTA in the presence of ammonium hydroxide and the ammonia-ammonium hydroxide buffer. The excess EDTA was then titrated with zinc chloride to the violet end point of Eriochrome BIack T.

A number of researchers proposed the direct titration of sulfate with lead nitrate, using a wide variety of indicators. The appearance of a yellow color due to lead iodide was used as the indicator. ${ }^{72}$ Eosin $^{73}$ changed from its yellowish flesh color to the red color of its lead salt at the end point. Diphenylcarbazone ${ }^{74}$ was applicable to the direct titrations due to the formation of a pale 
rose colored complex with lead at a $\mathrm{pH}$ of 4.0-5.6. In a $50 \%$ isopropanol solution at a pH of 6, PAR [4-(2-pyridylazo)resorcinol] was used as the indicator. 75

The use of dithizone as an indicator has been suggested by several researchers. Dithizone, which has a gieen color in acetone, forms a bright red complex with lead in acidic solutions (approximately pH 3). Nechiporenko 76 titrated sulfate directly with lead nitrate in a 30-40\% acetone medium, after adding a specified amount of hydrochloric acid. He was able to determine as little as $25 \mathrm{mg} / \mathrm{l}$. Calcium interfered and had to be removed using ion exchange. Navone 77 suggested the use of the reverse titration (i.e. titrating standard lead solution with a sulfate solution). Since ethanol was used as the solvent, the color change was from the red lead dithizonate to the blue color of the free indicator. This method required two titrations, one with the unknown sulfate solution and one with a standard sulfate solution of approximately the same concentration as the unknown. Calcium and phosphate were both found to interfere.

Niwa and Parry ${ }^{78}$ used a procedure similar to Nechiporenko's, but with a modification in the detection of the end point. The standard lead solution was added to the acidified sulfate sample in small increments and the absorbance of the solution was measured with a photometer at $620 \mathrm{~nm}$. The results were plotted and the end point located graph- 
ically. By using the photometric end point and an $80 \%$ acetone medium, Niwa and Parry were able to determine as litt]e as $20 \mathrm{mg} / \mathrm{l}$ of sulfate. Some cations, perchlorate, hydrogen peroxide, and high concentrations of chloride interfered with the method.

Barium and lead seemed to be the only two inorganic species that have been used for titrimetric determinations of sulfate. In 1915. Bruckmiller 79 proposed the use of the organic compound benzidine hydrochloride to determine sulfate in water. The sulfate was precipitated as the benzidine sulfate, filtered off, suspended in water, and titrated with standard sodium hydroxide in the presence of phenolphthalein. Iron(III) interfered but was easily removed by reduction to iron(II) with hydroxylamine hydrochloride before the sulfate was precipitated.

The major drawback to the benzidine method was the significant solubility of benzidine sulfate, $98 \mathrm{mg} / \mathrm{l}$ at $25^{\circ} .80$ Several attempts were made to minimize this problem. "Standard Methods" 52 recommended after filtration that the benzidine sulfate precipitate be washed with a saturated solution of benzidine sulfate instead of with plain distilled water, in order to prevent the dissolution of the precipitated sulfate. McConnell and Ingols ${ }^{81}$ chose to refrigerate the sample after the addition of the benzidine hydrochloride, and to wash the filtered precipitate with iced distilled water. According to McConnell and Ingols, their procedure 
improved the benzidine method by increasing the concentration range from $120-500 \mathrm{ppm}$ to $2.0-400 \mathrm{ppm}$.

Belcher and coworkers $80,82,83$ attempted to find new organic reagents that would have less soluble sulfates than benzidine. Although they successfully produced a number of new reagents, they applied only two of them to titrimetric sulfate determinations. Those two were $4,4^{\prime}$-diaminotolane with a solubility of $59 \mathrm{mg} / 1$ at $25^{\circ}$ and 4 -amino-4'chlorodiphenyl with a solubility of $15 \mathrm{mg} / 1$ at $25^{\circ}$. The recommended sulfate procedures were very similar to the benzidine procedure. The sulfate was precipitated, filtered, washed, dissolved or suspended in water, and titrated with sodium hydroxide using phenolphthalein or a mixed indicator of phenol red and bromothymol blue. Phosphate and aluminum interfered with both procedures. The sensitivity of the two methods was $10 \mathrm{mg}$ sulfate and $2.5 \mathrm{mg}$ sulfate respectively.

The titrimetric sulfate methods discussed thus far have required the precipitation of a sulfate compound. However, a few methods have been devised which do not involve precipitation.

A number of methods $84,85,86,87$ utilized the reduction of sulfate to hydrogen sulfide. All the methods were basically the same with minor modifications in the equipment, the reduction mixture, the absorbing solution, or the final titration method. The sample was placed in a 
reaction vessel and the reduction reagents were added. Among the reduction mixtures tried were a tin(II)-phosphoric acid mixture and a mixture of hydroiodic acid, hypophosphorous acid and hydrochloric acid. After the reduction reaction began, the hydrogen sulfide produced was absorbed in an appropriate solution for a subsequent titrimetric determination.

E. Rancke-Madsen ${ }^{84}$ absorbed the hydrogen sulfide in an iodine solution, prepared with potassium iodate, potassium iodide, cadmium sulfate and hydrochloric acid. The iodine and hydrogen sulfide reacted to form sulfur and iodide. The excess iodine was then titrated with sodium thiosulfate in the usual manner.

Kiba and coworkers ${ }^{85}$ chose to absorb the hydrogen sulfide in a solution of zinc acetate and acetic acid, while Volkov and 0stroumov ${ }^{86}$ chose to use cadmium acetate as the absorbing solution. In both cases, a standard iodine solution was added to the absorbing solution and the excess iodine was determined.

Archer ${ }^{87}$ used an absorbing solution of sodium hydroxide and acetone with a few micrograms of dithizone added. The resulting sulfidesolution, which is yellow, was titrated with mercuric or cadmium acetate. The end point was indicated by the appearance of a bright red color due to the formation of the metal dithizonate. Although an insoluble sulfide was formed, it did not mask the color 
change of the dithizone.

One other very unique titrimetric method for determining sulfates has been proposed. Dollman ${ }^{88}$ determined the sulfate as sulfuric acid. The sample was passed through a cationic exchange column in the hydrogen form. The effluent was collected and evaporated to $5 \mathrm{ml}$. The sample was then placed in an electric oven at $75^{\circ}$ to finish the evaporation. Ordinary volatile acids except phosphoric acid were driven off by this evaporation, leaving only sulfuric acid in the residue. This residue was dissolved in water and titrated with standard sodium hydroxide using bromocresol green as the indicator. Phosphate presented the most serious interference to the procedure.

\section{Colorimetric Methods}

The early development of sulfate methods was not limited to gravimetric or titrimetric procedures. Colorimetric procedures were also being developed. The early colorimetric procedures relied on the eye of the experimenter to make a visual comparison between the sample and standard solutions. With the advent of vacuum tubes, photomultiplier tubes, better optics, and some advanced electronic circuitry, researchers developed spectrophotometric instrumentation which was capable of providing 
usable data with greater reproducibility and speed.

One of the earliest colorimetric methods was proposed in 1912 by Brubaker. ${ }^{89}$ The procedure involved the measurement of the amount of chromate released when pure solid barium chromate was added to a sulfate sample. The barium sulfate precipitate and any remaining barium chromate were filtered off. The filtrate was made alkaline and was transferred to a colorimeter cylinder, where it was visually compared with standard chromate solutions. A blank determination had to be made to correct for the solubility of the barium chromate.

Other chromate procedures were to follow Brubaker's work. Urbach ${ }^{90}$ chose to determine the released chromate by reacting it with diphenylcarbazide and measuring the violet color produced. Babkin and coworkers ${ }^{91}$ added a barium sulfate suspension to the sample along with the barium chromate to enhance the complete precipitation of sulfate. The absorbance of the released chromate was measured in a $5 \mathrm{~cm}$ cuvette with a photocolorimeter.

Egami and Takahashi ${ }^{92}$ precipitated the sulfate with barium chloride and followed that with an alkaline solution of potassium dichromate to precipitate the excess barium. After adding additional base, the chromate was measured at $375 \mathrm{~nm}$ with $1 \mathrm{~cm}$ cuvettes. Sulfate in the range of $30-$ $900 \mu \mathrm{g}$ was determined using a standard calibration curve. Phosphate in large quantities interfered. 
Iwasaki and coworkers 93 proposed two possible variations of the chromate procedure. After precipitating the sulfate with a barium chromate suspension, ethanol and ammonia water were added to a $\mathrm{pH}$ of about 9.8 and the sample was allowed to sit for ten minutes before centrifugation. If the sample contained from 20-100 ppm, the absorbance of the resulting chromate solution was measured at $370 \mathrm{~nm}$ in $5 \mathrm{~mm}$ cells. For samples containing less than $20 \mathrm{ppm}$, diphenylcarbazide and acid were added and the absorbance of the resulting violet-colored solution was measured at $545 \mathrm{~nm}$. Lead, copper and phosphate interfered with the determination, even in small amounts.

Chromate was not the only substance used by early researchers for colorimetric determinations of sulfate. Iokhel'son 94 proposed the use of lead in a rather unique method. The sulfate was precipitated as lead sulfate, filtered, washed, and dissolved in sodium hydroxide. Sodium sulfide was added and the solution was shaken. The yellowish-brown color formed was visually compared to a lead standard prepared in a similar manner.

Klein 95 chose to use benzidine in his procedure. The sulfate was precipitated as benzidine sulfate, washed several times to purify, and then redissolved in acid. Through a series of organic reactions, the benzidine in solution was diazotized and coupled with a reagent which results in the formation of a violet color. The amount of 
color produced was read with a photoelectric colorimeter using a green filter. Since the color followed Beer's law, a standard could be run along with the sample using either a standard sulfate solution or a standard benzidine solution.

The use of barium chromate in a colorimetric method was to be the only barium method until 1957. When Bertolacini and Bamey 96 proposed the use of barium chloranilate as a reagent for sulfate determinations. In a $50 \%$ ethanol medium at $\mathrm{pH} 4$, solid barium chloranilate reacted with sulfate liberating an equivalent amount of chloranilate ion. The reddish-purple color of the chloranilate ion was measured in $1 \mathrm{~cm}$ cells at $530 \mathrm{~nm}$ vs. a blank prepared in the same manner. The amount of sulfate was determined from a standard calibration curve covering the concentration range of $2-400 \mathrm{ppm}$. Since cations such as aluminum, calcium, iron, and lead interfered, the sample was passed through an ion exchange column before the addition of the barium chloranilate.

Later work by Bertolacini and Barney 97 showed that the chloranilate ion could also be measured at $332 \mathrm{~nm}$. This wavelength proved to be more sensitive than $530 \mathrm{~nm}$. Hence samples of low sulfate content (as little as $0.06 \mathrm{ppm}$ ) were best determined at $332 \mathrm{~nm}$. Gales, Kaylor and Longbottom $^{98}$ have automated the barium chloranilate method using a Technicon Autoanalyzer. They measured the absorb- 
ance of the chloranilate ion at $520 \mathrm{~nm}$.

A number of the metalloindicators that were developed for use in sulfate titrations were found to be usable as colorimetric reagents. Budesinsky and Vrzalova 99 developed a method using Sulfonazo III (see Figure 1). The sulfate was precipitated with a known concentration of barium solution. After standing for twelve hours and filtering, the excess barium in solution was determined by adding a buffer at $\mathrm{pH} 2.4$ and a solution of Sulfanazo III. The absorbance of the resulting blue-colored barium complex was measured at $638 \mathrm{~nm}$ using $2 \mathrm{~cm}$ cells. Similar procedures were developed for dinitrosulfanazo III ${ }^{100}$ and for a new derivative, carboxynitrazo. ${ }^{101}$ In each case, interfering cations were removed via ion exchange before the determination was carried out.

Another titration indicator, Thorin, was used by Persson 102 in an automated colorimetric procedure. The method was used to determine low concentrations $(0-10 \mu \mathrm{g} / \mathrm{ml})$ of sulfate.

The need for a sensitive, fully automated procedure for determining sulfate led Lazrus, Lorange and Lodge 103 to develop a new colorimetric test using the reagent, methylthymol blue (MTB), $\left\{3,3^{\prime}\right.$-bis $[N, N$-bis (carboxymethyl)aminomethyl]thymolsulfonephthalein\}. 104 After passing the sample through an ion exchange resin to remove interfering cations, an alcoholic solution containing the barium-MTB 
complex (bright orange color) was added, and the solution was thoroughly mixed to allow complete precipitation of barium sulfate. Sodium hydroxide was added to bring the $\mathrm{pH}$ up to 12.8 , causing the MTB to change color to blue in the complexed form with barium or grey in the uncomplexed form. The absorbance of the uncomplexed MTB was measured at $465 \mathrm{~nm}$. The concentration range for the method was 0.5-50 ppm, but the range could be extended by diluting the sample.

Adamski and Villard ${ }^{105}$ modified the automated MTB method, applied it to water and wastewater samples, and compared the NITB method to the current routine laboratory methods for sulfate. Using a Technicon Autoanalyzer, they established three calibration ranges - $0-15 \mathrm{ppm}, 0-50 \mathrm{ppm}$, and $0-200 \mathrm{ppm}$. Their evidence indicated that the MTB method was satisfactory for routine determination of sulfate. McSwain, Watrous, and Douglass ${ }^{106}$ changed the NITB method by choosing to measure the decrease in the blue color of the barium methylthymol blue complex at $460 \mathrm{~nm}$.

Barium was not the only cation used for the determination of sulfate. It was known that certain cations, namely thorium and zirconium, formed stable complexes with sulfate. These complexes were to form the basis of numerous colorimetric procedures.

A number of metalloindicators formed distinctly colored, soluble complexes with both thorium and zirconium. 
The amount of sulfate in a sample could thus be determined by measuring the decrease in the absorbance of the cationindicator complex or by measuring the increase in absorbance of the free indicator. Other cations which form complexes with the indicators interfered but could be removed with an ion exchange column. Phosphate and fluoride interfered by forming complexes with the thorium and zirconium, and must be absent from the sample. Some of the indicators suggested were Pyrocatechol Violet, ${ }^{107}$ Alizarin Red ${ }^{107}$ Eriochromecyanine $\mathrm{R},{ }^{107}$ Alizarin, ${ }^{108}$ Acid Chromium Blue $K,{ }^{108}$ and SPADNS $\{4,5$-dihydroxy-3-[(p-sulfophenyl)azo $]-$ naphthalene-2,7-disulfonic acid trisodium salt $\}$ 107,109

Not all of the methods proposed allowed the use of either thorium or zirconium. Some methods required the specific use of only one of them. One of these methods was proposed in 1955 by Lambert, Yasuda and Grotheer. ${ }^{110}$ Their colorimetric procedure used a reagent containing thorium borate threated with an Amaranth dye. When the reagent was mixed with a sulfate solution, the thorium sulfate complex was formed releasing a proportional amount of the dye, which was determined colorimetrically at $521 \mathrm{~nm}$ with a $1 \mathrm{~cm}$ cell. Bicarbonate, fluoride and phosphate were the most serious interferences. The calibration range of the method was $0-400 \mathrm{ppm}$ sulfate.

Several other thorium methods were based on the decomposition or suppression of the color of a thorium-indicator 
complex through the formation of the thorium-sulfate complex. Palaty ${ }^{11}$ determined $0-50 \mathrm{mg} / \mathrm{l}$ sulfate using the indicator, Xylenol orange. The thorium-Xylenol orange complex was formed at $\mathrm{pH} 1.4$ and was measured at $553 \mathrm{~nm}$ in a $3 \mathrm{~cm}$ cell. Nasu ${ }^{112}$ determined $0.2-5 \mathrm{ppm}$ sulfate using morin in an alcoholic medium. The absorbance of the thoriummorin complex was measured at $410 \mathrm{~nm}$ against a reagent blank. Nasu, Kitagawa and Mori ${ }^{113}$ chose to use flavonol to measure sulfate in amounts of less than $100 \mu \mathrm{g}$. The decrease in absorbance was measured at $390 \mathrm{~nm}$ with a final solution $\mathrm{pH}$ of 2.6. In all of the methods, phosphate and fluoride were interferences.

Hems, Kirkbright and West ${ }^{114}$ developed a method using zirconium and methylthymol blue. The method was based on the ability of sulfate to catalyze the slow reaction between zirconium and methylthymol blue in acidic solution. A direct relationship between the amount of sulfate and the formation of the zirconium-NTB complex existed over the sulfate range of 0.1-2.4 ppm. Large amounts of sulfate inhibited the zirconium-MTB reaction completely owing to the formation of the more stable zirconium-sulfate complex. A development time of sixty minutes was necessary before the absorbance of the complex could be measured at $586 \mathrm{~nm}$ using $5 \mathrm{~mm}$ silica cells. As expected, phosphate and fluoride interfered.

Iron has also been used for determining sulfate. The 
formation of a sulfate complex with iron(III) was used by Gogue $1^{115}$ and by Babko and Markova. ${ }^{116}$ Goguel chose to measure the iron(III) sulfate complex directly at a wavelength of $325 \mathrm{~nm}$ for sulfate concentrations of $10-200 \mathrm{mg} / \mathrm{I}$ or at $355 \mathrm{~nm}$ for concentrations of $200-500 \mathrm{mg} / 1$. Phosphate, fluoride and excess iron(III) interfered. Babko and Markova chose an indirect procedure in which they added ferric thiocyanate to a sulfate sample and measured the absorbance of the remaining thiocyanate complex at $420 \mathrm{~nm}$. Fluoride and iron(III) interfered.

The colorimetric determinations of sulfate were not restricted to the use of metal ions. A number of reduction procedures were developed which utilized a spectrophotometric finish. One of the earliest reduction methods was developed by St. Lorant ${ }^{117}$ in 1929. The sulfate was reduced to hydrogen sulfide using hydroiodic acid, red phosphorus and formic acid. The hydrogen sulfide was trapped in a zinc acetate solution and treated with ferrous ammonium sulfate and p-aminodimethylaniline sulfate which resulted in the formation of methylene blue and methyl red in a ratio of 50:1. The sample was compared to a standard containing the two dyes in the same ratio. Johnson and Nishita ${ }^{118}$ used St. Lorant's method after modifiying the apparatus and reagents. They measured the methylene blue at $670 \mathrm{~nm}$ with $1 \mathrm{~cm}$ cells over the range of 1-300 $\mu \mathrm{g}$ of sulfate. Organic sulfur compounds and nitrate 
interfered in the determination. Gustafsson ${ }^{119}$ also used the methylene blue method but chose to use a different reducing mixture, consisting of hydroiodic acid and hypophosphorus acid in an acetate solution.

Davis and Lindstrom ${ }^{120}$ also proposed a reduction method but used a different colorimetric finish. A mixture of hydroiodic acid, acetic anhydride, and sodium hypophosphite was used to reduce the sulfate, and the hydrogen sulfide produced, was swept into a solution containing ferric ammonium sulfate, 1,10-phenanthroline and a chloroacetic acid-chloroacetate buffer. The ferric ion was reduced by the sulfide to ferrous ion, which reacted with the 1,10-phenanthroline to form a bright orange complex. This complex was measured at $510 \mathrm{~nm}$ vs. water, using $10 \mathrm{~cm}$ cells for a $0-10 \mu \mathrm{g}$ calibration curve, and $1 \mathrm{~cm}$ cells for a $0-100$ $\mu g$ calibration curve. Nitrite and other sulfur containing compounds interfered with the determination.

Recently, a novel reduction method was proposed by Maddalone, McClure and West. ${ }^{121}$ Sulfate was precipitated as 2-perimidinylammonium sulfate, " which was thermally de-

* This compound was originally developed by Stephen, 123 who named it 2-aminoperimidine sulfate. These researchers changed the name to perimidylammonium sulfate. After further consideration of the nomenclature rules, the compound has been renamed 2-perimidinylammonium sulfate, and this is the name that will be used throughout the remainder of this dissertation. 
composed in a nitrogen atmosphere at $500^{\circ}$ to yield sulfur dioxide. The sulfur dioxide was trapped and measured according to the West-Gaeke procedure. More details on this procedure will be provided in Chapter III.

A colorimetric method which is quite different from any of those already mentioned, was proposed by Ohlweiler and Meditsch. ${ }^{122}$ Their method was based on the color formed when sulfuric acid and saccharose were heated. The sulfuric acid was formed by passing a sulfate sample through a cation exchange column. The resulting solution was evaporated to dryness in the presence of saccharose and heated for sixty minutes at $85^{\circ}$. The residue was taken up in $10 \mathrm{ml}$ of water and the brownish-yellow color was measured at $420 \mathrm{~nm}$. The method was applicable to $0-40 \mathrm{ppm}$ sulfate.

\section{Spectrophotometric Methods}

Although colorimetry is perhaps the most widely known and used spectrophotometric technique, methods have been developed utilizing other spectrophotometric techniques, such as turbidimetry or nephelometry, flame photometry, atomic absorption, fluorimetry, and ultraviolet spectroscopy. Historically, turbidimetric methods were developed first with other methods being introduced as the instrument- 
ation and techniques became available.

The early turbidimetric methods were very much like the early colorimetric methods, in that they relied on a visual comparison of samples and standards. As with colorimetry, the development of reliable instrumentation made the procedures faster and more reproducible.

The first turbidimetric method was published in 1896 by J. I. D. Hinds. 124 He noted that when a solution of barium chloride was added to a sulfuric acid solution contained in a graduated glass cylinder, the flame of a candle held under the cylinder was obscured by the presence of the barium sulfate precipitate. By adjusting the height of the liquid in the cylinder, he was able to make the flame completely invisible. A direct correlation between the height of the liquid and the sulfate content of the sample was observed and was easily determined using a set of sulfate standards.

Jackson ${ }^{125}$ made several modifications to Hinds' method to improve its ease and accuracy. Differences in the intensity of the candle, in the distance of the candle to the bottom of the cylinder, and in the distance of the observer's eye to the top of the cylinder, as well as different observers, affected the results obtained by Hinds' method. Jackson devised a simple apparatus which 
helped to eliminate some of these problems. A standard candle of one candle power was placed at a given distance from the bottom of the cylinder, and the cylinder was held in place by a brass holder which was painted black inside to prevent reflection and which had a broad shield near the bottom to keep the strong light of the candle from the eye of the observer. The sample solution was first treated with barium chloride to precipitate barium sulfate and was then transferred between the cylinder and a beaker until the flame of the candle was no longer observed. By measuring the height of the solution and comparing it to standard samples, the percent sulfate in the sample was calculated.

The next major improvement in the turbidimetric method didn't appear until 1935, when Sheen, Kahler and Ross $^{126}$ proposed an improved procedure based on a new turbidimeter. Although the turbidimeter still required a visual comparison, it was more convenient since the sample would now require far less handling. The apparatus was designed in such a way that the sample solution was illuminated from two different directions by a light bulb. One narrow beam of light was directed through the sample vertically into an eye piece, while a second broad illumination occurred from the side of the sample. Due to the presence of barium sulfate crystals in the sample, this lateral illumination resulted in scattered light. When the 
analyst looked through the eye piece, she observed light of two different intensities. By turning a graduated drum knob connected to a slit under the sample, the intensity of the vertical light beam was increased or decreased until its intensity matched the intensity of the scattered light. The numerical setting of the drum knob was now read and the amount of sulfate in the sample was determined using standard calibration curves which plotted sulfate concentration against the numerical settings of the drum knob. Insertion of different filters between the slit and the sample allowed the preparation and use of four calibration ranges: $0-5 \mathrm{ppm}, 0-15 \mathrm{ppm}, 0-50 \mathrm{ppm}$, and $0-100 \mathrm{ppm}$. The color due to iron was the only notable interference, but corrections could be made for it.

In 1954, Thomas and Cotton ${ }^{127}$ proposed a turbidimetric method which utilized a spectrophotometer, thus eliminating the need for visual comparisons. The turbidity due to barium sulfate was formed in the usual manner by adding barium chloride to the sample. Using a Beckman Spectrophotometer, Model DU, the optical density of the sample was measured at $380 \mathrm{~nm}$ with $1 \mathrm{~cm}$ cells. Interference due to color or turbidity of the initial sample was automatically subtracted by reading the optical density of the initial sample concurrent with the treated sample. The calibration range was from $2-80 \mathrm{ppm}$ sulfate.

As techniques and instrumentation improved, the need 
to form a reproducible, uniform suspension of barium sulfate became very important. In the early methods, the formation of uniform, optimum size particles was aided by the addition of hydrochloric acid or a mixture of hydrochloric acid and sodium chloride. Later, stabilizing or suspending agents were added to improve the reproducibility and stability of the sulfate suspensions.

A wide variety of suspending agents and stabilizing mixtures were tried. Volmer and Frohlich ${ }^{128}$ added glycine and gum arabic, while Honda ${ }^{129}$ used gelatin as the suspending agent. Chaudhuri and coworkers ${ }^{130}$ prepared a medium of $50 \%$ glycerin, $10 \%$ glucose, $2.5 \%$ hydrochloric acid and $37.5 \%$ water, and measured the absorbance of the solution at $450 \mathrm{~nm}$. Rossum and Villarruz ${ }^{131}$ used a buffer solution consisting of magnesium chloride, sodium acetate, potassium nitrate, and acetic acid. The absorbance measurements were made at $420 \mathrm{~nm}$ with a $4 \mathrm{~cm}$ path length. Toennies and Bakay ${ }^{132}$ proposed a medium of ethanol, dipropylene glycol and water for their sulfate procedure.

The turbidimetric method was listed in the current edition of "Standard Methods"1 after the gravimetric method. According to "Standard Methods", the procedure was more rapid but was less accurate at most sulfate concentrations. The usual range was $0-40 \mathrm{mg} / \mathrm{l}$, although up to $60 \mathrm{mg} / \mathrm{I}$ may be determined. A conditioning reagent of glycerol, hydrochloric acid, water, ethanol, and 
sodium chloride was added to the sample before the addition of solid barium chloride. The solution was stirred for one minute and the turbidity was measured with a nephelometer or a spectrophotometer at $420 \mathrm{~nm}$ with a $4-5 \mathrm{~cm}$ path length. Calibration curves vere prepared in the same manner and must be checked after every three or four samples.

Although most turbidimetric and nephelometric methods utilize barium sulfate, several alternatives have been proposed. Omura ${ }^{133}$ developed a microbiological procedure for small quantities of sulfate in which a water sample was treated with the bacteria, Escherichia Coli, and incubated for $8-10 \mathrm{hrs}$ at $35^{\circ}$. The resulting growth was measured turbidimetrically and the sulfate determined from a calibration curve. Although most ions did not interfere, some sulfur compounds inhibited the bacterial growth.

Martin and Stephen ${ }^{134}$ proposed a nephelometric method in which the sulfate was precipitated with 4-amino-4'chlorodiphenyl hydrochloride. A stabilizing agent of peptone, gum ghatti, hydrochloric acid, and water was added to the sample before placing the sample in a nephelometer for measurement. A calibration curve in the range of $2.5-25 \mathrm{ppm}$ was prepared using the most concentrated standard to set the maximum reading of the nephelometer and distilled water to set the zero reading. Disadvantages 
of the method included the interference of fluoride and phosphate and the short shelf life of the stabilizing agent.

Another nephelometric method was developed by Stephen, 123 based on the precipitation of sulfate as 2-perimidinylammonium sulfate (see footnote on page 45 ). The reagent was added directly to a $5 \mathrm{ml}$ sample, diluted to $10 \mathrm{ml}$, and measured after ter minutes with a nephelometer. Calibration curves were prepared for three different concentration ranges: $0-0.5 \mathrm{ppm}, 0-1 \mathrm{ppm}$, and $0-5 \mathrm{ppm}$. An extensive examination showed that many other anions formed precipitates with the reagent, but most were not present in sufficient quantity in water samples to cause serious interferences. The most serious potential interferences were phosphate, fluoride, iodide and bromide.

Audouze and Bonometti ${ }^{135}$ took Stephen's procedure and automated it for use in determining sulfur pollutants in air and sulfates in water. Measurements were made at $465 \mathrm{~nm}$ after precipitating the sulfate at $\mathrm{pH} 5-7$.

The introduction of other spectrophotometric techniques didn't occur until 1957 and 1958, when flame photometric methods were introduced by Burriel and coworkers, 136 and Shaw. ${ }^{137}$ Both procedures were based on the precipitation of sulfate with a known quantity of barium and subsequent determination of the excess barium. Barium calibration curves were used to find the concentration of excess barium. 
The sulfate concentration was then found by calculation. Specific details pertaining to the flame conditions and the emission properties of barium were also investigated by both researchers. Burriel and coworkers determined sulfate in the range of $0-70 \mathrm{ppm}$, while Shaw measured $6-24 \mathrm{mg}$ sulfate at $515 \mathrm{~nm}$.

Cullum and Thomas ${ }^{138}$ used a slightly different approach. The sulfate was precipitated as barium sulfate, filtered, and dissolved in a solution of ammonium EDTA. The resulting solution was analyzed with a flame photometer equipped with two different filters, and the sulfate was determined from calibration curves prepared over the range of $0-1000$ ppm sulfate.

Pleskach and Chirkova ${ }^{139}$ developed a method similar to Shaw's. However, instead of preparing a calibration curve using barium standards, they chose to use sulfate standards treated in exactly the same manner as the samples. In this way any error due to the solubility of barium sulfate would be compensated for. All measurements were made at $493 \mathrm{~nm}$. At this wavelength serious background emission was observed due to potassium, sodium and calcium, making it necessary to run untreated samples for background correction. The method was successfully applied to samples containing less than $200 \mathrm{ppm}$ sulfate.

Crider and coworkers ${ }^{140}$ recently introduced a prototype instrument designed specifically to determine sulfate in 
aqueous solution. The instrument, using a hydrogen-rich hydrogen-air flame and a chemiluminescence detector, operated. in a manner similar to other flame instruments. Initial work showed that the instrument was capable of determining as little as $2 \mu \mathrm{g} / \mathrm{ml}$ sulfate. Further study on the instrument and its application to real samples was continuing at the time the work was piblished.

Another new flame technique has been proposed by Sand and Huber. 141 The technique, called flame emission inhibition titration, was based on the ability of sulfate to inhibit the flame emission signal of various cations, in this case, calcium. A standard calcium solution was slowly titrated into a sulfate sample, which was being aspirated into a hydrogen-air flame. The emission signal produced by the calcium was continuously measured using a $620 \mathrm{~nm}$ interference filter, and was recorded, resulting in a unique curve from which the titration endpoint was located. Sulfate contents as low as $0.2 \mathrm{ppm}$ were then determined by calculation. All interfering cations were removed by ion exchange prior to the titration.

Atomic absorption spectroscopy has also been used to determine sulfate. Dunk, Mostyn and Hoare ${ }^{142}$ determined 0-100 $\mu \mathrm{g} / \mathrm{ml}$ sulfate by precipitating the sulfate with a known concentration of barium and measuring the excess barium at $553.5 \mathrm{~nm}$ using an air-acetylene flame. Calibration curves were prepared with sulfate standards treated 
in the same manner as samples. Little and coworkers 143 also used atomic absorption, but chose to precipitate the sulfate as lead sulfate in $40 \%$ ethanol and determine the excess lead.

Looyenga and Huber ${ }^{144}$ have developed a new technique called atomic absorption inhibition titration, which is similar to the flame emission method described earlier. This particular method was based on the inhibition or depression of the atomic absorption signal of magnesium due to the presence of sulfate. The sulfate sample was titrated with a standard magnesium solution as the sample solution was being aspirated into a hydrogen-air flame. The magnesium absorption signal was continuously monitored at $285.2 \mathrm{~nm}$ and the titration curve was recorded. The endpoint of the titration was indicated by an increase in the absorption signal, and the sulfate concentration was calculated. Phosphate and silicate interfered and must be absent from the sample. Lin and Huber ${ }^{145}$ subsequently applied the technique to surface and drinking waters containing sulfate concentrations up to $30 \mathrm{ppm}$.

At about the same time that flame photometric methods were being introduced, Nazarenko and Shustova ${ }^{146}$ introduced a fluorometric method using the reagent, salicylfluorone [9-(o-hydroxyphenyl)trihydroxyfluorone], which forms a complex with thorium in weakly acid solution. The sulfate was complexed with excess thorium, which was then complexed 
with excess salicylfluorone. The excess reagent, which fluoresces a greenish-yellow color in ultraviolet light, was determined by comparison to standards in the filtered light of a mercury quartz lamp.

Two other fluorometric methods using throium complexes have been developed. Both methods were based on the suppression or quenching of the fluorescence of a thorium complex in the presence of sulfate, due to the formation of the thorium-sulfate complex. Guyon and Lorah ${ }^{147}$ used morin $\left(3,5,7,2^{\prime}, 4^{\prime}\right.$-pentahydroxyflavone), whose thorium complex fluoresces a bright green color under ultraviolet radiation. Determinations of $0-40 \mu \mathrm{g}$ of sulfate were conducted in an $80 \%$ ethanol medium at $\mathrm{pH} 2.35$ using a Coleman Model $12 \mathrm{~B}$ photofluorometer with a 5113 primary filter and a 3486 secondary filter. Nasu and coworkers ${ }^{113}$ used the thorium complex of flavonol to determine less than $100 \mu \mathrm{g}$ of sulfate in an ethanol medium of $\mathrm{pH}$ 2.6. The decrease in fluorescence was measured at $470 \mathrm{~nm}$. In both methods, aluminum, iron, fluoride, and phosphate interfered.

A fluorometric method based on a zirconium complex has been developed by $\operatorname{Tan}$ and West. ${ }^{148}$ When sulfate was present in a solution containing zirconium and Calcein blue at $\mathrm{pH}$ 1.9, a distinct increase in the fluorescence of the zirconium-Calcein blue complex was observed. The fluorescence increase was linear over the sulfate concentration 
range of 2-12000 ppm. Excitation and measurement of the complex occurred at $350 \mathrm{~nm}$ and $410 \mathrm{~nm}$ respectively. Fluoride, phosphate, oxalate, tartrate, iron(III), and cobalt(II) interfered with the determination.

The introduction of a number of new compounds for the precipitation of sulfate has led to the development of ultraviolet absorption methods using these same compounds. A. S. Jones and Letham ${ }^{149,150}$ precipitated 30-120 $\mu \mathrm{g}$ of sulfate with a known amount of 4-amino-4'-chlorodiphenyl hydrochloride. The excess reagent was determined at $254 \mathrm{~nm}$ in $1 \mathrm{~cm}$ cells. Phosphate was the only serious interference.

P. A. Jones and Stephen ${ }^{151}$ determined the excess 2-perimidinylammonium chloride at $305 \mathrm{~nm}$ with $1 \mathrm{~cm}$ silica cells. By varying the volumes of the reagent and the final solution, calibration ranges of $4-20 \mathrm{ppm}, 10-60 \mathrm{ppm}$, and 20-120 ppm were established. Phosphate, fluoride, nitrate, and bicarbonate interfered. Burns and coworkers ${ }^{152}$ developed a similar procedure for determining $0-30$ ppm sulfate in rainwater. They chose to add a small amount of 2-perimidinylammonium sulfate to act as a nucleating agent in the precipitation of the sulfate in the sample. Measurements were made at $305.5 \mathrm{~nm}$ with a $0.2 \mathrm{~cm}$ cell.

E. Electrochemical Methods

The determination of sulfate using electrochemical 
techniques has seen fewer variations in the basic chemical reactions than the previous techniques discussed. Precipitation of sulfate with barium or lead and reduction of sulfate to hydrogen sulfide were still the main reactions involved. Only the method of detection of a titration endpoint or the method of determination of a liberated species was changed. The methods used included potentiometry, conductimetry, amperometry, and polarography.

A significant number of potentiometric titration procedures have been developed, utilizing a wide variety of sensing electrodes. Direct measurement of the sulfate content was not possible, since sulfate-sensing electrodes had not been developed. Thus the titration procedures were indirect measurements, requiring the determination of another species whose concentration was relative to the sulfate concentration.

Anders Ringbom ${ }^{153}$ developed one of the first potentiometric titrations of sulfate. The sulfate was titrated with a solution of lead nitrate using a $\mathrm{Pb}_{2} \mathrm{Fe}(\mathrm{CN})_{6}$ $\mathrm{Fe}(\mathrm{CN})_{6}^{--}$electrode. Since a ten-fold excess of lead resulted in only a small change in the potential of the electrode, sulfate concentrations of less than $0.025 \mathrm{~N}$ made it difficult to locate the correct endpoint. Cassidy ${ }^{154}$ precipitated the sulfate in an alcoholic medium with an excess of lead and determined this excess by titration with potassium chromate. After all the excess 
lead was precipitated, the chromate underwent a hydrolysis reaction. This reaction occurred at a $\mathrm{pH}$ of 5.5 . Thus the titration endpoint was determined by measuring the solution $\mathrm{pH}$ with a standard glass electrode. Any substance which could act as a buffer, and thereby affect the solution $\mathrm{pH}$, was considered an interference and must be absent. The titration procedure devised by vail', Kremer and Mirnaya ${ }^{155}$ also used an excess of lead to precipitate the sulfate. The excess lead was titrated with sodium sulfide or thioacetamide using a sulfide-silver electrode that was previously developed by Kremer and Vail'. Unlike the electrode used by Ringbom, this electrode resulted in a titration curve with a large potential jump at the endpoint, making it possible it determine as little as $5 \mathrm{mg}$ sulfate.

The development and commercial introduction of a leadselective electrode provided Ross and Frant ${ }^{156}$ with a means of directly titrating sulfate. By adding an equal volume of dioxane to the sulfate sample before titrating it with a standard lead perchlorate solution, the endpoint break in the titration curve was considerably increased. The dioxane also decreased the solubility of the lead sulfate allowing as little as $5 \times 10^{-4} \mathrm{M}$ sulfate to be titrated conveniently. The lead electrode suffered from interferences due to copper, mercury, silver, and phosphate, while high concentrations of chloride, nitrate and bicarbonate decreased the endpoint potential break. 
While attempting to determine sulfate in sea water using the lead-selective electrode procedure of Ross and Frant, Mascini ${ }^{15}$ found it necessary to remove the high concentrations of chloride and bicarbonate. He accomplished this by using two different cation exchange columns. The first resin in the silver form removed the chloride and the second resin in the hydrogen or acid form removed the silver liberated by the first resin. At this point, the sample was acidic and the bicarbonate was eliminated. An aliquot of the sample was then diluted with 1,4-dioxane and titrated potentiometrically with lead nitrate using the lead electrode. Sulfate concentrations from 20-3000 ppm were successfully determined.

Lead was not the only titrant used. Vorob'ev 158 developed one of the first methods which utilized barium salts. Excess barium was added to precipitate the sulfate and this excess was titrated with potassium chromate. At the endpoint, the hydrolysis of chromate resulted in a decrease of the hydrogen ion concentration which was measured with an air electrode (platinum electrode saturated with air). The best results were obtained with sulfate concentrations of $50-100 \mathrm{mg} / 1$.

Miller 159 proposed a new electrode to be used for the direct potentiometric titration of sulfate with barium. The $\mathrm{Mol} \mathrm{MOO}_{3} \mathrm{IBaSO}_{4}$ electrode was sensitive to barium concentration changes in acid or neutral media. Much sharper 
titration curves were obtained in acid solutions, but the acid concentration must be kept below $0.05 \mathrm{~N}$ in order to obtain reliable results. The usable concentration range was 0.008 to $0.100 \mathrm{~N}$ sulfate.

Rechnitz, Iin and Zamochnick ${ }^{160}$ attempted to produce a sulfate-sensitive membrane electrode for use in the direct determination of sulfate. The sensing portion of the electrode consisted of a silicone rubber membrane impregnated with fine barium sulfate particles. Unfortunately the electrode was not particularly selective and direct measurements of sulfate solutions were unsatisfactory. However, the electrode was found to be usable as an indicator electrode in the titration of sulfate with barium chloride. Jasinski and Trachtenberg 161,162 based their potentiometric sulfate titration on an iron-selective electrode. The electrode was formed from an iron-doped chalcogenide glass, $\mathrm{Fe}_{2}\left(\mathrm{Ge}_{28} \mathrm{Sb}_{12} \mathrm{Se}_{60}\right)$, and responded to uncomplexed ferric ion. Sufficient ferric ion was added to the sulfate sample to form the soluble ferric-sulfate complex. As the resulting solution was titrated with barium chloride, the complex was broken up due to the formation of barium sulfate and ferric ion was released into the solution. This free iron was sensed by the electrode and a potential increase was observed. The endpoint of the titration occurred when the potential remained constant. The limit of detection using this electrode was $50 \mathrm{mg} / \mathrm{l}$. Potassium, magnesium 
and calcium posed the most serious interferences with this electrode.

Just recently several companies ${ }^{163}$ have introduced solid-state specific ion electrodes for sulfate. The electrodes commercially available through Chemtrix, Inc. and Sensorex were designed for the direct measurement of sulfate in the range of 10-100,000 ppm. Chromate, carbonate, phosphate, and lead interfered with the electrode. Conductometric titrations of sulfate were introduced several years before the potentiometric titration method of Ringbom. Kolthoff and Kameda ${ }^{164}$ found no general agreement among researchers on the reliability of conductometric titrations. Thus they conducted an in-depth study of the conductometric titration of various sulfates with barium chloride. The error in the titrations varied depending on the sample dilution, the alcohol content, the acidity, and the kind of cations present. They concluded that reproducible results could be obtained with samples containing small amounts of other electrolytes, 20-30\% alcohol, and a sulfate concentration above $46 \mathrm{mg} / \mathrm{l}$.

It remained for Rybnikova and Bal'zamova ${ }^{165}$ to apply the conductometric titration to water analysis. An equal volume of alcohol was added to the sample, the sample was titrated with barium acetate, and the electrical conductivity was measured after each addition of barium acetate. Satisfactory results were obtained for sulfate samples containing 
$15-800 \mathrm{mg} / \mathrm{l}$ only if the chloride concentration did not exceed $25 \mathrm{mg} / 1$.

Polsky ${ }^{166}$ proposed a conductometric sulfate method which did not require a titration. When an excess of barium was added to a sulfate sample, an increase in the specific conductance was observed, and if the amount of barium was kept constant, the increase varied inversely with the sulfate concentration. A standard sulfate curve was obtained by measuring the conductance of a standard before and after the addition of a constant amount of barium chloride and by plotting the difference in conductivity vs. the concentration of sulfate. A correction was necessary to account for other electrolytes in the sample, but this was done by preparing what was called a correction curve and by using this curve to prepare a final standard calibration curve. To determine the sulfate content of a water sample, the specific conductance of the sample was measured, the same constant amount of barium chloride was added, and the specific conductance was measured again. The difference in readings was calculated and the amount of sulfate was read directly from the calibration curve. The calibration range was from $0-100 \mathrm{ppm}$ sulfate. Johannesson ${ }^{167}$ developed a method for determining $0-10$ ppm sulfate in rain and other water samples. The sample was treated with a cation exchange resin, acid, and solid mercuric oxide to remove most other ionic species. Thus 
the conductivity measured was due almost entirely to sulfate. only a small correction was necessary for chloride and possibly nitrate.

o. I. Milner ${ }^{168}$ chose to titrate a sulfate sample and measure its conductivity with the use of a high-frequency oscillator. The apparatus which was used, employed a tuned-plate tuned-grid circuit, which responded to changes in the ionic conductance of a sample through an increase in the plate current. The titration of a $0.0001-0.01 \mathrm{~N}$ sulfate sample was conducted in a $30-40 \%$ alcohol medium with barium chloride as the titrant. The oscillator was operated at a frequency of 18.5 megacycles per second. After each addition of barium chloride, the current was measured and recorded. These values were plotted and the endpoint was determined graphically in the usual manner. The presence of large amounts of other ions (greater than $0.03 \mathrm{M}$ total electrolyte concentration) decreased the accuracy and sensitivity of the method. Jamieson 169 also chose the high-frequency titration approach. For $2-20 \mathrm{mg}$ of sulfate, the following titrants were compared: barium acetate, lead nitrate, octaamino$\mu$-nitrocobaltic tetranitrate, and hexaminecobaltic bromide. Interference studies with each of the titrants were also conducted with no one titrant being visibly superior to the others.

In 1940, Kolthoff and $\operatorname{Pan}^{170}$ introduced one of the 
first amperometric titration procedures for sulfate determination. The sulfate sample was titrated with a solution of lead nitrate at a dropping mercury electrode potential of -1.2 volts. After each increment of standard lead solution was added, the diffusion current due to the lead was measured and plotted. The endpoint was determined graphically in the usual manner. Best results were obtained with a medium of $20 \%$ ethanol and $0.01 \mathrm{M}$ hydrochloric acid. Large amounts of chloride and calcium interfered with the de termination.

Tenkovtsev ${ }^{171}$ proposed another amperometric titration based on the reduction of chromate on a mercury electrode. The sulfate was precipitated with barium, the solution $\mathrm{pH}$ was adjusted to 5.5-6.2 with base and ammonium acetate, and the excess barium was titrated with potassium chromate at an applied potential of zero volts. The procedure was capable of determining as little as $3-4 \mathrm{mg}$ of sulfate.

Polarographic determinations of sulfate appeared some years after the introduction of amperometric titration methods. One of the first procedures was developed by Horton and Thomason ${ }^{172}$ in 1951. The sulfate was reduced to hydrogen sulfide using a mixture of hydroiodic acid, hydrochloric acid, and hypophosphorous acid, with the sulfide being trapped by a cadmium chloride solution. The resulting cadmium sulfide precipitate was dissolved in hydrochloric acid and the cadmium was determined 
polarographically. The method was used for sulfate in the range of 15-150 $\mathrm{\mu g}$.

Two variations using the polarographic determination of lead were proposed. Matsumoto and Shibayama ${ }^{173}$ precipitated the sulfate with lead nitrate in an alcoholic medium. After filtration, the precipitate was dissolved in ammonium acetate and the lead content was determined using polarograms at -0.3 to -1.0 volts. Ohlweiler 174 chose to add an excess of lead nitrate to a sample containing alcohol and gelatin, and determined the excess lead in solution by polarography.

A number of indirect polarographic methods were developed based on the reduction of another anion whose concentration was related to the sulfate concentration. Mayer, Hluchan and Abel 175 determined $0.1-200 \mathrm{mg} / 1$ of sulfate by exchanging the sulfate for chromate through a barium chromate reagent. The reduction of chromate to Cr(III) occurred at -0.36 volts using the buffer system proposed. Serious interferences included calcium and any reducing agents which might be present in the sample. Humphrey and Laird ${ }^{176}$ exchanged the sulfate for the chloranilate ion, which undergoes a reversible two-electron reaction with chloranilic acid. A 5-100 ppm sulfate sample was placed in a 50\% aqueous methyl cellosolve medium buffered at $\mathrm{pH} 4.75$ with an acetate buffer. A small amount of solid barium chloranilate was added and stirred 
for thirty minutes. The maximum diffusion current was measured at .0 .5 volts Vs. SCE, and the sulfate content was determined from calibration curves.

Humphrey and Sharp ${ }^{177}$ recently introduced another polarographic method based on the exchange of iodate for sulfate. This resulted in essentially a twelve elcetron reduction reaction. Barium iodate was added to a sulfate sample in a 1:1 water-ethanol solvent, and the solution was thoroughly mixed and filtered. After addition of a small volume of perchloric acid, the solution was purged with nitrogen and the diffusion current was measured at -0.5 volts. The concentration range was from $3-46 \mathrm{ppm}$ sulfate.

F. Miscellaneous Methods

Not all of the sulfate methods can be classified into one of the five categories already discussed. A number of other interesting techniques have been utilized and should be mentioned. Some of these methods used radioisotopes, solution temperatures, the volume of a precipitate, spot tests and even a gas chromatograph.

The commercial availability of specific radioisotopes has led to the development of several sulfate methods. Bowen ${ }^{178}$ proposed a radiometric method using iodine-131. The isotope in the form of sodium iodide, was used in the 
synthesis of barium iodate. The labelled barium iodate was placed in a column similar to an ion exchange column and the sulfate sample was passed through it. Since barium sulfate was less soluble than barium iodate, the sulfate was exchanged for the iodate. The filtrate was collected in vials and counted using a well-type sodium iodide crystal set on the $0.36 \mathrm{MeV}$ gamma ray of the iodine-131. A blank correction was necessary to account for the solubility of the barium iodate. The method was applied to samples containing 180-9600 $\mathrm{\mu g}$ of sulfate.

Klehr 179 chose a more direct route by using the barium133 isotope to precipitate sulfate in the range of $0-500$ $\mathrm{mg} / \mathrm{l}$. After precipitation and filtration, either the precipitate or the filtrate was counted and the sulfate concentration was calculated.

The necessity of using large sample volumes has made the gravimetric determination of sulfate rather cumbersome. Through the use of the barium-133 isotope, Dimitt and Graham $^{180}$ were able to develop a procedure, which required only $0.1 \mathrm{ml}$ of sample. The sample containing $1-20 \mu \mathrm{g}$ of sulfate was placed in a small aluminum dish, $0.2 \mathrm{ml}$ of labelled barium chloride was added, and the sample was dried under a heat lamp. The precipitate was washed twice with methanol to remove the excess barium chloride. After a final drying, the aluminum dishes were placed under a sodium iodide-thallium activated crystal and counted for 
one minute. To improve the reproducibility, a nonionic surfactant was added to disperse the precipitate and to aid in the adherence of the precipitate to the dishes. In 1924, Dean and Watts ${ }^{181}$ introduced another sulfate technique -- the thermometric titration. When a compound such as barium sulfate was formed in solution, a change in the solution temperature was noted. By measuring the temperature after each addition of barium chloride, a titration curve was obtained and plotted, and the endpoint was located graphically. Milligram amounts of sulfate were necessary as the temperature changes observed were less than one degree.

Improvements in instrumentation and techniques led Williams and Janata 182 to investigate the thermometric titration of sulfate more closely. By connecting a thermistor to a recorder through an a.c. thermistor bridge, the temperature of the sample solution was automatically measured and recorded. The rate of addition of the barium perchlorate titrant and the chart speed were used to calculate the endpoint volume and hence, the sulfate content. By equilibrating the sample in a water bath before titrating and by using a 70\% ethanol medium, Williams and Janata were able to determine 1-25 $\mathrm{mg}$ of sulfate with resaonable speed and accuracy. Sodium fluoride, phosphate and arsenate interfered when present in amounts greater than the sulfate. 
Recently Dube and Kimmerle ${ }^{183}$ proposed another semiautomated thrmometric titration for $1-40 \mathrm{~g} / 1$ of sulfate. The sample was treated with hydrochloric acid, equilibrated, and titrated with standard barium chloride, using an automatic buret. The incorporation of a simple analog computer into the thermistor measurement circuitry enabled Dube and Kimmerle to obtain first and second derivative curves of the direct titration curve, thereby making it easier to locate the titration endpoint. The use of a strongly acidified sample eliminated many of the interfering anions.

While some researchers were measuring the temperature of a sulfate solution, others were measuring the volume of a sulfate precipitate. One of the first sedimetrical sulfate methods was developed by Arrhenius and Riehm ${ }^{184}$ in 1926. The small sample solution was placed ina centrifuge tube, acidified with hydrochloric acid, and treated with barium chloride. After centrifugation of the barium sulfate precipitate, the depth of the precipiate in the tube was measured. A previous calibration showed that a depth of $1.3 \mathrm{~mm}$ corresponded to $1 \mathrm{mg}$ of sulfate. Careful attention had to be paid to reaction conditions as the size of the precipitate varied greatly according to the conditions. This limited the method to the small concentration range of 4-16 mg of sulfate.

A similar procedure was developed by Toth and 
Lakatos $^{185}$ for determining $5-35 \mathrm{mg}$ of sulfate. They added hydrochloric acid and ammonium chloride to the sample before precipitating the sulfate at $85^{\circ}$ with barium chloride. After cooling, the sample was transferred to a centrifuge tube, which had been fitted with a calibrated capillary tube. The volume of the precipitate was read directly from the capillary tube calibration after centrifugation, and the amount of sulfate was calculated using a previously determined conversion factor. The sedimetrical approach was not the only method which required the use of small volumes of sample. A few drops of sample were sufficient for a spot test to be conducted. Feigl ${ }^{186}$ developed a sulfate spot test which utilized the red-brown barium rhodizonate precipitate. When a sulfate sample was added to the precipitate, the red-brown color disappeared due to the formation of insoluble barium sulfate. As little as $5 \mu \mathrm{g}$ of sodium sulfate were detectable.

Ballczo and Hodos ${ }^{187}$ used Feigl's spot test as the basis for their ring oven procedure for sulfate. First, sodium rhodizonate was washed into a ring $(12 \mathrm{~mm})$ using methanolic hydrochloric acid. This was followed by barium ritrate and sodium chloride, which resulted in the formation of the red barium rhodizonate. The excess barium was then washed out of the first ring into a second larger ring $(32 \mathrm{~mm})$ with methanolic hydrochloric acid. A drop of 
sulfate sample was added and washed to the first ring with hydrochloric acid, where it reacted with the barium rhodizonate, forming barium sulfate and rhodizonate ions. The freed rhodizonate ions were then washed into the second ring of barium, where the red barium rhodizonate was again formed. The color developed in the second ring was directly proportional to the sulfate content. The procedure was able to detect as little as $5 \mathrm{ng}$ of sulfate. Meditsch and Castiel ${ }^{188}$ developed another spot test procedure which they were able to quantify for 50-1000 ppm sulfate. After concentration and removal of chloride, the sample was passed through a cation exchange column, where the sulfate was converted to sulfuric acid. Ten microliters of sample were spotted on a filter paper and a drop of silver ethylenediamine chromate was added. The diameter of the red spot formed was logarithmically related to the sulfate concentration.

The final sulfate method to be described was a rather unique method utilizing a gas chromatograph. 189 Aqueous sulfate samples were evaporated to dryness and treated with a tin(II)-strong phosphoric acid reagent to reduce the sulfate to hydrogen sulfide. The amount of hydrogen sulfide was determined by gas chromatography using carbon dioxide as an intemal standard. A calibration curve for $1.32-13.2 \mathrm{mg}$ sulfate was prepared by plotting sulfate values vs. the peak area ratic of hydrogen sulfide to 
carbon dioxide. The method was also applicable to a wide variety of other sulfur compounds. 
CHAPTER III

EXPERINENTAL 


\section{A. Pyrolytic Method}

\section{Apparatus}

Sulfur Dioxide Permeation Tubes -- Liquid sulfur dioxide was sealed in $6 \mathrm{~mm}$ i.d. X $120 \mathrm{~mm}$ Teflon tubes with Teflon plugs at both ends. The tubes were placed in a thermostatted permeation chamber at $86^{\circ} \mathrm{F}$ with purified air constantly flowing through the chamber. Repeated weighings of the tubes over an extended period of time were used to determine the permeation rate of each tube. Two permeation tubes were used with permeation rates of $9.97 \mu \mathrm{g} / \mathrm{min}$ and $9.50 \mu \mathrm{g} / \mathrm{min}$.

Stir Plate -- A Thermolyne Model SP10105B Midget Stir Plate was used for heating samples. A larger model can be used when needed.

Beakers -- One $15 \mathrm{ml}$ Pyrex beaker was needed for each sample.

Hydrion Paper -- Hydrion A with a pH range of 2-4-68-10 was used for approximate $\mathrm{pH}$ determinations.

Volumetric Flasks -- One $10 \mathrm{mI}$ volumetric flask was used for each sample. Various other sizes (i.e. 1 liter, $250 \mathrm{ml}, 100 \mathrm{ml}, 50 \mathrm{ml}$ ) were required for the preparation of standard solutions and other reagents.

Pipets -- Transfer pipets of $1-10,15,20$, and $25 \mathrm{ml}$ were used to measure the original sample volumes and to prepare standard solutions. Eppendorf pipets of 10, 50, 
and $100 \mu 1$ volumes were used to prepare the pyrolysis samples. Thomas pipets with a $1 \mathrm{ml}$ delivery volume were used to add the p-rosaniline hydrochloride and formaldehyde for the spectrophotometric finish.

Pyrolysis Dishes -- Soft glass vials of various sizes $(18 \mathrm{~mm} \mathrm{o.d.} \mathrm{X} 120 \mathrm{~mm}, 21 \mathrm{~mm} \mathrm{o.d.X} 70 \mathrm{~mm}, 22 \mathrm{~mm} \mathrm{o.d.} \mathrm{X}$ $120 \mathrm{~mm}$ ) were cut $10 \mathrm{~mm}$ from the bottom to provide pyrolysis dishes with $16 \mathrm{~mm}, 19 \mathrm{~mm}$ or $20 \mathrm{~mm}$ i.d.'s.

Drying Oven -- An oven was set at $80^{\circ}$ for the slow evaporation of pyrolysis samples.

Pyrolysis Apparatus with Oven, Combustion Train, Injector System, and Flow System -- The entire system is shown in Figure 2. For the pyrolysis oven, a Sargent microcombustion furnace (S-21580) was modified to accept a $33 \mathrm{~mm}$ o.d. quartz tube. The original heating coils were utilized along with a Lindburg semi-cylindrical ceramic heating block (Model No. 50022, Type 76KS Unit, 350 watts, 57.5 volts), which was added to the top hinge of the over. The Lindburg heating block was regulated by a separate Variac. The two heating units were set to maintain an oven temperature of $500^{\circ}$. For the combustion train, a $33 \mathrm{~mm} \mathrm{o.d.}$ $34 / 45$ female ground glass joint was attached to one end of a $33 \mathrm{~mm} \mathrm{o.d.X} 360 \mathrm{~mm}$ quartz tube and an $11 \mathrm{~mm} \mathrm{o.d.X} 210 \mathrm{~mm}$ quartz tube was attached to the other end. A glass bubbler was connected to the quartz tube with $7 \mathrm{~mm}$ i.d. Teflon tubing, a 3-way stopcock, and glass tubing with a right- 
FIGURE 2

PYROLYSIS APPARATUS 


\section{PYROLYSIS APPARATUS}

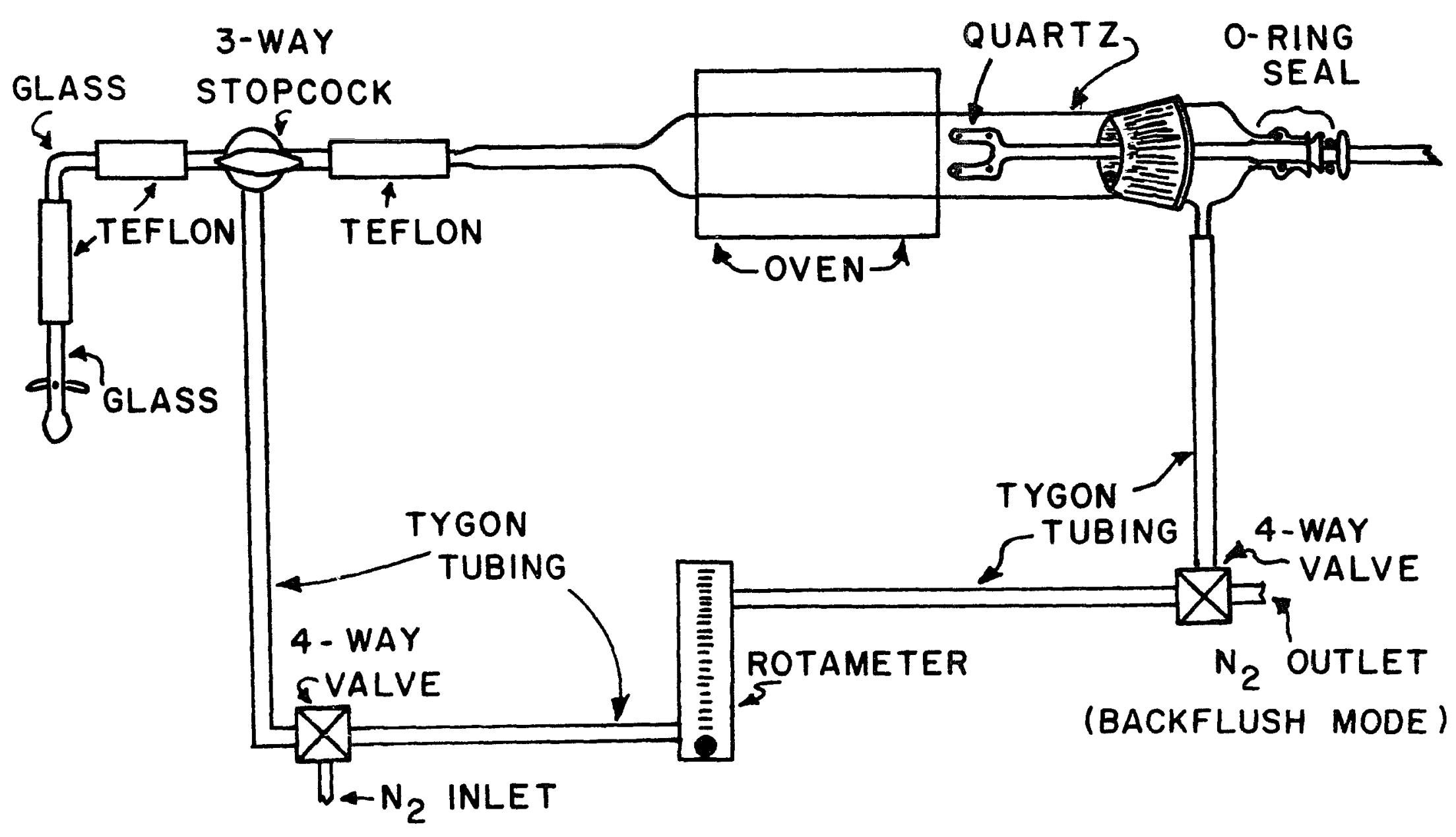


angle bend. The injection system was the same one used by Maddalone, et al, ${ }^{121}$ with the exception of the $6 \mathrm{~mm} 0 . \mathrm{d}$. quartz injection fork which was lengthened to $480 \mathrm{~mm}$ and redesigned to hold an 18-22 $\mathrm{mm}$ o.d. pyrolysis dish. For actual construction details, see reference 121 . The nitrogen flow system of $500 \mathrm{ml} / \mathrm{min}$ was operated in either a pyrolysis or backflush mode. In the pyrolysis mode, nitrogen flowed through the rotameter, into the oven via the injector system, and out the glass bubbler at the end of the combustion train. For the backflush mode, the two 4-way valves and the 3 -way stopcock were switched, allowing nitrogen to flow through the stopcock, into the oven and injector, and out through the 4-way valve. This allowed a nitrogen atmosphere to be maintained inside the oven, even when the injector system was disconnected at the ground glass joint to change pyrolysis samples.

Bubblers -- Twenty-nine mm X $116 \mathrm{~mm}$ Pyrex centrifuge tubes with pourspouts capable of holding approximately $50 \mathrm{ml}$ were used as part of the bubbler at the end of the combustion train.

Stop Watch -- A Meylan stopwatch, Brenet Model No. 55, was used to measure the pyrolysis time of $2 \frac{1}{2} \mathrm{~min}$ and the color development time of $30 \mathrm{~min}$.

I/I Repipet Dispenser -- A $10 \mathrm{ml}$ Repipet from Lab Industries was used to dispense the sodium tetrachloromercurate (II). 
Vials with Caps -- Sixteen mm X $125 \mathrm{~mm}$ borosilicate glass culture tubes with screw-on caps were used to hold the bubbler sample solutions for the spectrophotometric finish.

Spectrophotometer -- A Beckman DB set at $560 \mathrm{~nm}$ with a $1 \mathrm{~cm}$ cell was used.

\section{Reagents}

Standard Sulfate Solutions -- Sulfuric acid, sodium sulfate or potassium sulfate was used to prepare numerous standard sulfate solutions. Reagent grade sodium sulfate $\left(1.4787 \mathrm{~g} \mathrm{Na}_{2} \mathrm{SO}_{4}\right)$ or potassium sulfate $\left(1.8141 \mathrm{~g} \mathrm{~K}_{2} \mathrm{SO}_{4}\right)$ was dissolved in deionized water and diluted to $100 \mathrm{ml}$ to make a stock solution of $10 \mu \mathrm{g} / \mu 1$ sulfate $(10,000 \mathrm{ppm})$. These stock solutions were then diluted as necessary to provide additional standards. A $1 \mu \mathrm{g} / \mu \mathrm{I}$ sulfate standard was prepared by diluting $16.4 \mathrm{ml}$ of $0.1269 \mathrm{~N}$ sulfuric acid to $100 \mathrm{ml}$ with deionized water.

Cation Exchange Resin -- Dowex 50W-X8, $\mathrm{H}^{+}$form, 20-50 mesh, was used to form a column $8-10 \mathrm{~cm}$ in height.

Hydrochloric Acid, 1M -- Concentrated hydrochloric acid, reagent grade, was diluted to approximately $1 \mathrm{M}$. The exact concentration need not be known.

Sodium Tetrachloromercurate(II), 0.1M -- Reagent grade mercuric chloride $(27.2 \mathrm{~g})$ and sodium chloride (11.7 g) were dissolved and diluted to 1 liter with deionized water. 
2-Perimidinylammonium Bromide, 0.5\% -. The PDA-Br was synthesized according to the method of McClure ${ }^{190}$ and recrystallized from methanol before use. A fresh solution was prepared daily using $50 \mathrm{mg}$ of PDA-Br in $10 \mathrm{ml}$ of deionized water.

Formaldehyde, $0.2 \%$-- One-half milliliter of $37 \%$ formaldehyde was diluted to approximately $100 \mathrm{mI}$ with deionized water. The solution must be made fresh daily. p-Rosaniline Hydrochloride -- Reagent grade p-rosaniline, $0.64 \mathrm{~g}$, was dissolved in $240 \mathrm{ml}$ of concentrated hydrochloric acid and diluted to one liter with deionized water to provide a concentrated stock solution. The working solution was prepared by diluting $25 \mathrm{ml}$ of this stock solution to $100 \mathrm{ml}$ with deionized water.

Anion Interferences -- A $10 \mu \mathrm{g} / \mu \mathrm{I}$ stock solution was prepared for each anion tested, using sodium or potassium salts dissolved in deionized water. Ten milliliters of the stock was diluted to $100 \mathrm{ml}$ to provide a working solution of $1 \mu \mathrm{g} / \mu \mathrm{l}$. Additional dilutions were made as needed. Anions tested included: chloride, bromide, fluoride, bicarbonate, nitrate, hydrogen phosphate, dihydrogen phosphate, acetate, formate, oxalate, EDTA, and sulfite.

\section{Procedures}

a. Water Samples. -- If the water sample was turbid, it was filtered through a fine, ashless filter 
paper such as Whatman 41. Approximately $15-20 \mathrm{ml}$ of the water sample was run through the ion exchange column with the first $3-4 \mathrm{ml}$ being discarded and the next $10 \mathrm{ml}$ being collected and placed in a $15 \mathrm{ml}$ beaker. A blank of $10 \mathrm{ml}$ deionized water was treated along with the sample. Three drops of $1 \mathrm{M}$ hydrochloric acid were added $(\mathrm{pH}<2)$ and the sample was heated and maintained at or near boiling until approximately $5 \mathrm{ml}$ remained. The sample was cooled slightly and transferred quantitatively to a $10 \mathrm{ml}$ volumetric flask and diluted with deionized water. A $100 \mu \mathrm{I}$ aliquot of the sample and $300 \mu \mathrm{l}$ of $\mathrm{PDA}-\mathrm{Br}$ were added to a $19 \mathrm{~mm} \mathrm{i.d.}$ pyrolysis dish, mixed, and placed in the drying oven until dry (approximately one hour). Triplicate pyrolysis samples were prepared for each water sample and the blank. When the samples were dry, they were removed from the oven, cooled, and pyrolyzed as follows: 1. The flow system was set in the backflush mode. 2. The injection fork was withdrawn from the hot oven and the entire injection system was disconnected from the quartz tube at the ground glass joint. 3. After removing the previous sample dish, a new sample dish was placed on the injection fork, and the injection system was reconnected at the ground glass joint. SThe sample should be in the cool zone ahead of the pyrolysis oven at this point.) 4. The flow system was set in the pyrolysis mode. 5. A bubbler containing $10 \mathrm{mI}$ of the tetrachloromercurate(II) absorbing solution was 
placed on the end of the combustion train. 6. The sample and injection fork were pushed into the hot oven and pyrolyzed for $2 \frac{1}{2}$ minutes (measured with a stopwatch). 7. The bubbler was removed and the absorbing solution was poured into a vial and capped. 8. The bubbler end of the combustion train was rinsed with water. 9. The entire cycle beginning with step 1 was repeated for the remaining samples.

When all the samples have been pyrolyzed, $1 \mathrm{ml}$ of the formaldehyde solution and $1 \mathrm{ml}$ of the p-rosaniline solution were added to each vial. The violet color was allowed to develop for thirty minutes $( \pm 5 \mathrm{~min})$ and then the absorbance of each sample including the blank was measured at $560 \mathrm{~nm}$ with a $1 \mathrm{~cm}$ cell vs. air as the reference. Zero absorbance (A) was set with deionized water. After subtracting the blank value from the sample to obtain the net absorbance, the sulfate concentration was determined from a calibration curve, which was prepared using sodium sulfate standards (0-120 ppm) treated and pyrolyzed in the same manner as the samples.

A quick and easy preliminary test can be done on each water sample to determine the approximate sulfate concentration, and hence the appropriate sample or pyrolysis aliquot size. A $100 \mu l$ aliquot of the original untreated sample was placed in a pyrolysis dish and $300 \mu \mathrm{l}$ of PDA-Br was added. The amount of precipitate formed was compared to 
a $100 \mathrm{ppm}$ sulfate solution treated in the same manner. If the sample appeared to contain $<10 \mathrm{ppm}$, the pyrolysis aliquot was increased to $200 \mu \mathrm{l}$. If the sample contained $>120 \mathrm{ppm}$, the $10 \mathrm{ml}$ sample volume was decreased to $1-5 \mathrm{ml}$ depending on the amount of dilution desired. The dilution or concentration must be taken into account when calculating the original sulfate concentration.

After the determination was completed, the apparatus was cleaned to remove any organic debris or tetrachloromercurate(II) remaining in the combustion train. The quartz tube was disconnected from the remainder of the combustion train and cleaned by supplying oxygen instead of nitrogen and increasing the oven temperature to $700^{\circ}$. The other pieces of the combustion train were cleaned by rinsing with acetone and allowing them to air dry. The bubblers and vials were washed with soap and water, rinsed with 1:1 hydrochloric acid and deionized water, and allowed to air dry. The pyrolysis dishes can be reused after boiling with concentrated nitric acid, rinsing with deionized water, and air drying.

b. Sulfur Dioxide Calibration Curve. -- To prepare $500 \mathrm{ml}$ of stock solution containing $2.5 \mu \mathrm{g} / \mathrm{ml}$ sulfur dioxide, one of the two previously calibrated permeation tubes was placed in the permeation chamber at a temperature of $86^{\circ} \mathrm{F}$. Air, purified by passing it through a series of 
charcoal and silica gel filters, was swept through the chamber at a rate of 1 liter/min. Approximately $150 \mathrm{ml}$ of $0.1 \mathrm{M}$ sodium tetrachloromercurate(II) was put in a fritted glass bubbler and the bubbler was then connected to the permeation chamber. The system was allowed to run for an appropriate length of time, calculated from the permeation rate of the tube and the concentration and volume of the desired standard solution. At the end of the bubbling time, the bubbler was removed and the absorbing solution was transferred to a volumetric flask and diluted to volume with additional tetrachloromercurate(II).

For the calibration curve, aliquots of the stock solution were diluted with tetrachloromercurate(II) to make standards of $2,4,6, \ldots, 20 \mu \mathrm{g}$ sulfur dioxide per $10 \mathrm{ml}$. Ten $\mathrm{ml}$ of each of these standards plus a blank of $10 \mathrm{ml}$ tetrachloromercurate(II) were placed in capped vials and $1 \mathrm{ml}$ each of formaldehyde and p-rosaniline were added. The absorbance of each solution was read after 30 minutes \pm 5 at $560 \mathrm{~nm}$ with a $1 \mathrm{~cm}$ cell using air as the reference. The net absorbance was plotted vs. $\mu g$ sulfur dioxide per $10 \mathrm{ml}$ to obtain a calibration curve like the one shown in Figure 3.

c. Chloride Study. -- This study was undertaken to observe the effects of the amount of chloride on the recovery of sulfate using the pyrolysis technique. In addition, the 


\section{FIGURE 3}

SULFUR DIOXIDE CALIBRATION CURVE 


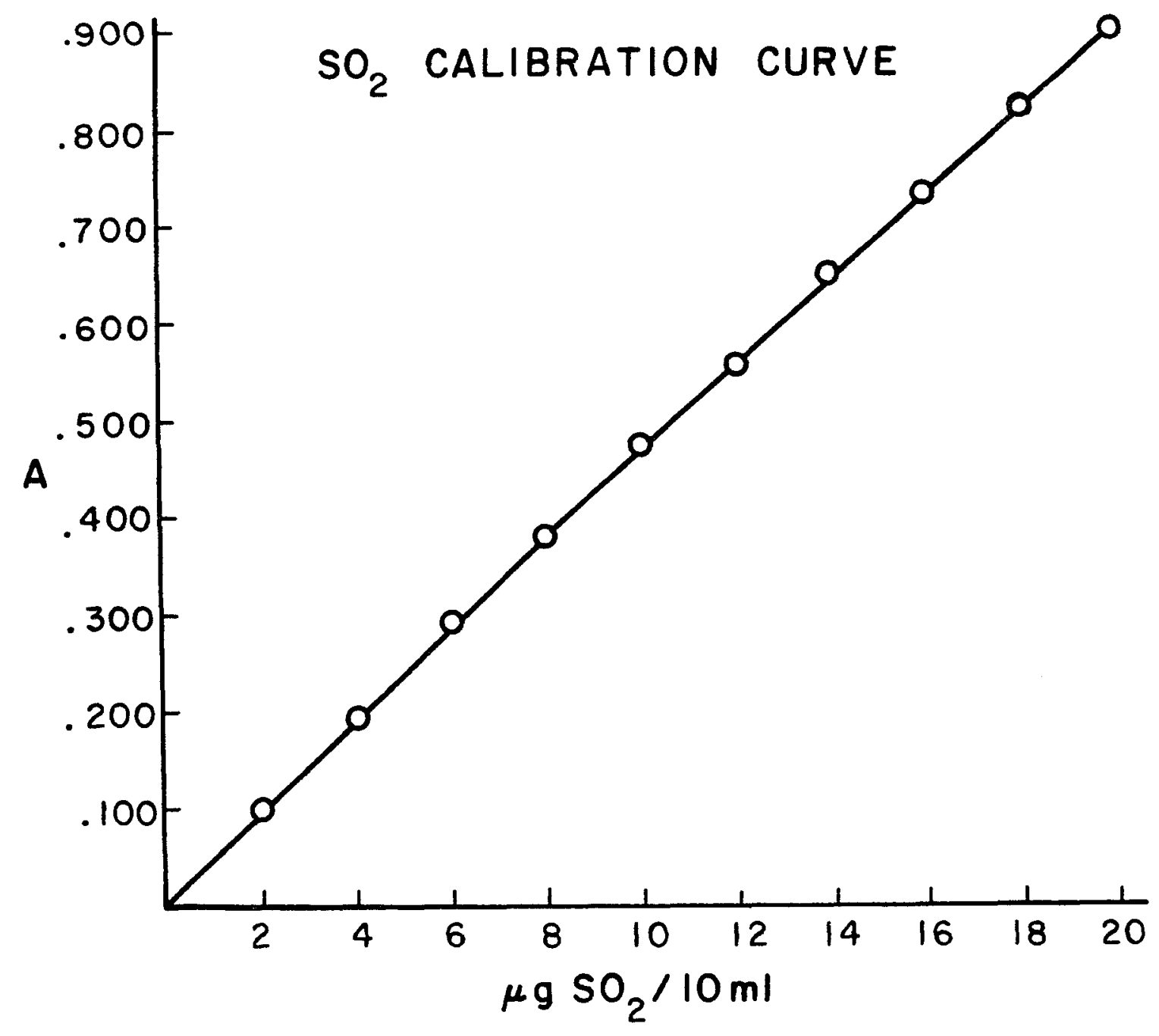


effects of the pyrolysis dish size and the volume of PDA-Br were investigated. Triplicate $10 \mu \mathrm{g}$ sulfate samples were used in each case by taking a $10 \mu l$ aliquot of a solution containing $1 \mu \mathrm{g} / \mu \mathrm{I}$ sulfate as sulfuric acid. Fifty, 70, or $100 \mu \mathrm{l}$ aliquots of a $1 \mu \mathrm{g} / \mu \mathrm{I}$ chloride solution (as potassium chloride) were used to give 50,70 , or $100 \mu \mathrm{g}$ of added chloride. The pyrolysis dish size used was either $16 \mathrm{~mm}$ or $20 \mathrm{~mm}$ i.d. After the sulfate and chloride were placed in the pyrolysis dish, PDA-Br was added in $200 \mu \mathrm{l}$, $250 \mu 1$, or $300 \mu 1$ aliquots. The samples were mixed, dried and pyrolyzed according to procedure a for water samples.

d. Anion Interference Study. -- This study was designed to test the effect of various anions on the pyrolysis blank and on the sulfate recovery using the pyrolysis technique. For the pyrolysis blank test, $10 \mu \mathrm{g}$ of an anion and $300 \mu \mathrm{l}$ of $\mathrm{PDA}-\mathrm{Br}$ were placed in a $19 \mathrm{~mm}$ i.d. dish, mixed, dried and pyrolyzed according to procedure a. For determining sulfate recoveries, $10 \mu \mathrm{g}$ of sulfate ( $10 \mu \mathrm{l}$ of the $1 \mu \mathrm{g} / \mu \mathrm{l}$ sulfuric acid standard), 10 or $100 \mu \mathrm{g}$ of an interfering anion (10 or $100 \mu \mathrm{l}$ of the $1 \mu \mathrm{g} / \mu \mathrm{I}$ anion solution), and $300 \mu \mathrm{I}$ of $\mathrm{PDA}-\mathrm{Br}$ were added to a $19 \mathrm{~mm}$ i.d. pyrolysis dish, mixed, dried and pyrolyzed as above. Triplicate analyses were run for all samples.

e. Bicarbonate Study. -- This study was designed to find the optimum conditions for the removal of bicarbonate using an acid treatment on the sample before its 
pyrolysis. A mixed sample containing 100 ppm sulfate, 200 ppm bicarbonate, $400 \mathrm{ppm}$ chloride, and $10 \mathrm{ppm}$ nitrate was prepared using the stock $10 \mu \mathrm{g} / \mu \mathrm{l}$ solutions of each anion. Deionized water was used as the blank and a $100 \mathrm{ppm}$ sulfate solution (as sodium sulfate) was used as the standard for recovery comparisons.

A $10 \mathrm{ml}$ aliquot of the sample was placed in a $15 \mathrm{ml}$ beaker and several drops of hydrochloric acid (6M, 3M, or 1M) were added until a $\mathrm{pH}$ of $<2$ was observed using $\mathrm{pH}$ paper. The sample was heated just below boiling until the volume was reduced to approximately $5 \mathrm{ml}$. In several experiments, the sample was carefully evaporated to dryness and the residue was redissolved in approximately $5 \mathrm{ml}$ of deionized water. After cooling, the $\mathrm{pH}$ was adjusted to 5-6 with ammonium hydroxide $(0.1 \mathrm{M}$ or $0.5 \mathrm{M})$ or ammonium acetate $(0.1 \mathrm{M}$ or $0.5 \mathrm{M})$ and the sample was quartitatively transferred to a $10 \mathrm{ml}$ volumetric flask and diluted to volume. This pH adjustment was omitted in some experiments, leaving the sample with a $\mathrm{pH}<2$. A $100 \mu 1$ aliquot of the sample and $300 \mu \mathrm{l}$ of $\mathrm{PDA}-\mathrm{Br}$ were placed in a $19 \mathrm{~mm}$ i.d. pyrolysis dish, mixed, dried, and pyrolyzed as in procedure a. Blanks and standards were treated in the same way, using triplicate analyses.

Any variations or exceptions to this procedure will be noted in the next chapter. 
B. Gravimetric Method

The method used was the recognized reference method as found in Standard Methods for the Examination of Water and Wastewater, Part 156B. ${ }^{1}$

\section{Apparatus and Reagents}

Reagents. -- The methyl red indicator, hydrochloric acid, barium chloride, and silver nitrate-nitric acid reagents were prepared according to the Standard Methods directions.

Apparatus. -- In addition to a drying oven, a desiccator, and an analytical balance, the following speciric pieces of equipment were used.

Cation Exchange Column -- Dowex 50W-X8 resin, $\mathrm{H}^{+}$form, 20-50 mesh, was used to form a column $20 \mathrm{~cm}$ in height.

Beakers -- One $250 \mathrm{ml}$ Pyrex beaker with a watch glass to cover it, was used for each sample.

Hot Plate -- A Thermolyne Model SP-A1025B Stir Plate was used for heating samples. Sintered Glass Filter Funnels -- One funnel of fine (F) porosity and supporting filtration equipment were needed for each sample. The funnels were cleaned, rinsed with nitric acid and deionized water, and dried to a constant weight in an oven set at $110^{\circ}$. They were cooled 
and stored in a desiccator until used.

\section{Procedure}

An appropriate aliquot of each water sample was run through the ion exchange column. Several samples required concentration and were placed on a hot plate for evaporation. The samples were then heated and acidified, and the sulfate was precipitated with $10-15 \mathrm{ml}$ of the barium chloride reagent. The precipitate was digested overnight at approximately $80^{\circ}$. After filtration using the previously weighed and numbered filter funnels, the samples were dried to a constant weight at $110^{\circ}$ and the sulfate concentration was calculated.

C. Turbidimetric Method

The method used was taken from Standard Methods for the Examination of Water and Wastewater, Part $156 \mathrm{C},{ }^{1}$ and from the 1975 Annual Book of ASTM Standards, Part 31, D516-68 (1974).2

1. Apparatus and Reagents

Reagents. -- The reagents were prepared according to Standard Methods directions using sodium sulfate for the standard solution.

Apparatus. -- In addition to the necessary beakers, pipets, stopwatch, and measuring spoon, the following specific pieces of equipment were used. 
Magnetic Stirrer -- A Thermolyne Model SP10105B Midget Stir Plate with magnetic stirring bar was used with the stirring rate set the same for each sample. Spectrophotometer -- A Cary 14 recording spectrophotometer set at $420 \mathrm{~nm}$ was used with a set of $5 \mathrm{~cm}$ silica cells.

\section{Procedure}

Five milliliters of the conditioning reagent were added to $100 \mathrm{ml}$ of a water sample (or an aliquot of sample made up to $100 \mathrm{ml}$ ). After placing the sample on the stirring plate, a spoonful of barium chloride crystals was added and the solution was stirred for one minute. The sample was then allowed to stand undisturbed for four minutes. After a final stirring of $15 \mathrm{sec}$, the sample was poured into a $5 \mathrm{~cm}$ cell and the optical density was measured with the Cary 14 vs. the reagent blank. The sulfate concentration was determined from a calibration curve prepared by the same procedure. The calibration curve covered the range of $0-40 \mathrm{ppm}$ at $5 \mathrm{ppm}$ intervals.

\section{Barium Chloranilate Spectrophotometric Method}

The original method of Bertolacini and Barney 96 was used for samples containing over $50 \mathrm{ppm}$ sulfate while their modified method 97 was used for samples of under $50 \mathrm{ppm}$. 


\section{Apparatus and Reagents}

Reagents. - The barium chloranilate and the phthalate buffer were prepared as given in Reference 96. Sodium sulfate was used for the standard sulfate solutions.

Apparatus. -- In addition to the necessary beakers, pipets, $100 \mathrm{ml}$ volumetric flasks, funnels, filter paper, and a mechanical shaker, the following specific pieces of equipment were used.

Cation Exchange Column -- Dowex 50W-X8 resin, $\mathrm{H}^{+}$ form, 20-50 mesh, was used to form a column $20 \mathrm{~cm}$ in height. Spectrophotometer -- A Beckman DB set at either $530 \mathrm{~nm}$ or $332 \mathrm{~nm}$ was used with $1 \mathrm{~cm}$ quartz cells.

2. Procedure

After passing the sample through the ion exchange column, a $25 \mathrm{ml}$ aliquot was transferred to a $100 \mathrm{ml}$ volumetric flask. Ten milliliters of phthalate buffer and $50 \mathrm{ml}$ of ethanol were added and the solution was diluted to volume with deionized water.

For samples containing less thar; 50 ppm sulfate, $0.2 \mathrm{~g}$ of solid barium chloranilate was added and the sample was mechanically shaken for fifteen minutes. After filtering off the excess reagent and barium sulfate, the absorbance of the filtrate was measured at $332 \mathrm{~nm} \mathrm{vs}$. a reagent blank. 
For samples containing more than $50 \mathrm{ppm}$ sulfate, $0.3 \mathrm{~g}$ of solid barium chloranilate was added and the sample was treated as before. The absorbance of the filtrate was measured at $530 \mathrm{~nm}$ vs. a reagent blank.

Sulfate concentrations were determined using calibration curves prepared by both procedures for sulfate in the ranges of $0-40 \mathrm{ppm}$ and $0-400 \mathrm{ppm}$ respectively.

E. Stephen's Nephelometric Method

Stephen introduced 2-perimidinylammonium chloride (PDA-Cl) as a reagent for sulfate in 1970, using it in a nephelometric procedure. ${ }^{123} \mathrm{His}$ procedure was followed using PDA-Br as the precipitant.

1. Apparatus and Reagents

Reagents. -- A $0.5 \%$ solution of $\mathrm{PDA}-\mathrm{Br}$ was used while sodium sulfate was used for standards of $0-10 \mathrm{ppm}$.

Apparatus. -- Pipets $(1-5 \mathrm{ml})$ and $10 \mathrm{ml}$ volumetric flasks were needed. Due to the unavailability of a nephelometer, the Beckman DB set at $420 \mathrm{~nm}$ was used with $1 \mathrm{~cm}$ cells.

2. Procedure

A $1-5 \mathrm{ml}$ aliquot of the water sample was placed in a $10 \mathrm{ml}$ volumetric flask. Four milliliters of the PDA-Br solution was added and the sample was diluted to volume with deionized water. The sample was mixed well and allowed 
to sit for fifteen minutes before the absorbance was measured vs. deionized water. Five milliliters of deionized water were treated as the blank. Sulfate concentrations were determined from a calibration curve of 0-10 ppm sulfate prepared using a $5 \mathrm{ml}$ sample aliquot with the above procedure. 
CHAPTER IV

RESULTS AND DISCUSSION 
A. Pyrolytic Method

Several years ago, work on a sulfuric acid aerosol determination led to the development of a sulfate procedure. This procedure 121 which was based on the precipitation of sulfate as the 2-perimidinylammonium sulfate, appeared to be potentially applicable to water analysis. An in depth study was initiated to investigate the potential interferences and how they might be removed, and to develop a procedure for determining sulfate in natural and drinking waters.

1. Background Information

In 1970, W. I. Stephen 123 introduced a new reagent for sulfate, 2-perimidinylammonium chloride (PDA-Cl). He used this reagent to precipitate the 2-perimidinylammonium sulfate, (PDA) ${ }_{2} \mathrm{SO}_{4}$, which he then determined nephelometrically. Although (PDA) ${ }_{2} \mathrm{SO}_{4}$ was more soluble than barium sulfate $\left(20 \mathrm{mg} / 1\right.$ at $18^{\circ} \mathrm{vs} .2 .5 \mathrm{mg} / \mathrm{l}$ at $\left.25^{\circ}\right)$, Stephen found it useful for small quantities of sulfate $(0-5 \mathrm{ppm})$. He suggested its use for water analysis, but he did not provide any actual data to substantiate that suggestion. During the course of this work, the opportunity to check his suggestion was provided, and the data and results obtained will be discussed in Section B -- Field Studies. 
One major drawback to the use of PDA-CI was the lengthy cumbersome synthesis proposed by Stephen. It was also difficult to obtain a clean sulfur-free product, even after repeated recrystallizations. Thus this reagent might never have been used, had it not been for the introduction of an improved synthesis by G. L. McClure ${ }^{190}$ in 1973. McClure obtained the $\mathrm{PDA}^{+}$reagent as its bromide salt instead of the chloride. This synthesis was faster, cleaner, and more convenient, and had a better yield than stephen's synthesis.

With sufficient clean reagent now in hand, Maddalone, et al. ${ }^{121}$ proceeded to develop the pyrolytic method for sulfate, which they then applied to a sulfuric acid aerosol determination. ${ }^{191}$ The pyrolytic method was based on two reactions, the precipitation reaction and the pyrolysis reaction. (See Figures 4 and 5.) Small sulfate samples of $0-50 \mu \mathrm{g}$ were placed in $16 \mathrm{~mm}$ i.d. pyrolysis dishes and $200 \mu \mathrm{l}$ of PDA-Br were added, resulting in the precipitation of the silky white (PDA) ${ }_{2} \mathrm{SO}_{4}$ (Figure 4 ). After evaporation of excess solvent, the samples were pyrolyzed in an oven at $500^{\circ}$ in a nitrogen atmosphere. The thermal decomposition of the $(P D A)_{2} \mathrm{SO}_{4}$ resulted in the quantitative formation of sulfur dioxide (Figure 5), which was trapped and determined according to the westGaeke procedure. 192

The effect of other anions was studied by both Stephen 
FIGURE 4

PRECIPITATION REACTION 


\section{PRECIPITATION REACTION}

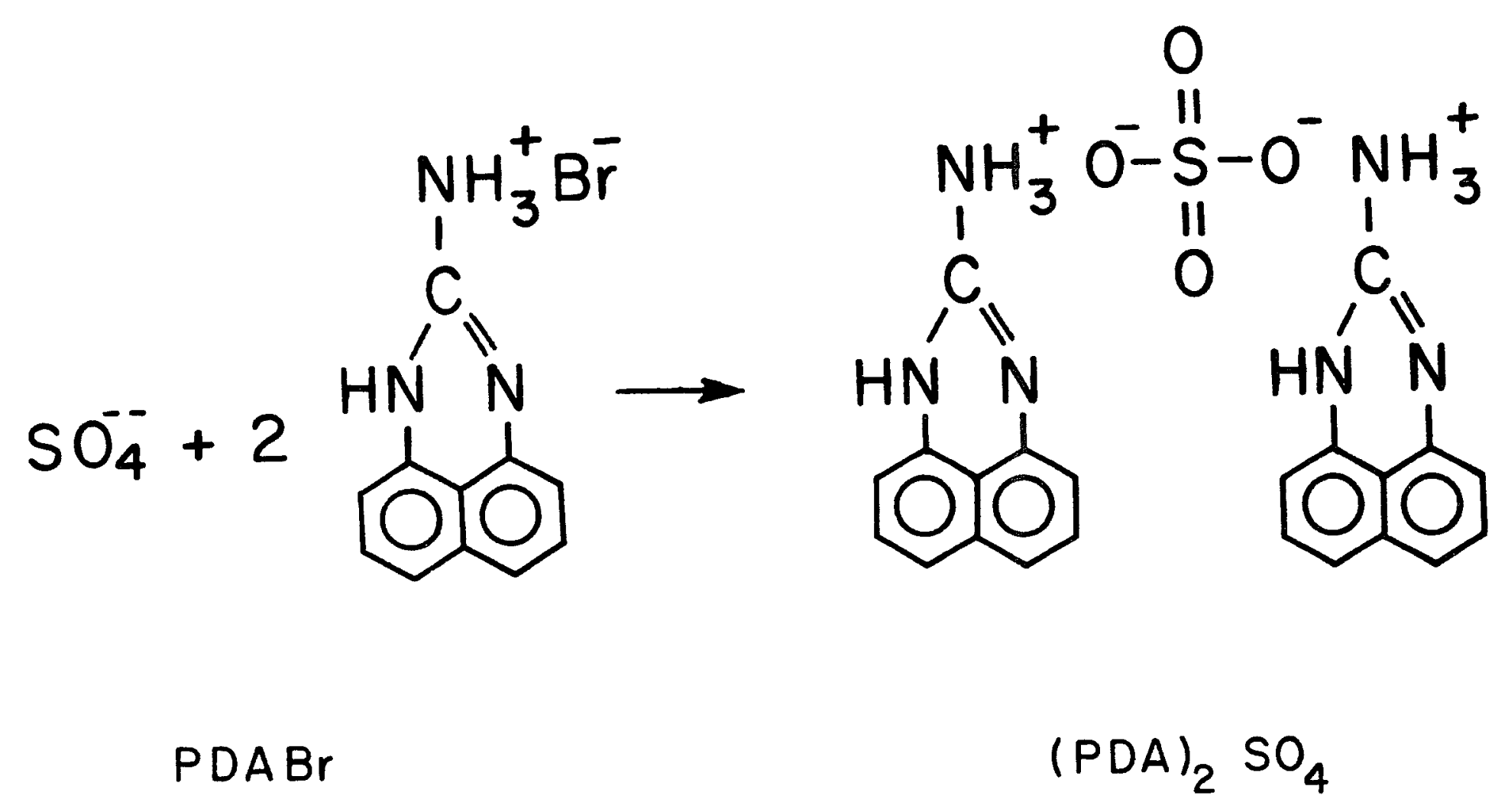


FIGURE 5

PYROLYSIS REACTION 
PYROLYSIS REACTION

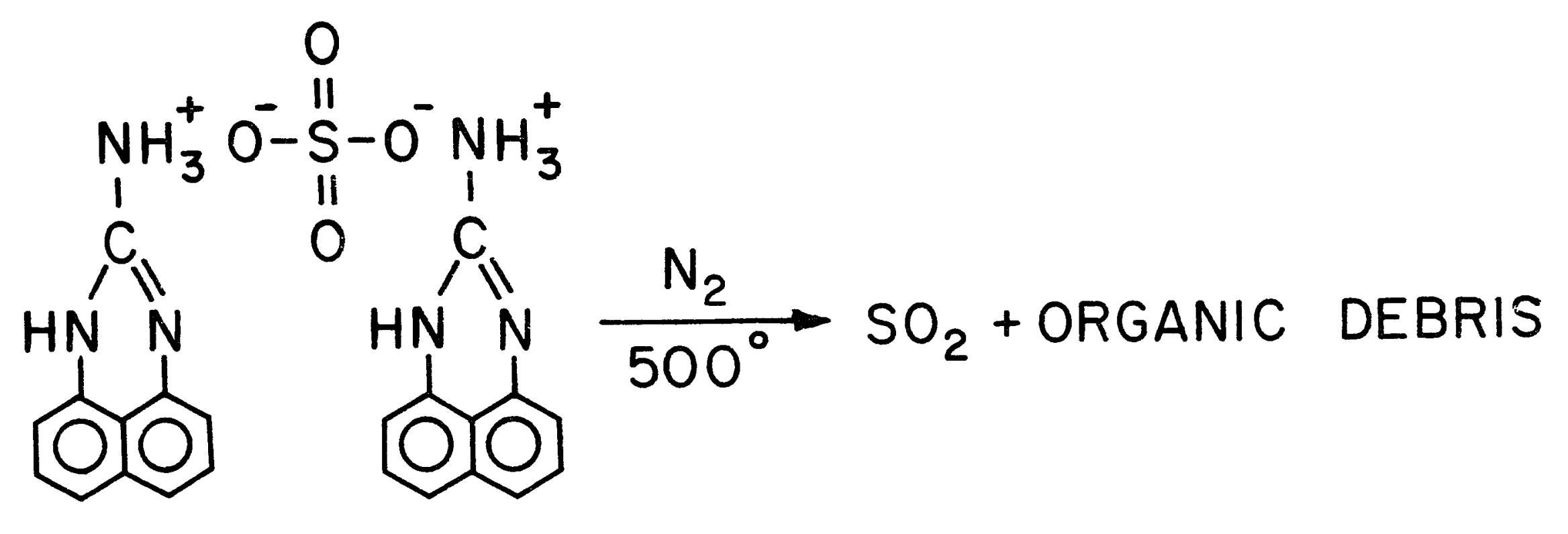


and Maddalone. Stephen surveyed a large number of anions and found that most of them would precipitate as their PDA salts. However he concluded that at least 10-fold amounts of these arions could be tolerated in his procedure without causing large errors. Maddalone, on the other hand, chose to look at the pyrolysis reaction of the PDA salts of phosphate, carbonate, and nitrate to determine their effect on the pyrolysis blank. He noted no increase in the blank values for those three anions. Thus a more extensive study of the anions was required to determine which anions might interfere with the sulfate recovery in the pyrolysis procedure and what concentration levels of these anions could be tolerated.

In order to determine sulfate recovery values for all the interference studies and to monitor the efficiency of the pyrolysis reaction with varying sample constituents, a sulfur dioxide calibration curve was used. After pyrolysis, the sulfur dioxide was determined colorimetrically (WestGaeke procedure) and the concentration was read directly from the calibration curve. The sulfate concentration was then calculated and compared to the amount of sulfate originally placed in the sample. (See Appendix A for calculations.)

2. Interference Studies Some early unpublished work of Maddalone's indicated 
that chloride, bicarbonate, phosphate, and nitrate could be interferences in a water analysis using the pyrolysis procedure. Most drinking water and natural water samples contain small amounts of phosphate and nitrate, and larger amounts of chloride and bicarbonate. Thus the elimination of chloride and bicarbonate was deemed necessary, and the development of the finished sulfate method was centered around them. An acid treatment was proposed for the removal of bicarbonate, leaving chloride as the most serious potential interference. Thus a study of the concentrations at which chloride interfered and of possible ways to eliminate its effects was undertaken.

The choice of 50,70 and $100 \mu \mathrm{g}$ of chloride for the concentration study was not completely arbitrary. Calculations based on early designs of the final water procedure showed that these amounts of chloride would be present in the final pyrolysis aliquot, when the original sample contained 500, 700 and $1000 \mathrm{ppm}$ chloride. Thus, if conditions were found in which $50 \mu \mathrm{g}$ of chloride did not interfere, then most water samples could be done under the same conditions, since most waters do not contain over $500 \mathrm{ppm}$ chloride. If conditions could be found to remove the $100 \mu \mathrm{g}$ chloride interference, then hydrochloric acid could possibly be used for the acid treatment of bicarbonate without any effect on the recovery of sulfate.

Using Maddalone's original procedure, the data in 
Table 3 was obtained. As shown, the sulfate recovery decreased as the chloride concentration increased from $50 \mu \mathrm{g}$ to $100 \mu \mathrm{g}$. It was suggested that the amount of PDA-Br be increased to see if the recovery could be improved.

Table 4 shows the results of increasing the volume and hence the amount of PDA-Br added to the pyrolysis sample. Increasing the PDA-Br volume to $250 \mu 1$ significantly increased the recovery over the use of $200 \mu 1$, even at the $100 \mu \mathrm{g}$ chloride level. However the addition of $300 \mu \mathrm{I}$ of PDA-Br showed a decrease in recoveries for the standards containing no chloride as well as for the chloride samples. Although the actual sulfate recoveries were lower for $300 \mu 1$, the data between samples and standards was more consistent; that is, there was less deviation between the sample sulfate recoveries and the recoveries of a standard run on the same day. SThe last column in Table 4 shows the difference between sample and daily standard recoveries.)

In order to improve the overall sulfate recoveries, a larger dish size was suggested. When $250 \mu 1$ or $300 \mu 1$ of PDA-Br were used with the $16 \mathrm{~mm}$ pyrolysis dishes, a heavy uneven coating of the dish resulted upon solvent evaporation. By using a larger dish and hence a larger surface area, a thin even coating of the dish was anticipated, resulting in better sulfate recoveries.

The results of the effect of a larger dish size are 
TABLE 3

CHLORIDE CONCENTRATION STUDY

$16 \mathrm{~mm}$ dish, $200 \mu \mathrm{IPD}-\mathrm{Br}$

\begin{tabular}{lrc}
\hline$\mu \mathrm{g} \mathrm{SO}_{4}{ }^{-}$ & $\mu \mathrm{g} \mathrm{Cl}^{-}$ & $\mathrm{SO}_{4}=$ Recovery \\
\hline 10 & $-\cdots$ & $102.2 \%$ \\
10 & 50 & $94.1 \%$ \\
10 & 70 & $77.1 \%$ \\
10 & 100 & $75.6 \%$
\end{tabular}


TABLE 4

EFFECT OF INCREASED VOLUNE OF PDA-BR

$10 \mu \mathrm{g} \mathrm{SO}_{4}=16 \mathrm{~mm}$ dish

\begin{tabular}{|c|c|c|c|c|}
\hline$\mu \mathrm{g} \mathrm{Cl}{ }^{-}$ & $\begin{array}{l}\text { Volume } \\
\text { PDA-Br }\end{array}$ & $\mathrm{SO}_{4}=\begin{array}{l}\text { Sample } \\
\text { Recovery }\end{array}$ & $\begin{array}{c}\text { Standard } \\
\mathrm{SO}_{4}=\text { Recovery }\end{array}$ & Difference \\
\hline-- & $250 \mu 1$ & $101.7 \%$ & --- & --- \\
\hline 50 & $250 \mu 1$ & $98.6 \%$ & $100.2 \%$ & $-1.4 \%$ \\
\hline 70 & $250 \mu 1$ & $96.9 \%$ & $100.2 \%$ & $-3.1 \%$ \\
\hline 100 & $250 \mu 1$ & $90.0 \%$ & $96.8 \%$ & $-6.8 \%$ \\
\hline--- & $300 \mu 1$ & $98.4 \%$ & --- & --- \\
\hline 50 & $300 \mu I$ & $90.3 \%$ & $90.3 \%$ & 0 \\
\hline 70 & $300 \mu I$ & $88.9 \%$ & $90.3 \%$ & $-1.4 \%$ \\
\hline 100 & $300 \mu I$ & $96.0 \%$ & $96.4 \%$ & $-0.4 \%$ \\
\hline
\end{tabular}


given in Table 5. The actual sulfate recoveries for both the standards and the samples were significantly improved by the use of the larger dish. However, the agreement between sample and standard recoveries, observed with $300 \mu 1$ of $\mathrm{PDA}-\mathrm{Br}$ and a $16 \mathrm{~mm}$ dish, was lost, although very little variation in the differences themselves (last column, Table 5) was observed between the $250 \mu l$ and the $300 \mu l$ samples.

In the case of the $300 \mu l$ of $\mathrm{PDA}-\mathrm{Br}$, the relative deviation for a set of 15 standards was improved with the $20 \mathrm{~mm}$ dish (relative deviation $= \pm 1.4 \%$ ) compared to the $16 \mathrm{~mm}$ dish $( \pm 2.9 \%)$. These relative deviations and the sulfate recoveries seemed to indicate that the close agreement of standard and sample for the $16 \mathrm{~mm}$ dish was related to the large amount of material present in a small area (i.e., to the dish size and the PDA-Br volume), and, as such, did not reflect any chloride effects. Mole ratio calculations of total anions to PDA-Br, based on hypothetical values for various anions in a water sample, showed that $300 \mu l$ of PDA-Br would be needed to insure the complete precipitation of sulfate.

Based on these mole ratio calculations, the relative deviation for the standard, and the improved sulfate recoveries for both the standard and the sample, the $20 \mathrm{~mm}$ i.d. dish and the $300 \mu \mathrm{l}$ of $\mathrm{PDA}-\mathrm{Br}$ were selected for use in the remaining studies. As shown, up to $100 \mu \mathrm{g}$ of chloride 
TABLE 5

EFFECT OF 20 NIM ID PYROLYSIS DISH

$10 \mu \mathrm{g} \mathrm{SO} \mathrm{SO}_{4}=$

\begin{tabular}{|c|c|c|c|c|}
\hline$\mu \mathrm{g} \mathrm{Cl}^{-}$ & $\begin{array}{l}\text { Volume } \\
\text { PDA-Br }\end{array}$ & $\mathrm{SO}_{4}=\stackrel{\text { Sample }}{\text { Recovery }}$ & $\begin{array}{c}\text { Standard } \\
\mathrm{SO}_{4}=\text { Recovery }\end{array}$ & Difference \\
\hline--- & $250 \mu 1$ & $102.4 \%$ & -- & -- \\
\hline 50 & $250 \mu 1$ & $102.4 \%$ & $102.8 \%$ & $-0.4 \%$ \\
\hline 70 & $250 \mu \mathrm{I}$ & $98.4 \%$ & $101.7 \%$ & $-3.3 \%$ \\
\hline 100 & $250 \mu 1$ & $98.2 \%$ & $102.8 \%$ & $-4.6 \%$ \\
\hline--- & $300 \mu 1$ & $101.1 \%$ & --- & --- \\
\hline 50 & $300 \mu I$ & $101.1 \%$ & $101.7 \%$ & $-0.6 \%$ \\
\hline 70 & $300 \mu I$ & $96.8 \%$ & $100.1 \%$ & $-3.3 \%$ \\
\hline 100 & $300 \mu 1$ & $94.8 \%$ & $100.1 \%$ & $-5.3 \%$ \\
\hline
\end{tabular}


can be tolerated with only a $5 \%$ decrease in sulfate recoveries. A later experiment in which $400 \mu 1$ of PDA-Br were tried, showed no increase in sulfate recoveries over the use of $300 \mu I$ of PDA-Br.

If a sample contained more than $100 \mu \mathrm{g}$ of chloride per $10 \mu \mathrm{g}$ of sulfate, the sample could be diluted such that the chloride level was below $100 \mu \mathrm{g}$. Since this would also dilute the sulfate concentration, a dilution study was made to ascertain a lower limit for sulfate in the presence of $100 \mu \mathrm{g}$ of chloride. Table 6 shows that a 1:20 ratio of sulfate to chloride produced results identical to the standard. In the case of the 1:50 ratio, only a 5\% decrease in recovery was observed, indicating that a sample dilution could be made without grossly affecting the sample recovery. After finishing the chloride studies, a study of other anion interferences was undertaken. The main purpose of the study was to determine which anions would interfere with the pyrolysis blank or the sulfate recovery and at what concentration levels this would occur. Several of the anions studied (acetate, formate, oxalate, and EDTA) are not usually found in potable waters, but they were included in hopes of finding a noninterfering anion whose corresponding acid could be used for the treatment and removal of bicarbonate.

The effect of each anion on the pyrolysis blank was studied first by adding $10 \mu \mathrm{g}$ of an anion to the $300 \mu \mathrm{I}$ 


\section{TABLE 6}

\section{DILUTION STUDY}

$20 \mathrm{~mm}$ dish, $300 \mu \mathrm{I}$ PDA-Br

\begin{tabular}{cccc}
\hline$\mu \mathrm{g} \mathrm{SO}_{4}=$ & $\mu \mathrm{g} \mathrm{Cl}^{-}$ & $\mathrm{SO}_{4}=\begin{array}{c}\text { Sample } \\
\text { Recovery }\end{array}$ & $\mathrm{SO}_{4}{ }^{-}: \mathrm{Cl}^{-}$ \\
\hline 5 & --- & $90.0 \%$ & $-\cdots$ \\
5 & 50 & $90.3 \%$ & $1: 10$ \\
5 & 100 & $90.0 \%$ & $1: 20$ \\
2 & --- & $101.5 \%$ & $-\cdots$ \\
2 & 50 & $96.0 \%$ & $1: 25$ \\
2 & 100 & $96.0 \%$ & $1: 50$
\end{tabular}


PDA-Br blank. As expected, the only anion which showed an increase in blank values was sulfite. For the other anions, the blank values remained essentially constant (within the usual deviation for the blank).

The anion concentration levels studied were 10 or 100 $\mu \mathrm{g}$ of anion to $10 \mu \mathrm{g}$ of sulfate $(1: 1$ or $1: 10$ ratio of sulfate to anion) for all the anions except phosphate which was also done at a $1 \mu \mathrm{g}$ level. The results of the 10 and $100 \mu \mathrm{g}$ studies are given in Tables 7 and 8 respectively. As shown in Table 7 at the $10 \mu \mathrm{g}$ level, chloride, bromide, fluoride, nitrate, acetate, oxalate, and EDTA were essentially noninterfering, while bicarbonate and formate showed only minor interference. The phosphate posed the most serious interference at this concentration level, as shown by the large decrease in sulfate recovery.

As a result of this large decrease, phosphate was tried at the $1 \mathrm{\mu g}$ level with $10 \mu \mathrm{g}$ of sulfate (10:1 ratio of sulfate to anion). OnIy minor interference was observed at this concentration with a decrease in recoveries from standard to sample of $8.0 \%$ for hydrogen phosphate and $3.8 \%$ for dinydrogen phosphate.

At the $100 \mu \mathrm{g}$ level (Table 8), significant decreases in sulfate recovery were observed for all the anions except chloride, bromide, acetate, and EDTA. Based on these results and the results obtained in the blank studies, it was concluded that the interference occurred in connection 
TABLE $?$

$10 \mu \mathrm{g}$ ANION INTERFERENCE STUDY

$10 \mu \mathrm{g} \mathrm{SO}{ }_{4}=20 \mathrm{~mm}$ dish, $300 \mu \mathrm{lDA}-\mathrm{Br}$

\begin{tabular}{|c|c|c|c|}
\hline Anion & $\mathrm{SO}_{4}=\stackrel{\text { Sample }}{\text { Recovery }}$ & $\mathrm{SO}_{4} \stackrel{\text { Standard }}{=}$ Recovery & Difference \\
\hline Chloride & $93.0 \%$ & $92.0 \%$ & $+1.0 \%$ \\
\hline Bromide & $91.4 \%$ & $90.0 \%$ & $+1.4 \%$ \\
\hline Fluoride & $91.7 \%$ & $92.6 \%$ & $-0.9 \%$ \\
\hline Bicarbonate & $87.9 \%$ & $93.0 \%$ & $-5.1 \%$ \\
\hline Nitrate & $90.6 \%$ & $89.4 \%$ & $+1.2 \%$ \\
\hline Hydrogen Phosphate & $80.1 \%$ & $91.4 \%$ & $-11 \cdot 3 \%$ \\
\hline Dihydrogen Phosphate & $61.1 \%$ & $87.0 \%$ & $-25.9 \%$ \\
\hline Acetate & $93.0 \%$ & $92.6 \%$ & $+0.4 \%$ \\
\hline Formate & $88.5 \%$ & $92.0 \%$ & $-3.5 \%$ \\
\hline Oxalate & $88.8 \%$ & $88.5 \%$ & $+0.3 \%$ \\
\hline EDTA & $89.1 \%$ & $87.3 \%$ & $+1.8 \%$ \\
\hline
\end{tabular}


TABLE 8

$100 \mu \mathrm{g}$ ANION INTERFERENCE STUDY

$10 \mu \mathrm{g} \mathrm{SO}{ }_{4}=, 20 \mathrm{~mm}$ dish, $300 \mu 1 \mathrm{PDA}-\mathrm{Br}$

\begin{tabular}{lccc}
\hline \multicolumn{1}{c}{ Anion } & $\mathrm{SO}_{4}=$ Sample \\
Recovery & $\mathrm{SO}_{4}=$ & Standard \\
Recovery & Difference \\
\hline Chloride & $88.5 \%$ & $91.8 \%$ & $-3.3 \%$ \\
Bromide & $92.0 \%$ & $90.0 \%$ & $+2.0 \%$ \\
Fluoride & $49.7 \%$ & $92.6 \%$ & $-42.9 \%$ \\
Bicarbonate & $74.0 \%$ & $92.6 \%$ & $-18.6 \%$ \\
Nitrate & $35.4 \%$ & $89.4 \%$ & $-54.0 \%$ \\
Hydrogen Phosphate & $66.3 \%$ & $89.7 \%$ & $-23.4 \%$ \\
Dihydrogen Phosphate & $65.3 \%$ & $86.0 \%$ & $-20.7 \%$ \\
Acetate & $84.9 \%$ & $92.6 \%$ & $-7.7 \%$ \\
Formate & $35.3 \%$ & $92.0 \%$ & $-56.7 \%$ \\
Oxalate & $74.7 \%$ & $89.7 \%$ & $-15.0 \%$ \\
EDTA & $81.5 \%$ & $87.3 \%$ & $-5.8 \%$
\end{tabular}


with the precipitation and evaporation of the (PDA) ${ }_{2} \mathrm{SO}_{4}$ sample, possibly through co-precipitation, occlusion, or formation of mixed salts.

It should be noted that, as expected, sulfite showed an increase in sulfate recoveries at these levels and hence, must be absent from samples. The acid treatment for bicarbonate should also remove any sulfite which might be present.

Although it appears that most anions interfere with this water analysis procedure, it should be noted that these anions are seldom found over or near a 1:1 concentration ratio with sulfate in potable water systems (with the obvious exception of chloride and bicarbonate). Thus most of the anions would pose no serious interference problems unless a water sample was highly polluted.

Bicarbonate, on the other hand, is present in water samples and precautions must be taken to eliminate its interference effects. The method proposed to accomplish this, consisted of treating the bicarbonate with acid and heating to drive off the carbon dioxide formed:

$$
\mathrm{HCO}_{3}{ }^{-}+\mathrm{H}^{+} \rightleftarrows \mathrm{H}_{2} \mathrm{CO}_{3}=\mathrm{H}_{2} \mathrm{O}+\mathrm{CO}_{2} \uparrow
$$

A number of acids were suggested including hydrochloric, nitric, acetic, formic, oxalic, and chloroacetic acids. Based on the earlier interference studies, hydrochloric acid was tried first and found to be effective. Thus none 
of the other acids were even utilized.

The $\mathrm{pH}$ of the sample and the effective use of $\mathrm{pH}$ played an important role in the development of this method. Bicarbonate will form a flocculent, voluminous, white precipitate with $\mathrm{PDA}^{+}$at a $\mathrm{pH}$ of 9 . However, a carbonate solution with a higher $\mathrm{pH}(>10)$ gives no precipitate because the PDA-Br is destroyed at that pH. Stephen noted in his nephelometric procedure that the best precipitate characteristics were obtained at a pH of 5. Maddalone's early work with the pyrolysis procedure was done using sulfuric acid solutions $(\mathrm{pH}<2)$ with no loss in recoveries noted. As the work proceeded, it became clear that below a $\mathrm{pH}$ of 10 , the actual $\mathrm{pH}$ value was not critical and could vary significantly without any loss in sulfate recovery. In the initial studies, the sample contained only sulfate and bicarbonate (100 ppm each), since the purpose was to find out if an acid treatment was effective in removing the bicarbonate. Later studies used a mixed solution of $100 \mathrm{ppm}$ sulfate, $200 \mathrm{ppm}$ bicarbonate, $400 \mathrm{ppm}$ chloride, and $10 \mathrm{ppm}$ nitrate as a synthetic sample, to evaluate the overall effectiveness of various treatment procedures.

Originally, it was thought that after the acid treatment, the $\mathrm{pH}$ would need to be raised to approximately five before taking out the pyrolysis aliquots. Thus, both the acid and base concentrations were varied to find the optimum 
conditions. At the same time, the sulfate standard was also varied to determine which one (sulfuric acid, sodium sulfate or potassium sulfate) would be suitable for preparing the final calibration curve, and if it would be absolutely necessary to treat the standard in the same manner as the sample. The results of these initial studies are given in Tables 9 and 10 .

The data for the sulfate standards, shown in Table 9, is the average value obtained over a considerable period of time for each given standard. The untreated standards were prepared directly by placing $100 \mu \mathrm{l}$ of a $100 \mathrm{ppm}$ sulfate solution in a $19 \mathrm{~mm}$ dish, adding $300 \mu \mathrm{l}$ of $\mathrm{PDA}-\mathrm{Br}$, mixing, drying, and pyrolyzing as before. The worst results were obtained with potassium sulfate. The recovery values from day to day tended to be erratic and unpredictable and indeed they were both the highest and the lowest recovery values obtained for any of the standards. Even the relative deviations were consistently the largest among the three compounds. Thus potassium sulfate was rejected as the standard solution to use.

The sulfuric acid and sodium sulfate standards showed comparable recovery values with less than $1 \%$ difference between treated and untreated samples, although the actual recovery was slightly lower for the sodium sulfate samples. Although the relative deviation for the untreated sulfuric acid samples appears as the highest value in this table, 


\section{TABLE 9}

SULFATE STANDARD STUDY

\begin{tabular}{ccc}
\hline Sample & $\%$ Recovery & $\begin{array}{c}\text { Relative } \\
\text { Deviation }\end{array}$ \\
\hline $\mathrm{H}_{2} \mathrm{SO}_{4}$ - untreated & $92.3 \%$ & $\pm 3.3 \%$ \\
$\mathrm{H}_{2} \mathrm{SO}_{4}-$ treated $^{*}$ & $91.4 \%$ & $\pm 1.4 \%$ \\
$\mathrm{~K}_{2} \mathrm{SO}_{4}-$ untreated & $94.2 \%$ & $\pm 2.9 \%$ \\
$\mathrm{~K}_{2} \mathrm{SO}_{4}-$ treated & \\
& $88.5 \%$ & $\pm 2.9 \%$ \\
$\mathrm{Na}_{2} \mathrm{SO}_{4}-$ untreated & $89.7 \%$ & $\pm 2.6 \%$ \\
$\mathrm{Na}_{2} \mathrm{SO}_{4}$ - treated & $89.4 \%$ & $\pm 2.0 \%$ \\
& &
\end{tabular}


it should be noted that this value was based on 86 samples taken over a period of three months. The other data was based on considerably fewer samples taken in a period of one month. In fact, the sulfuric acid data and relative deviation indicates the excellent day-to-day reproducibility for the pyrolysis procedure. The relative deviation obtained on any one given day with a set of samples was normally less than $\pm 2.0 \%$. On a daily basis, the relative deviations for sodium sulfate samples were slightly higher than for the sulfuric acid samples, but overall, they were a bit more consistent as the data in Table 9 indicates.

From a recovery standpoint, the sulfuric acid appeared to be the best standard to use, with sodium sulfate being considered quite acceptable. It was decided to use the sodium sulfate for standards since it was felt that sodium sulfate was more representative of the species actually found in water samples. It was also decided that the standards should be treated in the same way as the samples for consistency, but that, as the data showed, the treatment could be omitted at the discretion of the analyst.

While the standards work was being done, the effects of various hydrochloric acid concentrations and ammonium hydroxide concentrations were also being evaluated. Table 10 contains some representative data. At the higher acid concentrations ( $6 \mathrm{M}$ and $3 \mathrm{M}$ ), the results tended to be erratic, due in part to the use of potassium sulfate, but 
TABLE 10

BICARBONATE REPIOVAL STUDY

EFFECT OF VARIOUS ACID AND BASE CONCENTRATIONS

$$
\begin{gathered}
\text { Sample }-100 \mathrm{ppm} \mathrm{SO}_{4}=100 \mathrm{ppm} \mathrm{HCO}_{3}{ }^{-} \\
\text {Standard - } 100 \mathrm{ppm} \mathrm{SO}_{4}=
\end{gathered}
$$

\begin{tabular}{ccc}
\hline Treatment & $\begin{array}{c}\text { Sample } \\
\mathrm{SO}_{4}=\text { Recovery }\end{array}$ & $\begin{array}{c}\text { Standard } \\
\mathrm{SO}_{4}=\text { Recovery }\end{array}$ \\
\hline $\mathrm{M} \mathrm{HCl}, 1 \mathrm{~N} \mathrm{NH}_{4} \mathrm{OH}$ & $84.5 \% \pm 4.1 \%$ & $83.9 \% \pm 2.7 \%$ \\
$3 \mathrm{M} \mathrm{HCl}, 1 \mathrm{~N} \mathrm{NH}_{4} \mathrm{OH}$ & $92.3 \% \pm 2.6 \%$ & $88.8 \% \pm 2.0 \%$ \\
$3 \mathrm{M} \mathrm{HCl}, 0.5 \mathrm{M} \mathrm{NH}_{4} \mathrm{OH}$ & $73.1 \% \pm 9.9 \%$ & $92.6 \% \pm 2.0 \%$ \\
$1 \mathrm{M} \mathrm{HCl}, 0.5 \mathrm{M} \mathrm{NH}_{4} \mathrm{OH}$ & $90.3 \% \pm 1.1 \%$ & $90.3 \% \pm 1.3 \%$
\end{tabular}


due mainly to the effects of adding large amounts of chloride, shown by calculation to be greater than $100 \mu \mathrm{g}$. The best results were obtained with 1 M hydrochloric acid and $0.5 \mathrm{M}$ ammonium hydroxide with the complete agreement between standard and sample indicating that the bicarbonate had been effectively removed.

To be sure of these results, the treatment procedure using $1 \mathrm{M}$ hydrochloric acid and $0.5 \mathrm{M}$ ammonium hydroxide was repeated with recoveries of $88.5 \% \pm 2.3 \%$ and $82.5 \% \pm 1.4 \%$ for standard and sample respectively being obtained. However, it was noted that the final $\mathrm{pH}$ of the samples was different for the two experiments. In the first experiment, the final sample $\mathrm{pH}$ was seven, whereas in the second experiment the final sample $\mathrm{pH}$ was ten. This high $\mathrm{pH}$ may have caused the low recoveries by destroying the PDA-Br.

Repeating this one experiment pointed out the difficulty in accurately controlling and establishing a $\mathrm{pH}$ of five with $0.5 \mathrm{M}$ ammonium hydroxide. As little as one or two drops could change the $\mathrm{pH}$ well beyond the desired value of five. Thus it was desired to find a more effective method of raising the $\mathrm{pH}$.

Several possible alternatives were suggested including the use of an ammonium acetate buffer added dropwise, and the use of a set volume $(1 \mathrm{ml})$ of a weaker ammonium hydroxide solution (0.1M) or an ammonium acetate buffer (0.1M). At this point, it was also decided that the sample 
should be more representative of a water sample and hence the synthetic sample was used. Table 11 contains the results of experiments using these conditions. As shown, the ammonium acetate buffer gave poor results at both concentrations with low recoveries and high relative deviations. Although no sample treatment at all gave recoveries comparable to the $1 \mathbb{M}$ hydrochloric acid and $0.5 \mathbb{M}$ ammonium hydroxide, the relative deviations were much higher. Thus, the best overall results were still obtained with the $1 \mathbb{N}$ hydrochloric acid and $0.5 \mathrm{M}$ ammonium hydroxide.

At this point, a question was raised concerning the necessity of adjusting the $\mathrm{pH}$ to five after the acid treatment, since this step was time-consuming and cumbersome. Two altematives were suggested, both of which would simplify the procedure. The first alternative was to evaporate the sample completely to dryness after the hydrochloric acid addition, thereby ensuring complete destruction of the bicarbonate and driving off any excess hydrochloric acid. The second alternative was to make no $\mathrm{pH}$ adjustment at all to the sample after boiling with the hydrochloric acid, thereby leaving the $\mathrm{pH}$ at $<2$. This altemative appeared feasible since sulfuric acid standards had previously been used without an pH adjustment and excellent results had been obtained. Another sample containing $1000 \mathrm{ppm}$ bicarbonate was also added at this time to determine which, if any of the proposed procedures, would remove gross 
TABLE 11

BICARBONATE RENOVAL STLDY

CONTROL OF pH

Standard - $100 \mathrm{ppm} \mathrm{SO}_{4}=$

Sample - $100 \mathrm{ppm} \mathrm{SO}_{4}=200 \mathrm{ppm} \mathrm{HCO}_{3}{ }^{-}$,

$400 \mathrm{ppm} \mathrm{Cl}^{-}, 10 \mathrm{ppm} \mathrm{NO}_{3}^{-}$

Treatment $\mathrm{SO}_{4} \stackrel{\text { Sample }}{=}$ Recovery $\quad \mathrm{SO}_{4} \stackrel{\text { Standard }}{=}$ Recovery

None

$86.7 \% \pm 5.0 \%$

$89.4 \% \pm 3.9 \%$

$1 \mathrm{M} \mathrm{HCl}, 0.1 \mathrm{M} \mathrm{NH}_{4} \mathrm{OH}$

$88.1 \% \pm 2.8 \%$

$84.2 \% \pm 3.8 \%$

$1 \mathrm{M} \mathrm{HCl}, 0.5 \mathrm{M} \mathrm{NH}_{4} \mathrm{OH}$

$86.0 \% \pm 3.8 \%$

$89.4 \% \pm 1.7 \%$

$1 \mathrm{M} \mathrm{HCl}, 0.1 \mathrm{M} \mathrm{NH} \mathrm{NH}_{4} \mathrm{AC}$

$87.5 \% \pm 3.4 \%$

$83.1 \% \pm 3.9 \%$

$1 \mathrm{M} \mathrm{HCl}, 0.5 \mathrm{M} \mathrm{NH} 4 \mathrm{Ac}$

$78.5 \% \pm 9.9 \%$

$83.6 \% \pm 9.7 \%$ 
amounts of bicarbonate. Table 12 lists the results of this procedures

Although the evaporation procedure produced the best results for standards, it also produced the lowest results for samples. The results for the other two procedures were almost identical, except in the case of the $1000 \mathrm{ppm}$ bicarbonate. Even then, the difference between standard and sample recoveries was almost identical for the two procedures $(-6.0 \%$ for the $0.5 \mathrm{NI}$ ammonium hydroxide method and $-6.4 \%$ for no $\mathrm{pH}$ adjustment). Clearly, no one procedure was superior to the other two. Thus, on the basis of simplicity and speed, it was decided to use the $1 \mathrm{M}$ hydrochloric acid treatment with no $\mathrm{pH}$ adjustment after boiling.

\section{Sulfate Calibration Curve}

The preparation of a calibration curve based on the chosen procedure was the next step toward completing the method's development. Sodium sulfate standards from $0-120$ $\mathrm{ppm}$ at $10 \mathrm{ppm}$ intervals, plus $150 \mathrm{ppm}, 200 \mathrm{ppm}$, and $250 \mathrm{ppm}$ standards, were prepared using a stock solution of $1000 \mathrm{ppm}$ sulfate. A $10 \mathrm{ml}$ aliquot of each concentration was placed in a $15 \mathrm{ml}$ beaker, three drops of $1 \mathrm{M}$ hydrochloric acid were added (to a $\mathrm{pH}<2$ ), and the samples were heated to boiling until approximately $5 \mathrm{ml}$ remained. Each sample was transferred quantitatively to a $10 \mathrm{ml}$ volumetric flask and diluted to volume with deionized water. A blank 


\section{TABIE 12}

BICARBONATE RENOVAL STUDY

COMPARISON OF THREE PROPOSED PROCEDURES

Standard -- $100 \mathrm{ppm} \mathrm{SO}_{4}=$

Treatment $\quad \mathrm{SO}_{4} \stackrel{\text { Standard }}{=}$ Recovery

$1 \mathrm{M} \mathrm{HCI}, 0.5 \mathrm{M} \mathrm{NH}_{4} \mathrm{OH}$

1M HCl, evaporation

$1 \mathrm{M} \mathrm{HCl}$

$$
\begin{aligned}
& 86.4 \% \pm 3.1 \% \\
& 89.1 \% \pm 1.7 \% \\
& 86.0 \% \pm 3.0 \%
\end{aligned}
$$

$$
\text { Sample -- } 100 \mathrm{ppm} \mathrm{SO}_{4}=200 \mathrm{ppm} \mathrm{HCO}_{3}^{-}, 400 \mathrm{ppm} \mathrm{CI}^{-}, 10 \mathrm{ppm} \mathrm{NO}_{3}^{-}
$$

$1 \mathrm{M} \mathrm{HCl}, 0.5 \mathrm{M} \mathrm{NH} \mathrm{NH}_{4} \mathrm{OH}$

$$
\begin{aligned}
& 90.0 \% \pm 1.3 \% \\
& 90.0 \% \pm 2.6 \% \\
& 90.3 \% \pm 0.9 \%
\end{aligned}
$$$$
87.8 \% \pm 3.1 \%
$$

$1 \mathrm{M} \mathrm{HCl,} \mathrm{evaporation}$$$
85.4 \% \pm 1.6 \%
$$

$1 \mathrm{M} \mathrm{HCI}$$$
87.8 \% \pm 1.7 \%
$$

$$
\text { Sample -- } 100 \mathrm{ppm} \mathrm{SO}_{4}=1000 \mathrm{ppm} \mathrm{HCO}_{3}^{-}, 400 \mathrm{ppm} \mathrm{Cl}^{-}, 10 \mathrm{ppm} \mathrm{NO}_{3}^{-}
$$

$1 \mathrm{M} \mathrm{HCl}, 0.5 \mathrm{M} \mathrm{NH} \mathrm{NH}_{4} \mathrm{OH}$

$1 \mathrm{M} \mathrm{HCl,} \mathrm{evaporation}$

$1 \mathrm{M} \mathrm{HCI}$

$$
\begin{aligned}
& 88.5 \% \pm 2.3 \% \\
& 90.0 \% \pm 2.1 \% \\
& 84.9 \% \pm 2.2 \%
\end{aligned}
$$

$82.5 \% \pm 1.4 \%$

$66.9 \% \pm 4.9 \%$ $78.5 \% \pm 2.6 \%$ 
of $10 \mathrm{ml}$ deionized water was treated in the same manner. Triplicate $100 \mu \mathrm{l}$ aliquots were placed in $19 \mathrm{~mm}$ pyrolysis dishes, $300 \mu \mathrm{l}$ of $\mathrm{PDA}-\mathrm{Br}$ were added to each one, and the samples were mixed, dried, and pyrolyzed as before. The net absorbance values obtained were plotted vs. ppm sulfate in the original $10 \mathrm{ml}$ sample, resulting in a calibration curve like the one shown in Figure 6.

As observed, the calibration curve was not linear over the entire range of $0-120 \mathrm{ppm}$. Instead the curve contained two distinct linear portions from 0-90 ppm and 90-120 ppm. This break can be attributed to two different factors: The colorimetric determination of sulfur dioxide used in the procedure contained a very slight break at approximately $6 \mu \mathrm{g}$ sulfur dioxide per $10 \mathrm{ml}$ (see Figure 3); the calculated sulfate recovery for the sulfate samples in the $0-90 \mathrm{ppm}$ range averaged 90\%, while for the samples from 90-120, the recoveries fell off to $86 \%$. Fortunately both the recoveries and the break in the sulfur dioxide curve are very reproducible, making it possible to use the entire $0-120$ ppm range for water samples.

Samples of 150,200 , and $250 \mathrm{ppm}$ sulfate were also tried. However, at this level, the data became erratic and non-reproducible, as indicated by sulfate recovery values from 60-80\%. Thus for samples containing more than $120 \mathrm{ppm}$ sulfate, a smaller sample volume $(<10 \mathrm{ml})$ or a sample dilution before taking the $10 \mathrm{ml}$ sample volume, was 
FIGURE 6

SULFATE CAIIBRATION CURVE 


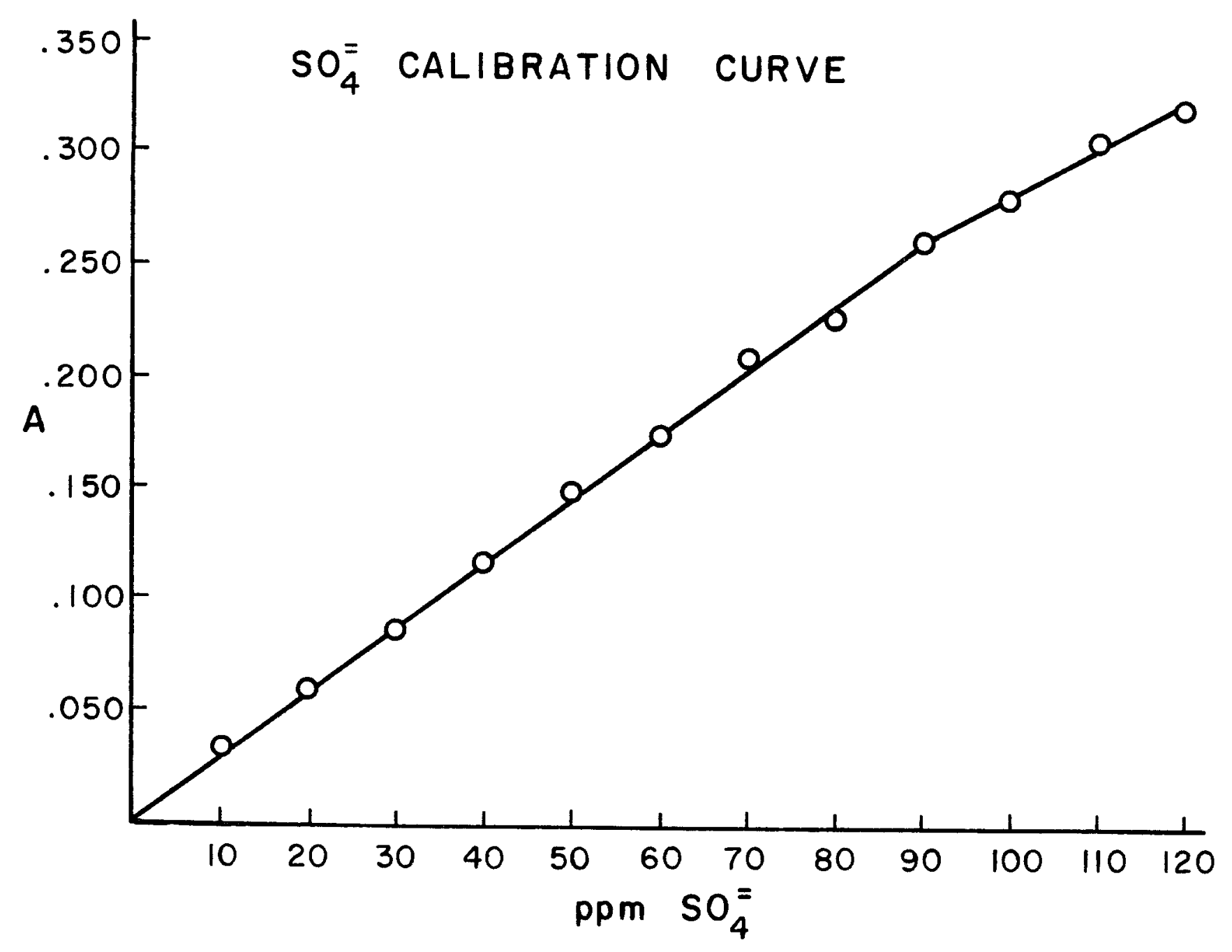


recommended.

The precision and sensitivity of the method were determined using the $100 \mathrm{ppm}$ sulfate sample and the reagent blank. Some typical data are shown in Table 13. The sensitivity was defined as 2.5 times the standard deviation $(\sigma)$ of the blank, giving a value of $1.8 \mathrm{ppm}$ sulfate. With this work completed, the method was ready to be applied to actual water samples.

B. Field Studies

The field studies for this procedure utilized two different approaches. The first approach consisted of comparing the results obtained using the pyrolytic method and four other established sulfate methods. For the second approach, samples from an independent laboratory were analyzed by the pyrolytic method and the results were compared to those of the independent laboratory. In both cases, the samples were selected so as to cover a broad range of sulfate concentrations and water conditions.

1. Comparison of Five Methods

The comparison of the pyrolytic method, the gravimetric method, ${ }^{1}$ the turbidimetric method, ${ }^{1,2}$ the barium chloranilate spectrophotometric method, 96,97 and Stephen's nephelometric method ${ }^{123}$ was conducted first. Table 14 
TABLE 13

PRECISION OF THE METHOD*

Net Absorbance Values

\begin{tabular}{c} 
Blank \\
\hline .036 \\
.040 \\
.042 \\
.039 \\
.040 \\
.036 \\
.040 \\
.039 \\
.039 \\
.040 \\
.040 \\
.040 \\
\hline
\end{tabular}

$100 \mathrm{ppm} \mathrm{SO}_{4}=$

.288

.291

.280

.278

.282

.280

.280

.282

.292

.279

.291

.288

.276

.039

$=$

Mean

.284

$\pm .002=$

$\sigma$

$\pm .006$

$\pm 4.4 \%=$

$=\quad$ Relative

$=$

$\pm 2.0 \%$

* See Appendix A for methods of calculation. 


\section{TABLE 14}

SULFATE DATA (PPM) FOR THE FIVE METHODS

\begin{tabular}{|c|c|c|c|c|c|c|}
\hline Sample & $\mathrm{pH}$ & $\begin{array}{l}\text { Pyrolytic } \\
\text { Method }\end{array}$ & $\begin{array}{l}\text { Gravi- } \\
\text { metric }\end{array}$ & $\begin{array}{l}\text { Turbid- } \\
\text { imetric }\end{array}$ & $\begin{array}{l}\text { Barium } \\
\text { Chlor- } \\
\text { Anilate }\end{array}$ & $\begin{array}{l}\text { Stephen's } \\
\text { Nephelo- } \\
\text { metric }\end{array}$ \\
\hline $\begin{array}{c}\text { Baton Rouge, } \\
\text { La. }\end{array}$ & 8.67 & $10.4 \pm 0.5$ & 9.8 & $10.4 \pm 0.3$ & $6.96 \pm 0.19$ & $43.2 \pm 7.3$ \\
\hline $\begin{array}{c}\text { Gamavillo, } \\
\text { Ia. }\end{array}$ & 7.86 & $11.3 \pm 1.9$ & 12.6 & $13.6 \pm 0.2$ & $13.24 \pm 1.04$ & $71.0 \pm 2.4$ \\
\hline Kenner, La. & 9.61 & $54.9 \pm 1.9$ & 52.8 & $54.4 \pm 0.8$ & $46.80 \pm 0.84$ & $61.2 \pm 0.3$ \\
\hline $\begin{array}{c}\text { Natchitoches, } \\
\text { La. }\end{array}$ & $7 \cdot 32$ & $48.4 \pm 0.5$ & 43.6 & $45.2 \pm 0.4$ & $41.20 \pm 0.99$ & $52.0 \pm 1.0$ \\
\hline $\begin{array}{c}\text { San Francisco, } \\
\text { Calif. }\end{array}$ & 7.44 & $2.6 \pm 0.6$ & --- & $2.6 \pm 0.1$ & $1.80 \pm 0.27$ & $1.0 \pm 0.1$ \\
\hline $\begin{array}{c}\text { Diamondhead, } \\
\text { Miss. }\end{array}$ & 8.67 & $8.2 \pm 0.3$ & 9.1 & $9.5 \pm 0.1$ & $7.60 \pm 0.40$ & $19.8 \pm 0.5$ \\
\hline Natchez, La. & 8.25 & $<2$ & -- & $<2$ & --- & $2.5 \pm 1.0$ \\
\hline
\end{tabular}


contains the results obtained for the seven drinking water samples studied.

These samples repuesented a variety of water sources and as such the water treatment procedures used on these waters ranged from extensive water purification and chlorination (Kenner, La. sample) to no treatment whatsoever (Natchez, La. sample). Several samples were known to be from underground streams (Garnavillo, Iowa and Baton Rouge, La.), while one sample was a well water sample (Natchez, La.). At least two of the samples (Kenner, La. and San Francisco, Calif.) were from large municipal water treatment facilities where some type of water treatment is done before the water goes to homes and businesses. Some of the water systems were known to be continuously chlorinated while others were chlorinated only at regular periodic intervals or as needed. After each sample was collected, it was not treated in any way and was stored in polyethylene bottles until used.

Triplicate samples were run for all the methods except the gravimetric method. The low sulfate concentrations and the limited quantity of sample precluded doing more than one gravimetric determination for the Gamavillo, Ia., Baton Rouge, La., and Diamondhead, Miss. samples and two gravimetric determinations for the Kenner, La. and Natchitoches, La. samples. The San Francisco, Calif. and Natchez, La. waters could not be done at all since prelim- 
inary calculations showed that approximately two liters of sample would have been required for a single determination. As shown in Table 14, the results for the gravimetric, turbidimetric, and pyrolytic methods agreed within the accepted deviations for each method. The barium chloranilate spectrophotometric results were consistently lower than the other methods for all the samples except Garnavillo. Due to the limited use of this method and the small amount of data obtained forthis study, no explanation of this low data was readily discernible.

Some of the most unusual results were obtained with Stephen's nephelometric method. The results were significantly higher in all cases except San Francisco. This could be accounted for by the presence of bicarbonate, which precipitated as the $\mathrm{PDA}-\mathrm{HCO}_{3}$. The presence of $\mathrm{PDA}-\mathrm{HCO}_{3}$ was immediately obvious, as its appearance was quite different from the $(\mathrm{PDA})_{2} \mathrm{SO}_{4}$. Thus, a sample with little or no sulfate could give a nephelometric reading, as was the case with the Natchez, Baton Rouge, and Garnavillo samples. As a result of this work, the usefulness of Stephen's method for water samples is highly questionable. The study originally included a direct titrimetric procedure using the Sulfanazo III indicator. 59 However the method proved to be too insensitive at the concentration levels of these samples. Possibly the use of larger sample volumes would have resulted in usable data, but at 
this point in the study, only small volumes of sample remained $(<100 \mathrm{ml})$. Thus the method had to be eliminated from the study.

The pyrolytic method was repeated several times to verify the data and finalize the procedure. After the first set of data was obtained, it was noted that the sulfate concentrations were quite low as compared to the nephelometric or gravimetric results. In an attempt to improve these results, the water samples were run though a cation exchange column to eliminate any cations which might be coprecipitating or forming mixed salts with the $(\mathrm{PDA})_{2} \mathrm{SO}_{4}$. Table 15 shows that a significant improvement in results was observed between exchanged and non-exchanged samples. Thus the ion exchange step was made a permanent part of the pyrolysis method.

This first set of data also indicated the need to use a larger pyrolysis aliquot for samples containing less than $10 \mathrm{ppm}$. Table 16 shows the data obtained when $100 \mu \mathrm{I}$ or $200 \mu l$ aliquots were used. The relative deviations were much lower in all cases with the larger aliquot, although only the San Francisco water and the Garnavillo water showed significant improvements in the observed sulfate concentrations.

2. Comparison of Data Between Two Laboratories Although the results of the methods comparison study 
TABLE 15

PYROLYTIC NETHOD

USE OF AN ION EXCHANGE COLUNN

\begin{tabular}{lcc}
\hline \multicolumn{1}{c}{ Sample } & $\begin{array}{c}\text { Non- } \\
\text { Exchanged }\end{array}$ & Exchanged \\
\hline Baton Rouge & $9.3 \mathrm{ppm} \pm 0.2$ & $10.4 \mathrm{ppm} \pm 0.5$ \\
Gamavillo & $3.2 \mathrm{ppm} \pm 1.1$ & $11.3 \mathrm{ppm} \pm 1.9$ \\
Diamondhead & $6.5 \mathrm{ppm} \pm 0.7$ & $8.2 \mathrm{ppm} \pm 0.3$ \\
San Francisco & N.D. & $2.6 \mathrm{ppm} \pm 0.6$ \\
Kenner & $20.5 \mathrm{ppm} \pm 1.25$ & $54.9 \mathrm{ppm} \pm 1.9$ \\
Natchitoches & $25.5 \mathrm{ppm} \pm 4.1$ & $48.4 \mathrm{ppm} \pm 0.5$ \\
Natchez & N.D. & $<2$
\end{tabular}

N.D. -- none detectable; blank readings observed. 
TABLE 16

PYROLYTIC NETHOD

PYROLYSIS ALIQUOT SIZE

\begin{tabular}{lcc}
\hline Sample & $100 \mu l$ aliquot & $200 \mu l$ aliquot \\
\hline Baton Rouge & $10.6 \mathrm{ppm} \pm 0.6$ & $10.2 \mathrm{ppm} \pm 0.4$ \\
Gamavillo & $9.7 \mathrm{ppm} \pm 1.2$ & $12.9 \mathrm{ppm} \pm 0.3$ \\
Diamondhead & $9.1 \mathrm{ppm} \pm 1.1$ & $8.0 \mathrm{ppm} \pm 0.3$ \\
San Francisco & N.D. & $2.5 \mathrm{ppm} \pm 0.6$
\end{tabular}

N.D. - none detectable; blank readings observed. 
indicated that the pyrolytic method compared favorably to other existing sulfate methods, another study was deemed recessary to insure against any operator bias in the above methods comparison study. Mr. Ves Shirley of the Louisiana Stream Control Commission, Division of Water Pollution Control, provided our laboratory with $25 \mathrm{ml}$ of thirteen different water samples. The routine analyses conducted by the Water Pollution Control Laboratory yielded the water quality data given in Table 17. As shown, a wide variety of sample constituents and concentrations was obtained.

After the sulfate concentrations were determined by our laboratory via the pyrolytic method, the data was compared to the data obtained by the water Pollution Control Laboratory via the barium sulfate turbidimetric method. Table 18 shows the sulfate data from both laboratories. The data for two of the samples (5806A and 8803A) was unavailable from the Water Pollution Control Laboratory. Upon examination of the data, a number of discrepancies were noted between the two laboratories. Differences in experimental procedures and conditions accounted for most of these discrepancies. The Water Pollution Control Laboratory made only one sulfate determination per water sample, whereas in our laboratory, triplicate determinations were made for each sample. Thus, no relative deviations were obtainable for the turbidimetric method. If the accepted relative deviation 
TABLE 17

WATER QUALITY DATA

Louisiana Stream Control Commission, Water Pollution Control Division

\begin{tabular}{|c|c|c|c|c|c|c|c|}
\hline $\begin{array}{l}\text { Sample } \\
\text { Parameter }\end{array}$ & 8502 & 8503 & 9701 & 7701 & 8802 & 5806 & 8803 \\
\hline $\begin{array}{l}\text { Alkalinity } \\
\left(\mathrm{mg} / 1 \mathrm{CaCO}_{3}\right)\end{array}$ & 231 & 320 & 66 & 116 & 18 & 23.6 & 25.0 \\
\hline $\mathrm{pH}$ & 7.4 & $7 \cdot 5$ & 7.5 & $8 \cdot 3$ & $7 \cdot 3$ & 7.8 & 7.9 \\
\hline $\begin{array}{l}\text { Hardness } \\
\qquad\left(\mathrm{mg} / 1 \mathrm{CaCO}_{3}\right)\end{array}$ & 92 & 150 & 69 & 170 & 18 & 1205 & 1195 \\
\hline Turbidity (J.T.U.) & 120 & 120 & 85 & 33 & 43 & 3 & 6 \\
\hline Total Solids & 522 & 532 & 294 & 366 & 194 & 7932 & 8328 \\
\hline Dissolved Solids & 210 & 236 & 164 & 324 & 96 & 7910 & 8272 \\
\hline Chloride (mg/l) & 40.3 & 38.6 & $19 \cdot 3$ & 29 & 16.0 & 4150 & 4375 \\
\hline Sulfate $(\mathrm{mg} / \mathrm{l})$ & 22 & 22 & 7 & 42 & 11 & 540 & 560 \\
\hline Sodium (mg/l) & 23 & 25 & 15 & 25 & 11 & 1220 & 1230 \\
\hline $\begin{array}{l}\text { Dissolved Oxygen } \\
\quad(\mathrm{mg} / \mathrm{l})\end{array}$ & 6.2 & 6.1 & 4.0 & 6.3 & 6.7 & 3.1 & 3.8 \\
\hline Color & 30 & 30 & 30 & 20 & 30 & 20 & 20 \\
\hline
\end{tabular}


TABLE 18

SULFATE DATA (PPN) FROM TWO LABORATORIES

USING DIFFERENT METHODS

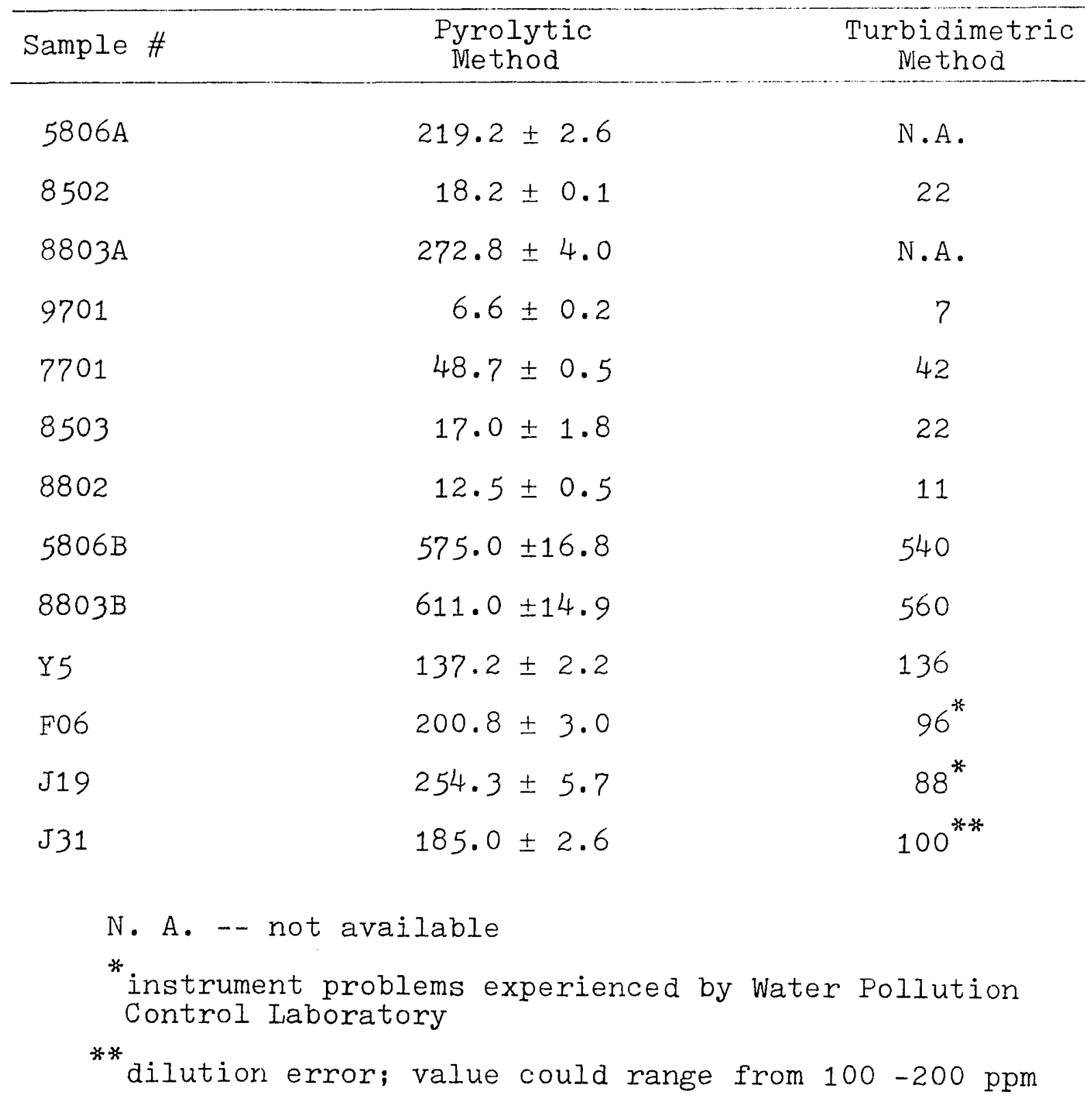


of $\pm 10 \%$ is applied to the turbidimetric data, the results of the two laboratories show a much closer agreement.

The last three samples in Table 18 showed large differences between the two laboratories. The Water Pollution Control Laboratory acknowledged that they had some problems in the analysis of these samples. Instrument problems occurred with two samples (FO6 and J19), and a dilution error occurred with the last sample (J31). Data obtained from the Water Pollution Control Laboratory showed that the value for sample J31 could vary from 100-200 ppm, depending on how the slope of the calibration curve at its lower end was Grawn. A small change in this slope resulted in small changes in sulfate values $(2-4 \mathrm{ppm})$, which were greatly magnified when the sample dilution (1:49) was taken into account. Unfortunately the Water Pollution Control Laboratory was unable to repeat their analysis. However, our laboratory had sufficient sample remaining for those three water samples that a turbidimetric analysis could be done. Table 19 shows that the sulfate concentrations were much higher than reported by the Water Pollution Control Laboratory. The turbidimetric values obtained by our laboratory showed much closer agreement with the pyrolytic values. On the basis of these two studies, it was felt that the pyrolytic method compared favorably to existing methods and could easily be used for routine analysis. 
TABLE 19

SULFATE DATA BETWEEN TWO LABS

USING THE TURBIDIMETRIC METHOD

Sample

$\frac{\text { Turbidimetric Method }}{\text { WPC }}$

Pyrolytic

Method

F06

$96 \mathrm{ppm}$

191 ppm

$200.8 \mathrm{ppm}$

J19

$88 \mathrm{ppm}$

$263 \mathrm{ppm}$

$254 \mathrm{ppm}$

J31

$100 \mathrm{ppm}$

$200 \mathrm{ppm}$

$185 \mathrm{ppm}$ 
CHAPTER V

CONCLUSION

142 
The need for analytical procedures for the routine analysis of our waters has led to the development of a new method for the determination of sulfate. This new method was based on the precipitation of sulfate as 2-perimidinylammonium sulfate with the subsequent pyrolysis of this compound to form sulfur dioxide, which was determined colorimetrically. Interferences were removed prior to the precipitation through the use of an ion exchange column and an acid treatment.

The pyrolytic method has a number of advantages over currently used procedures. The first advantage is imnediately obvious upon beginning the procedure. The water sample size used is $10 \mathrm{ml}$ or less, depending on the concentration of sulfate in the water. For a sample containing $0-120 \mathrm{ppm}$ sulfate, which is the working range of the method, a $10 \mathrm{ml}$ aliquot is required. If a sample contains more than $120 \mathrm{ppm}$, an aliquot of $1-5 \mathrm{ml}$ can be used.

For most procedures, the sample size is fixed by the procedure, and only after the analysis has been completed, does the analyst know whether or not the sample will fall within the working range of his particular method. If it does not fall in the range, the sample must be diluted or concentrated, and reanalyzed, thereby requiring 
additional analyst time, additional reagents and additional expense.

This repetition was avoided in the pyrolytic method through the use of a quick and simple spot test. The spot test was done with a $100 \mu I$ water sample, $300 \mu I$ of the $\mathrm{PDA}-\mathrm{Br}$ reagent, and a pyrolysis dish for some other convenient container such as a black spot plate). By visually comparing the amount of precipitate in the samples to the amount of precipitate in several standards $(10 \mathrm{ppm}$, $100 \mathrm{ppm}$, and $250 \mathrm{ppm}$ ), a fair approximation of the sulfate content could be obtained. Thus for concentrated samples (>120 ppm), the initial sample size could be adjusted before the analysis was begun. If the sample showed low sulfate concentrations ( $<10 \mathrm{ppm})$, the sample size was maintained at $10 \mathrm{ml}$, but the pyrolysis aliquot could be increased from 100 to $200 \mu 1$ to obtain more reliable results.

Besides having a working range of 0-120 ppm sulfate, which is readily expandable, the pyrolytic method has a sensitivity of $1.8 \mathrm{ppm}$ with a relative standard deviation of $\pm 2.0 \%$. This compares favorably with the relative standard deviation of the gravimetric method $( \pm 2.0 \%)$ and is better than the relative standard deviation of the turbidimetric method $( \pm 10 \%)$. The pyrolytic method also allows for triplicate analses to be done using one $10 \mathrm{ml}$ water sample, whereas the other methods require additional 
sample for each analysis. Thus statistical data can easily and readily be made available.

The pyrolytic method is easy to operate and relatively inexpensive for it requires no elaborate or sophisticated equipment beyond the typical laboratory spectrophotometer. A simple pyrolysis oven can be constructed using a Variac, two Lindberg ceramic heating units, and a quartz tube. Most of the reagents needed are also readily available. One of the few drawbacks to this procedure is the current unavailability of the reagent, 2-perimidinylammonium bromide, Presently, the reagent must be synthesized by anyone wishing to use this procedure, although it should be noted that the synthesis is simple, easy, and quick, and that the two starting materials needed are readily available. Efforts are currently under way to have the reagent commercially prepared and marketed.

One problem that is universal to all procedures is interferences. With the pyrolytic method, the most serious interferences were removed before the sulfate was precipitated. For most drinking and natural water samples, the concentration of any potential interferences remaining in the sample is too low to cause any interference problems. Only in grossly polluted waters would one be likely to observe any interference effects, particularly if the water contained high concentrations of phosphate. 
One factor which analyst's consider when choosing a routine analytical method, is the time required for the analysis. For one sample, the gravimetric method takes approximately 24 hours, while the turbidimetric method requires approximately fifteen minutes, not including the calibration work. Currently, using our existing experimental set-up, the pyrolytic method falls between those two times, requiring approximately six hours for a sample. It should be noted that two to ten samples can be done in the same amount of time, making it advantageous to analyze more than one sample.

Future work on this procedure will be aimed at improving and speeding up the analysis time. A number of suggestions and ideas have been proposed. The use of a microwave oven has been suggested for faster evaporations of sample and solvent in the acid treatment step and in the pyrolysis sample preparation, respectively. Another suggestion involved the direct determination of the sulfur dioxide produced by the pyrolysis step, by attaching a sulfur analyzer to the pyrolysis oven. This would eliminate the thirty minute color development time required by the West-Gaeke procedure. The possibility of automating the pyrolysis procedure has also been proposed and would certainly enhance the use of this method on a routine basis. 


\section{LITERATURE CITED}

1. M. J. Taras, et al., eds. Standard Methods for the Examination of water and Wastewater. 13 th ed. New York: American Public Health Association, 1971. Part 156.

2. 1975 Annual Book of ASTN Standards, Part 31, Water. Philadelphia: American Society for Testing and Materials, 1975. Designation: D 516-68 (1974).

3. I. M. Kolthoff and E. B. Sandell. T'extbook of Quantitative Inorganic Analysis. 3rd ed. New York: The Macmillan Company, 1952.

4. C. Mahr and K. Krauss, Z. Anal. Chem., 128:477-84 (1948). Chem. Abs. 43:3316b.

5. R. Belcher and D. Gibbons, I. Chem. Soc., 1952: 4216-8.

6. Robert $C$. Weast, ed. CRC Handbook of Chemistry and Physics. 48th ed. Cleveland: The Chemical Rubber Company, 1967.

7. L. W. Andrews, Am. Chem. J., 11:567-71 (1889).

8. J. I. B. Smith, S. African J. Sci., 16:174-6 (1919). Chem. Abs. $14: 2314$.

9. D. Koszegi, z. Anal. Chem., 77:203-9 (1929). Chem. Abs. 23:3874.

10. H. Roemer, 2. Anal. Chem., 49:490-2 (1910). Chem. Abs. 5:440.

11. W. Geilmann and G. Bretschneider, Z. Anal. Chem., $139: 412-23$ (1953). Chem. Abs. 48:503a.

12. K. Jellinek and H. Ens, Z. Anorg. Allgem. Chem., $124: 185-202$ (1922). Chem. Abs. 17:249.

13. F. Repiton, Mon. Sci., 24:382-4. Chem. Abs. 5:440.

14. K. Jellinek and J. Czerwinski, Z. Anorg. Allgem. Chem., 130:253-62 (1923). Chem. Abs. 18:640.

15. H. Roth, Z. Angew. Chem., 39:1599-601 (1926). Chem. Abs. 21:1074. 
16. F. G. Germuth, J. Am. Water Works Assoc., 19:607-9 (1928).

17. M. Dominikiewicz, Przemysl Chem., 14:241-5 (1930). Whem. Abs. 24:50́09.

18. J. R. Andrews, Ind. Eng. Chem. Ana]. Ed., 3:361-2 (1931).

19. G. G. Manov and P. L. Kirk, Ind. Eng. Chem.e Anal. Ed., 9:198-2.00 (1937).

20. R. Howden, Chem. News, 117:383 (1918). Chem. Abs. $13: 545$.

21. D. Northall-Laurie, Analyst, 56:526-7 (1931).

22. E. P. Schoch, Ind. Eng. Chem., 19:112-5 (1927).

23. S. Shinkai, Japan Analyst, 2:432-3 (1953). Chem. Abs. 48:6320i.

24. A. C. D. Rivett, Chem. News, 118:253-4 (1919). Chem. Abs. $13: 1804$.

25. 0. Macchia, I'industria Chimica, 4:480-3 (1929). Chem. Abs. $24: 38$.

26. B. I. Soibel'man, Zh. Anal. Knim., 3:258-63 (1948). Chem. Abs. 43:8968d.

27. J. L. Lambert and D. J. Manzo, Anal. Chim. Acta, $54: 530-2(1971)$.

28. H. Atkinson, Analyst, 50:590-600 (1925).

29. A. Bahrdt, Z. Anal. Chem., 70:109-19 (1927). Chem. Abs. 21:1506.

30. W. Davey and J. R. Gwilt, J. Appl. Chem., 5:474-6 (1955).

31. R. Strebinger and I. V. Zombory, Z. Anal. Chem., 79:1-8 (1929). Chem. Abs. 24:569.

32. L. de Zombory, Magyar Chem. Folyoirat, 41:189-92 (1935). Chem. Abs. 30:2879.

33. A. Mutschin and R. Pollak, Z. Anal. Chem., 108: 309-16 (1937). Chem. Abs. 31:4223. 
34. E. Minami and K. Watanuki, Bunseki Kagaku, 8: 175-9 (1959). Chem. Abs. 34:25600b.

35. W. Hertyk and Z. Gregorowicz, Zesz. Nauk. Politech. Slask. Chem., No. 30, 35-43 (1966). Chem. Abs. 66: $43468 \mathrm{p}$.

36. J. R. Munger, R. W. Nippler and R. S. Ingols, Anal. Chem., 22:1455-7 (1950).

37. R. Belcher, D. Gibbons and T. S. West, Chemistry and Industry, 1954:127-8.

38. R. Belcher, D. Gibbons and T. S. West, Chemistry and Industry, 1954:850-1.

39. R. Sijderius, Anal. Chim. Acta, 11:28-32 (1954).

40. E. Wanninen, Suomen Kemistilehti, 29B:184-8 (1956). Chem. Abs. $51: 4878 \mathrm{~d}$.

41. A. Casini, Ann. Chim. (Rome), 46:697-702 (1956). Chem. Abs. $51: 4212 f$.

42. E. A. Bozhevol'nov and S. U. Kreingol'd, Metody Analiza Khim. Reaktivov i Preparatov, Gos. Kom. Sov. Min. SSSR po Khim., No. 4, 131-3 (1962). Chem. Abs. 61:3691f.

43. J. Novak, Vodni Hospodarstvi, 12:486-7 (1962). Chem. Abs. 59:1378g.

44. M. Effenberger, Chem. Listy, 52:1501-5 (1958). Chem. Abs. 52:19711f.

45. J. R. McCallum, Can. J. Chem., 34:921-5 (1956).

46. A. W. Wellings, Trans. Faraday Soc., 28:561-4 (1932).

47. J. C. Giblin, Analyst, 58:752-3 (1933).

48. W. C. Schroeder, Ind. Eng. Chem., Anal. Ed., 5: 403-6 (1933).

49. R. T. Sheen and H. I. Kahler, Ind. Eng. Chem., Anal. Ed., 8:127-30 (1936).

50. S. W. Lee, J. H. Wallace, Jr., W. D. Hand, and N. B. Hannay, Ind. Eng. Chem., Anal. Ed., 14:839-40 (1942). 
51. C. L. Ogg, C. O. Willits and F. J. Cooper, Anal. chem., 20:83-5 (1948).

52. G. E. Symons, ed. Standard Methods for the Examination of Water and Sewage. 9 th ed. New York: American Public Health Association, 1946. Part 43. Sulfate.

53. B. K. Handa, Indian J. Chem., 3:368 (1965).

54. J. S. Fritz and M. Q. Freeland, Anal. Chem., 26: $1593-5(1954)$.

55. J. S. Fritz and S. S. Yamanura, Anal. Chem., 27: $1461-4(1955)$.

56. 0. Menis, D. L. Manning and R. G. Ball, Anal. Chem., $30: 1772-6(1958)$.

57. L. V. Markova, Ukrain. Khim. Zhur., 23:89-91 (1957). Chem. Abs. 51:10311f.

58. S. B. Savvin, Yu. M. Dedkov and V. P. Makarova, Zh. Anal. Khim., 17:43-47 (1962).

59. B. Budesinsky and I. Krumlova, Anal. Chim. Acta, $39: 375-81$ (1967).

60. K. F. Novikova, N. N. Basargin and M. F. Tsyganova, Zh. Anal. Khim., 16:348-51 (1961).

61. A. A. Nogina and G. G. Kobyak, Uch. Zap., Permsk. Gos. Univ., 25:73-8 (1963). Chem. Abs. 61:1611a.

62. Z. K. Karalova and N. P. Shibaeva, Zh. Anal. Khim., $19: 258-60(1964)$.

63. S. B. Savvin, T. G. Akimova, V. P. Dedkova, and G. M. Varshal, Zh. Anal. Khim., 24:1868-70 (1969).

64. V. I. Kuznetsov and N. N. Basargin, Zavodskaya Lab., $31: 538-41(1965)$.

65. N. N. Basargin and A. A. Nogina, Zh. Anal. Khim., $22: 394-8$ (1967). Chem. Abs. 67:25344m.

66. B. Budesinsky, Microchem. J., 14:242-8 (1969).

67. B. Oddo and A. Beretta, Gazz. Chim. Ital., 39: 671-5. Chem. Abs. 5:845.

68. G. Finch, Chem. Ztg., 36:782-3. Chem. Abs. 6:3245. 
69. F. Kenny, R. B. Kurtz, I. Beck, and I. Lukosevicius, Anal. Chem., 29:543-6 (1957).

70. I. Odler and J. Gebauer, Chem. Zvesti, 15:563-7 (1961). Chein. Abs. 56:6660f.

71. A. F. del Riego, Bol. Inst. Espan. Oceanog., 120: 13 pp. (1965). Chem. Abs. 64:7867g.

72. 2. Mindalev, 2. Anal. Chem., 75:392-5 (1928). Chem. Abs. 23:1080.

73. J. E. Ricci, Ind. Eng. Chem., Anal. Ed., 8:130-2 (1936).

74. G. N. Nechiporenko, Gidrokhim. Materialy, 26:207-17 (1957). Chem. Abs. 51:17031e.

75. R. Puschel, E. Lassner and P. L. Reiser, Z. Anal. Chem., 166:401-6 (1959). Chem. Abs. 53:16798f.

76. G. N. Nechiporenko, Izvest. Akad. Nauk SSSR, Otdel Khim. Nauk, 1958:359-61.

77. R. Navone, J. Am. Water Works Assoc., 51:932-4 (1959).

78. U. Niwa and E. P. Parry, Chemist-Analyst, 49: $102-5(1960)$.

79. F. W. Bruckmiller, J. Ind. Eng. Chem., 7:600-2 (1915).

80. R. Belcher, M. Kapel and A. J. Nutten, Anal. Chim. Acta, 8:146-9 (1953).

81. J. W. McConnell and R. S. Ingols, Water \& Sewage Works, $97: 330-2$ (1950).

82. R. Belcher, A. J. Nutten and W. I. Stephen, J. Chem. Soc., 1953:1334-7.

83. R. Belcher, A. J. Nutten, E. Parry, and W. I. Stephen, Analyst, $81: 4-8$ (1956).

84. E. Rancke-Madsen, Acta Chem. Scand., 3:773-7 (1949).

85. T. Kiba, 'T. Takagi, Y. Yoshimura, and I. Kishi, Bul1 Chem. Soc. Japan, 28:641-4 (1955).

86. I. I. Volkov and E. A. Ostroumov, Zh. Anal. Khim., $13: 686-90(1958)$. 
87. E. E. Archer, Analyst, $81: 181-2$ (1956).

88. G. W. Dollman, Envirormental Sci. \& Tech., 2:1027-9 (1968).

89. H. W. Brubaker, J.Am. Chem. Soc., 34:284-5 (1912).

90. C. Urbach, Mikrochemie, 14:321-30 (1934). Chem. Abs. $28: 6886$.

91. G. N. Babkin, Ya. F. Veber and M. E. Averbukh, Izv. Vysshikh Uchebn. Zavedenii, Khim. i Khim. Tekhnol., 9:154-6 (1966). Chem. Abs. 65:6916b.

92. F. Egami and N. Takahashi, Bull. Chem. Soc. Japan, $30: 442-4(1957)$.

93. I. Iwasaki, S. Utsumi, K. Hagino, T. Tarutani, and T. Ozawa, Bull. Chem. Soc. Japan, 30:847-51 (1957).

94. D. B. Iokhel'son, Ukrain. Khem. Zhur., 9:25-8 (1934). Chem. Abs. $28: 7387$.

95. B. Klein, Ind. Eng. Chem., Anal. Ed., 16:536-7 (1944).

96. R. J. Bertolacini and J. E. Barney, II, Anal. Chem., $29: 281-3(1957)$.

97. R. J. Bertolacini and J. E. Barney, II, Anal. Chem., $30: 202-5(1958)$.

98. M. E. Gales, Jr, , W. H. Kaylor and J. E. Longbottom, Analyst (London), 93:97-100 (1968).

99. B. Budesinsky and D. Vrzalova, Z. Anal. Chem., 210:161-6 (1965).

100. Kanagawa Prefectural Pollution Control Center. Tech. Rept., Air Pollution Yokohama-Kawasaki Ind. Area, no. 15:236-9 (1973). Air Pollution Abs. 1975:44436.

101. T. V. Petrova, N. Khakimkhodzhaev and S. B. Savvin, Izv. Akad. Nauk SSSR, Ser. Khim., 1970:259-65. Chem. Abs. 73:31191z.

102. G. A. Persson, Air Water Pollut. 10:845-52 (1966). Chem. Abs. 66:40528x.

103. A. Lazrus, E. Lorange and J. P. Lodge, Jr., Advan. Chem., 73:164-71 (1968). 
104. J. Korbl and R. Pribil, Chem. Listy, 51:1061-7

(1957). Chem. Abs. 51:11915a.

105. J. M. Adamski and S. P. Villard, Anal. Chem., 47: 1191-4 (1975).

106. M. R. McSwain, R. J. Watrous and J. E. Douglass, Anal. Chem., 46:1329-31 (1974).

107. V. Palaty, Chemistry \& Industry, 1960:176.

108. A. K. Babko and I. V. Markova, Zavodskaya Lab., $24: 524-8$ (1958). Chem. Abs. 54:10631i.

109. V. F. Holz and H. Kremers, Landwirt. Forsch., Sonderh., 28:189-201 (1973). Chem. Abs. 80:100045p.

110. J. L. Lambert, S. K. Yasuda and M. P. Grotheer, Anal. Chem., 27:800-1 (1955).

111. V. Palaty, Talanta, 10:307-10 (1963).

112. T. Nasu, Bunseki Kagaku, 18:1183-8 (1969) Chem. Abs. $72: 24452 \mathrm{~m}$.

113. T. Nasu, T. Kitagawa and T. Mori, Bunseki Kagaku, 19:673-80 (1970). Chem. Abs. 73:52053w.

114. R. V. Hems, G. F. Kirkbright and T. S. West, Talanta, 16:789-96 (1969).

115. R. Goguel, Anal. Chem., 41:1034-8 (1969).

116. A. K. Babko and L. V. Markova, Ukrain Khim. Zhur., 25:505-8 (1959). Chem. Abs. 54:8466d.

117. I. St. Lorant, Z. Physiol. Chem., 185:245-66 (1929). Chem. Abs. $24: 1402$.

118. C. M. Johnson and H. Nishita, Anal. Chem., 24: $736-42$ (1952).

119. L. Gustafsson, Talanta, 4:227-35 (1960).

120. J. B. Davis and F. Lindstrom, Anal. Chem., 44: $524-32$ (1972).

121. R. F. Maddalone, G. L. McClure and P. W. West, Anal. Chem., 47:316-9 (1975). 
122. 0. A. Ohlweiler and J. de 0. Meditsch, Anal. Chim. Acta, 25:233-7 (1961).

123. W. I. Stephen, Anal. Chim. Acta, 50:413-22 (1970).

124. J. I. D. Hinds, J. Am. Chem. Soc., 18:661-70 (1896).

125. D. D. Jackson, J. Am. Chem. Soc., 23:799--806 (1901).

126. R. T. Sheen, H. I. Kahler and E. M. Ross, Ind. Eng. Chem., Anal. Ed., 7:262-5 (1935).

127. J. F. Thomas and J. E. Cotton, Water \& Sewage Works, $101: 462-5(1954)$.

128. W. Volmer and F. Frohlich, Z. Anal. Chem., 126: 401-4 (1944). Chem. Abs. 40:147.

129. M. Honda, J. Chem. Soc. Japan, Pure Chem. Sect., $70: 55-7$ (1949). Chem. Abs. 45:4169h.

130. J. C. Chaudhuri, A. D. Purohit and T. N. Bhargava, Current Sci. (India), 31:418 (1962). Chem. Abs. $58: 5380 \mathrm{c}$.

131. J. R. Rossum and P. A. Villarruz, J. Am. Water Works Assoc., 53:873-6 (1961).

132. G. Toennies and B. Bakay, Anal. Chem., 25:160-5 (1953).

133. T. Omura, Repts. Liberal Arts Fac. Shizuka Univ., Nat. Sci., No. 7:43(1955). Chem. Abs. 51:642i.

134. J. M. Martin and W. I. Stephen, Anal. Chim. Acta, $39: 175-80(1967)$.

135. B. Audouze and G. Bonometti, Inform. Chim., No. 107: 223-6 (1972). Chem. Abs. $77: 69743 \mathrm{~b}$.

136. F. Burriel, J. Ramirez-Munoz and M. L. Rexach-M. de Lizarduy, Anal. Chim. Acta, 17:559-69 (1957).

137. W. M. Shaw, Anal. Chem., 30:1682-9 (1958).

138. D. C. Cullum and D. B. Thomas, Analyst, 85:688-9 (1960).

139. I. I. Pleskach and G. D. Chirkova, Zavodskaya Lab., $37: 168-70$ (1971). 
140. W. L. Crider, N. P. Barkley, M. J. Knott, and R. W. Slater, Jr., Ana1. Chim. Acta, 47:237-41 (1969).

141. J. R. Sand and C. O. Huber, Anal. Chem., 48:1331-5 (1976).

142. R. Dunk, R. A. Mostyn and H. C. Hoare, Atomic Absorption Newletter, 8:79-81 (1969).

143. I. P. Little, R. Reeve, G. M. Proud, and A. Iulham, J.Sci. Food Agr., 20:673-6 (1969). Chem. Abs. 72:

144. R. W. Looyenga and C. O. Huber, Anal. Chim. Acta, $55: 179-83(1971)$.

145. C. I. Lin and C. O. Huber, Anal. Chem., 44:2200-4 (1972).

146. V. A. Nazarenko and M. B. Shustova, Zavodskaya Lab., 24:1344-6 (1958). Chem. Abs. 54:13985b.

147. J. C. Guyon and E. J. Lorah, Anal. Chem., 38:155 (1966).

148. L. H. Tan and T. S. West, Analyst, $96: 281-5$ (1971).

149. A. S. Jones and D. S. Letham, Chemistry \& Industry, $1954: 662-3$.

150. A. S. Jones and D. S. Letham, Analyst, 81:15-18 $(1956)$.

151. P. A. Jones and W. I. Stephen, Anal. Chim. Acta, 64:85-92 (1973).

152. D. T. Burns, J. S. Coy, W. P. Hayes, and D. M. Kent, Mikrochimica Acta (Wien), 1974:245-248.

153. A. Ringbom, Acta Acad. Aboensis, Math. Phys., 8: No. 5, 142 pp. (1934). Chem. Abs. 29:3261.

154. N. G. Cassidy, Analyst, $81: 169-75$ (1956).

155. E. I. Vail', V. A. Kremer and A. P. Mirnaya, Zh. Anal. Khim., 15:369-70 (1960).

156. J. W. Ross, Jr. and M. S. Frant, Anal. Chem., 41: 967-9 (1969).

157. M. Mascini, Analyst, $98: 325-8$ (1973). 
158. N. I. Vorob'ev, Zavodskaya Lab., 12:375-6 (1946). Chem. Abs. $40: 7455$.

159. A. D. Miller, Zh. Anal. Khim., 11:615-20 (1956).

160. G. A. Rechnitz, Z. F. Lin and S. B. Zamochnick, Anal. Letters, $1: 29-33$ (1967).

161. R. Jasinski and I. Trachtenberg, Anal. Chem., 44 : 2373-6 (1972).

162. R. Jasinski and I. Trachtenberg, Anal. Chem., 45: 1277-9 (1973).

163. Commercial literature available through: Chemtrix, Inc., $135 \mathrm{~N}$. W. Adams, Hillsboro, Oregon 97123; and Sensorex, Bentley Laboratories, Inc., 17502 Armstrong Avenue, Irvine, California 92705.

164. I. M. Kolthoff and T. Kameda, Ind. Eng. Chem., Anal. Ed., 3:129-33 (1931).

165. A. I. Rybnikova and I. N. Bal'zamova, Zavodskaya Lab., 11:160-3 (1945). Chem. Abs. 40:1426.

166. J. W. Polsky, Anal. Chem., 19:657-60 (1947).

167. J. K. Johannesson, New Zealand J. Sci., 1:423-4 (1958). Chem. Abs. 53:12536a.

168. O. I. Milner, Anal. Chem., 24:1247-9 (1952).

169. G. R. Jamieson, J.Appl. Chem. (London), 7:81 (1957).

170. I. M. Kolthoff and Y.-D. Pan, J.Am. Chem. Soc., $62: 3332-5(1940)$.

171.V. V. Tenkovtsev, Zh. Anal. Khim.e 12:504-7 (1957).

172. A. D. Horton and P. F. Thomason, Anal. Chem., 23: $1859-60$ (1951).

173. K. Matsumoto and M. Shibayama. J. Pharm. Soc. Japan, 73:656-8 (1953). Chem. Abs. 47:9530f.

174. 0. A. Ohlweiler, Anais Assoc. Brasil Quim., 19: 139-40 (1960). Chem. Abs. 56:9894a.

175. J. Mayer, E. Hluchan and E. Abel, Anal. Chem., $39: 1460-1(1967)$. 
176. R. E. Humphrey and C. E. Laird, Anal. Chem., 43: 1895-7 (1971).

177. R. E. Humphrey and S. W. Sharp, Anal. Chem., 48: $222-3(1976)$.

178. H. J. M. Bowen, Analyst, 95:665-7 (1970).

179. E. H. Klehr, Isotop. Radiat. Technol., 9:44-7 (1971). Chem. Abs. 76:37247f.

180. R. L. Dimitt and E. R. Graham, Anal. Chem., 48: 604-6 (1976).

181. P. M. Dean and 0. O. Watts, J.Am. Chem. Soc., $46: 855-8(1924)$.

182. M. B. Williams and J. Janata, Talanta, 17:548-51 (1970).

183. G. Dube and F. M. Kimmerle, Anal. Chem., 47:285-9 (1975).

184. 0. Arrhenius and H. Riehm, Medd. Vetenskapsakad. Nobelinst., 6: No. 14, 69 pp. (1926). Chem. Abs. $20: 2469$.

185. A. Toth and B. Lakatos, Magyar Kem. Folyoirat, 61:239-45 (1955). Chem. Abs. 52:7934c.

186. Fritz Feigl. Spot Test, Vol. I, Inorganic Applications. Amsterdam: Elsevier Publishing Co., 1954.

187. H. Ballczo and M. Hodos, Mikrochim. Acta, 1960: 267-71.

188. J. de0. Meditsch and V. Castiel. Anais. Assoc. Brasil Quim., 20:49-53 (1961). Chem. Abs. 58:20f.

189. S. Ito and T. Hara, Nippon Kagaku Zasshi, 90 : 1027-30 (1969). Chem. Abs. 72:28148q.

190. G. I. McClure, Anal. Chim. Acta, 64:289-91 (1973).

191. R. F. Maddalone, R. L. Thomas and P. W. West, Environmental Sci. \& Tech., 10:162-8 (1976).

192. P. W. West and G. C. Gaeke, Anal. Chem., $28: 1816-9$ (1956). 


\section{APPENDIX A}

\section{CALCULATIONS}

$$
\begin{aligned}
\mu g \text { sulfate } & =\mu g \text { sulfur dioxide } X \frac{64.04}{96.06} \\
& =\mu g \text { sulfur dioxide } X \quad 1.5
\end{aligned}
$$$$
\% \text { Recovery }=\frac{\mu g \text { sulfate calculated }}{\mu g \text { sulfate originally added }} \times 100 \%
$$

Mean $=\bar{x}=\frac{\Sigma x}{N}$, where $N=$ number of $\mathrm{x}$ values

Standard Deviation $=\sigma=\sqrt{\frac{\sum(x-\bar{x})^{2}}{N}}$

Relative Standard Deviation $=\frac{\sigma}{\bar{x}} \times 100 \%$ 
LeeAnn Marie Thoma was born on October 28, 1949 in Garnavillo, Iowa. She was educated in the Garnavillo Community School System, earning a high school diploma in 1967. Four years of undergraduate work at the University of Northern Iowa followed. During those years, she worked as a teaching assistant for the Department of Chemistry, and as a research assistant to Dr. James C. Chang, maintaining his reference files, and synthesizing and analyzing inorganic compounds. She received her Bachelor of Arts degree in chemistry and mathematics in 1971 .

Since August of 1971, Ms. Thoma has been enrolled as a graduate student in chemistry at Louisiana State University, working toward the Doctor of Philosophy degree under Professor Philip W. West. She worked as a graduate assistant teaching undergraduate laboratory classes during that time. Currently she is employed as a special projects chemist with the ARCO Chemical Company in Channelview, Texas, where she will remain after her graduation.

In her leisure time, Ms. Thoma enjoys sewing and needlecrafts, reading, listening to music, playing the piano, and traveling. 


\section{EXAMINATION AND THESIS REPORT}

Candidate: $\quad$ LeeAnn Marie Thoma

Major Field: $\quad$ Chemistry

Title of Thesis: A Pyrolytic Method for the Determination of Sulfate in Water

Approved:
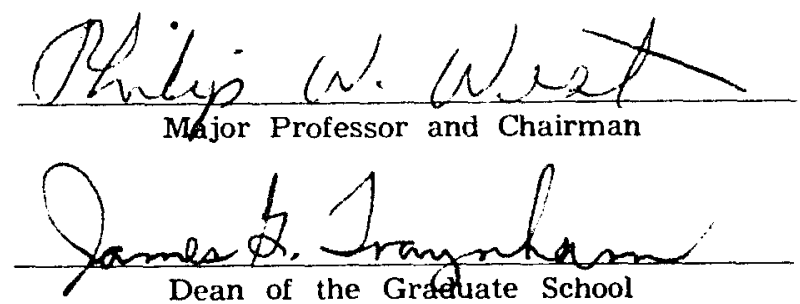

EXAMINING COMMITTEE:

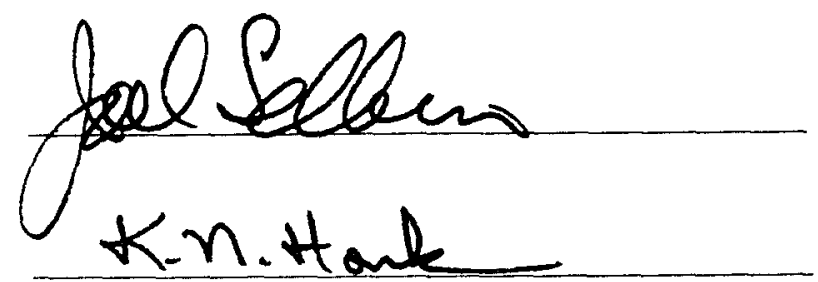
Rudblharders.

Date of Examination: 